\title{
Tulane
}

Tulane Economics Working Paper Series

\section{Understanding the Dynamics of Labor Income Inequality in Latin America}

\author{
Carlos Rodríguez-Castelán \\ Poverty and Equity Global Practice \\ World Bank \\ crodriguezc@worldbank.org \\ Nora Lustig \\ Department of Economics \\ Tulane University \\ nlustig@tulane.edu
}

\author{
Luis F. López-Calva \\ Poverty and Equity Global Practice \\ World Bank \\ lflopezcalva@worldbank.org
}

Working Paper 1608

August 2016

\begin{abstract}
Since the early 2000s, after a long period of wide and persistent gaps, Latin America has experienced a steady decline in income inequality. This paper presents evidence of a trend reversal in labor income inequality, which is considered the main factor behind such a decline in income inequality across the region. Our analysis shows that, while labor income inequality increased during the 1990s, with heterogeneous experiences across countries, it fell in a synchronized way across countries beginning in the early 2000s. This systematic decline was supported by an expansion in real hourly earnings among the bottom of the wage distribution and, to a lesser extent, the middle part of the earnings distribution, thus reducing both upper and lower tail inequality. This trend reversal is explained by a lower dispersion of earnings among workers with observable different attributes and by a much less extensive dispersion of residual labor inequality. Regarding the earnings differentials among workers with observable different attributes, our analysis concludes that the decline in labor inequality in Latin America has been closely associated with a reduction in the college/primary education premium and in the urban-rural earnings gap, coupled with a steady drop in the high school/primary education premium, which accelerated markedly since the 2000s, as well as a reduction in the experience premium across all age-groups.
\end{abstract}

Keywords: Inequality, Labor Incomes, Education Premium, Experience Premium, Latin America. JEL codes: D63, E24, J21, J31, O54 


\title{
Understanding the Dynamics of Labor Income Inequality in Latin America
}

\author{
Carlos Rodríguez-Castelán, ${ }^{*}$ Luis F. López-Calva ${ }^{\dagger}$ Nora Lustig, ${ }^{\ddagger}$ and Daniel Valderrama $\$$
}

August 10, 2016

\begin{abstract}
Since the early 2000s, after a long period of wide and persistent gaps, Latin America has experienced a steady decline in income inequality. This paper presents evidence of a trend reversal in labor income inequality, which is considered the main factor behind such a decline in income inequality across the region. Our analysis shows that, while labor income inequality increased during the 1990s, with heterogeneous experiences across countries, it fell in a synchronized way across countries beginning in the early 2000s. This systematic decline was supported by an expansion in real hourly earnings among the bottom of the wage distribution and, to a lesser extent, the middle part of the earnings distribution, thus reducing both upper and lower tail inequality. This trend reversal is explained by a lower dispersion of earnings among workers with observable different attributes and by a much less extensive dispersion of residual labor inequality. Regarding the earnings differentials among workers with observable different attributes, our analysis concludes that the decline in labor inequality in Latin America has been closely associated with a reduction in the college/primary education premium and in the urban-rural earnings gap, coupled with a steady drop in the high school/primary education premium, which accelerated markedly since the 2000s, as well as a reduction in the experience premium across all age-groups.
\end{abstract}

Keywords: Inequality, Labor Incomes, Education Premium, Experience Premium, Latin America

JEL codes: D63, E24, J21, J31, O54

\footnotetext{
The authors would like to thank Oscar Barriga Cabanillas, Sarah Knob, Julián Messina, Joana Silva, Robert Zimmermann, and the participants at both the author workshop and the decision meeting of the Regional Study on Wage Inequality organized by the Office of the Chief Economist, Latin America and Caribbean Region, World Bank. The findings, interpretations, and conclusions in this paper are entirely those of the authors. They do not necessarily represent the view of the World Bank Group, its Executive Directors, or the countries they represent.

* Senior Economist, Poverty and Equity Global Practice, World Bank. E-mail: crodriguezc@worldbank.org.

† Lead Economist, Poverty and Equity Global Practice, World Bank. E-mail: lflopezcalva@worldbank.org.

¥ Samuel Z. Stone Professor of Latin American Economics and Director of the Commitment to Equity Institute at Tulane University. Professor Lustig is also nonresident senior fellow at the Center for Global Development and the Inter-American Dialogue. E-mail nlustig@tulane.edu.

『Research Analyst, Poverty and Equity Global Practice, World Bank. E-mail: dvalderramagonza@worldbank.org.
} 


\section{Introduction}

Latin America has been characterized as a region with an excess of inequality for being a middle-income region (Londoño and Székely 2000). It ranks as the second most unequal region in the world, after Sub-Saharan Africa, a position that holds independent of the metric used to measure welfare, whether consumption or income (Alvaredo and Gasparini 2015). Although inequality in Latin America is still substantial today, the region is also known to have experienced a turning point in the trend in the early 2000s (Gasparini et al. 2011), changing from a slightly increasing trend during the 1990s to a steady decline since the early 2000s (López-Calva and Lustig 2010). This represents a sharp contrast with what has occurred in other developing regions, particularly in Eastern Europe and Central Asia and in East Asia and the Pacific, where income inequality has been on the rise since the early 2000s (Alvaredo and Gasparini 2015). ${ }^{5}$

The literature on the rise and fall of income inequality is vast. Following the seminal studies of Gasparini et al. (2009) and López-Calva and Lustig (2010), a growing body of literature has documented the turning point in total income inequality and has hypothesized about the potential supply, demand, and institutional factors that may be associated with the unique equalizing momentum of the region during the 2000s. ${ }^{6}$ Together with this literature, a large number of country-level studies have gone deeper in exploring the main factors associated with the observed narrowing in inequality. These factors include fiscal policy (Higgins and Pereira 2014; Jaramillo 2014; Lustig and Pessino 2014; Scott 2014), economic cycles (Ferreira and Schady 2009; Gasparini and Cruces 2010), institutional changes (Fairris 2003; Maurizio 2014), trade liberalization (Attanasio, Goldberg, and Pavcnik 2004; Bastos and Silva 2008; Esquivel and Rodríguez-López 2003; Gonzaga, Menezes, and Terra 2006; Revenga 1997; Verhoogen 2008), and labor misallocations due to an unbalanced expansion of the coverage of education (Campos Vázquez, López-Calva, and Lustig 2016; Levy and López-Calva 2016). Most of these papers examine how variations in policies, institutions, and external conditions influence reductions in income inequality through their major components, including labor earnings, nonlabor incomes (such as land, capital income, rents, and remittances), and demographics.

However, the ample evidence documenting changes in total income inequality in Latin America sharply contrasts with the scarce evidence about the facts behind changes in labor income inequality across the region. Little is known about the trends in labor income inequality in the last two decades, and most studies concentrate solely on understanding the drivers behind the fall in the education premium (Manacorda, Sánchez-Páramo, and Schady 2010; Gasparini et al. 2011), ${ }^{7}$ or the potential effect of a tertiary education expansion (Batiston et al. 2011). Even where the education premium is an essential piece, it is not the bulk of labor income inequality. ${ }^{8}$ This study aims to fill this gap by taking stock of the main determinants of labor income inequality and the earnings structure in Latin America over the past two decades with an emphasis on the trend reversal in labor income inequality observed across the region since the early 2000s.

This paper is related to Azevedo et al. (2013), although that paper focuses the analysis on the decomposition method proposed by John, Murphy, and Pierce (1993) rather than documenting changes in labor inequality in Latin America. ${ }^{9}$ Our study aims to fill several gaps in the literature on the stylized facts

\footnotetext{
5 See also Lakner and Milanovic (2013); Williamson (2015).

${ }^{6}$ See Gasparini and Lustig (2011); Lustig, López-Calva, and Ortiz-Juárez (2013, 2015); World Bank (2011, 2013); Cornia (2014); de la Torre et al. (2014, 2015); Cord et al. (2016); Cord, Genoni, and Rodríguez-Castelán (2015); Székely and Mendoza (2016).

7 These studies have used a supply and demand framework to estimate a Tinbergen ratio between supply and technology (1974). In this framework proposed by Katz and Murphy (1992), an increase in the relative supply of skilled workers should result in a fall in their relative remuneration, while a positive change in the relative demand for this type of worker would increase the wage-skill premium; here, skill is defined by education because perfect substitutability across workers with different experience is assumed. Several studies have applied this framework to Latin American countries, for instance, Mexico (Montes Rojas 2006), Chile (Gallego 2011), Panama (Galiani 2009), Manacorda et al. (2010) on the five largest economies in Latin America, and Gasparini et al. (2011), which is the broadest study in terms of spatial coverage (17 Latin American countries) and time coverage (1990s and 2000s). Recently, Fernandez and Messina (2016) applied the framework, including variations in the experience premium, to selected Latin American countries.

8 A typical Mincer equation controlling only for education levels will lead to an R-squared of less than 0.3 , independent of the country and year of the sample. This fact generally holds across the world.

${ }^{9}$ Although, at the country level, there is a growing literature on the main drivers behind changes in labor income inequality, most of these studies are heterogeneous in terms of indicators, sample, data sources, and trimming criteria, making regional conclusions a difficult
} 
around the trend in earnings inequality in Latin America during the last two decades. To a lesser degree, it also seeks to contrast these trends with those of other middle- and high-income countries in the world. To analyze the trend in labor income inequality, we aim to document changes in the inequality of the earnings structure (relative returns of different skills/attributes). We also analyze the context of these changes in terms of real earnings growth because different movements in real earnings could lead to the same change in relative returns to different attributes, but not to the same conclusions about the underlying causes. Finally, our paper presents a set of stylized facts on the variance in earnings across workers of observable different characteristics (the earnings structure) and the variance across workers with observable equal characteristics, which is defined in the literature as residual earnings inequality and corresponds to the variance that cannot be explained by the differences among workers in a set of observed characteristics. Unlike Azevedo et al. (2013), we are not imposing any assumption about the dynamics of the residual distribution.

By conducting our analysis at the regional level, we enhance the external validity of our results, while obtaining broad estimates of a common underlying trend in the distribution of labor market earnings in the region. In particular, we use data from the SEDLAC database on 17 countries in Latin America, which cover around 90 percent of the population. This allows us to identify underlying factors that are beyond specific country contexts (political, institutional, or economic). In addition, analyzing data since the early 1990s allows us to define whether the factors considered important in the 2000 s were also present during the previous decade, when labor market inequality showed a different trend. In other words, by taking a long-term perspective, we can test whether the reverse of previous trends in overall inequality implied a reverse in previous trends in other factors, or a surge in new forces that were previously absent.

Our main finding is that, after a period of modest expansion in wage dispersion, Latin America experienced a trend reversal in labor income inequality after 2002. We find evidence of a parallel movement between total income inequality and labor income inequality, which is no surprise because labor earnings represent about 80 percent of the total household income distribution in any Latin American country. ${ }^{10}$ In particular, the unweighted average Gini coefficient of labor income inequality fell from 0.473 in 2002 to 0.410 in 2013. According to our analysis, this significant drop in earnings inequality is robust to the choice of aggregation method, ${ }^{11}$ inequality measure, ${ }^{12}$ period of analysis, or the selection of countries in the construction of the regional aggregate. This phenomenon of declining labor inequality was observed in 16 of the 17 countries on which we have comparable data for the 2000s. Only Costa Rica experienced an increase in labor income inequality over the last decade.

Our analysis also shows that the decline in labor income inequality was supported by a substantial expansion in real hourly earnings at the bottom of the distribution. ${ }^{13}$ In particular, since 2002, the labor incomes associated with relatively low-paying jobs (those in the bottom decile of the earnings distribution) have risen by more than 50 percent in real terms, which is significantly higher than the 15 percent growth among more well paid workers (those in the top decile of the earnings distribution) and also higher than the 32 percent growth rate experienced in the median of the distribution. In contrast, the increase in regional labor income inequality during the 1990s was supported by a reduction in real earnings at the bottom of the distribution, while the rest showed null or slightly positive growth in real earnings.

Our second set of results highlights a steady decline in the education premium in Latin America since the early 2000s that has been driven by larger growth in labor earnings among less well educated workers relative

task. Moreover, most of these studies only explain the trend in the 2000s, which leads to a bias in their findings because they do not observe a period with different trends - the 1990s — to test their hypotheses. See, for instance, Paz and Urrutia (2015) on Peru; Ariztizabal et al. (2015) on Bolivia, Colombia, and Ecuador. Among these studies, Messina and Fernandez (2016) is the only one that analyzes the long-term trends in Argentina, Brazil, and Chile.

${ }^{10}$ See, for instance, World Bank (2011) and Cord et al. (2016), which document that labor earnings represent about 80 percent of total household income in most Latin American countries.

11 Both the weighted and unweighted regional averages converge qualitatively in the fall of labor income inequality, albeit they report some differences in terms of the trend during the 1990s.

12 Our analysis also reaches this conclusion based on the Theil index, the mean log deviation, the Atkinson index, and the $90 / 10$ ratio. ${ }^{13}$ Labor earnings and wages represent different concepts. Our analysis focuses on labor earnings, which consider the earnings of both wage employees and self-employed workers. Even if we may sometimes use the term wage or wages, our results always refer to labor earnings. 
to workers with high school or college educational attainment. This drop in the education premium has been coupled with a steady fall in the experience premium, which has been accelerating since the early 2000s, a novel fact from a regional perspective. The most experienced workers have seen a reduction by almost half in their experience premium with respect to younger workers. Indeed, after 2002, most countries in the region experienced rapid reductions in these premiums. Moreover, we find evidence that the gender wage gap has narrowed consistently since the mid-1990s, but it has been almost stagnant during the first decade of the 2000s, which suggests a weak relation between the gender earnings gap and the trend reversal. We also find that the urban-rural earnings gap widened in the 1990s, but then narrowed sharply during the 2000s, closely related with what happened with overall labor inequality.

Our third set of results shows evidence that the narrowing in the earnings dispersion across different workers, although important, is still only a minor part of the reduction in earnings inequality. In contrast, more than half of the reduction in labor income inequality was derived from a reduction in the variance of the earnings of workers with similar characteristics, what is known in the literature as residual earnings inequality. This latter fact requires further investigation to clarify the extent to which this has been due to compositional changes.

The reminder of this paper is organized as follows. Section 2 describes the data and sample criteria. Section 3 documents the trend in labor income inequality observed in Latin America over the last two decades, its most salient characteristics, and a comparison with other countries in the world. Section 4 presents a diagnostic of how changes in the earnings structure, specifically, changes in the relative returns to different types of workers, may have played a role in the trend in labor income inequality in Latin America; it also documents how residual labor inequality is the most important factor in this trend. Section 5 concludes.

\section{Data: From noise to signal for identifying regional trends}

Most stylized facts on Latin America are produced using harmonized national household surveys from the SEDLAC Project. ${ }^{14}$ The surveys are collected by the respective national statistics offices (NSOs) and harmonized through the SEDLAC Project. These microdata cover 17 countries over a span of 20 years, which account for 90 percent of the population in the region. Annex A provides more detail on the microdata used in this study for each country and each year. In addition, part of the analysis in section 3 uses aggregated information on República Bolivariana de Venezuela to present a more comprehensive picture on labor income inequality in Latin America. There is information on a yearly basis for all countries with the exception of Chile and Mexico, which collect data every two or three years, and Guatemala and Nicaragua, which collect household survey data about every five years. ${ }^{15}$ All the surveys have a labor module to collect information on labor income after taxes, which is the main variable of interest in this study. Next, we provide a detailed description of the use we make of this variable.

An additional contribution of this study is the effort to minimize the intrinsic noncomparability of surveys over long periods of time. A salient characteristic of household surveys in developing countries is that they are living tools that undergo changes in structure, the phrasing of questions, sample design, and frequency, among other features, from time to time. There is thus a cost of comparability in the country series for those indicators that are more sensitive to the specific change. The large majority of the studies that are not country specific do not mention how they deal with the effect that the changes in the survey features have on the comparability of their estimates. We break with this tradition and work on four different areas, which are described below.

First, we use unique information about the comparability of surveys on the same country in terms of income aggregates (see table A.1) to define circa years (see table B.1) that minimize the measurement error of

\footnotetext{
${ }^{14}$ For more information, see the SEDLAC Project webpage, at http://sedlac.econo.unlp.edu.ar/eng/.

15 The SEDLAC dataset allows cross-country comparisons of household welfare. The data cover 17 countries, which account for 90 percent of the population in the region. The countries are Argentina (urban only), Bolivia, Brazil, Chile, Colombia, Costa Rica, the Dominican Republic, Ecuador, El Salvador, Guatemala, Honduras, Mexico, Nicaragua, Panama, Paraguay, Peru, and Uruguay (urban only). See annex A for more details on the specific combination of country-year surveys included in the analysis. See SEDLAC (SocioEconomic Database for Latin America and the Caribbean), Center for Distributive, Labor, and Social Studies, Universidad Nacional de La Plata, La Plata, Argentina and World Bank, Washington, DC, http://sedlac.econo.unlp.edu.ar/eng/statistics.php.
} 
changes during the 1990s and 2000s. ${ }^{16}$ This information has been provided by the Team for Statistical Development for Latin America at the World Bank. ${ }^{17}$ This allows us to identify more accurate trends at the country level. Since the breaks in comparability are not synchronized in the timing or the direction of the impact in our indicator of interest (labor income distribution and the earnings structure), there is no expected important effect on the regional aggregate constructed on a yearly basis.

Second, we use the most recent population projections based on the most recent census to adjust surveys that have not been updated. This procedure is carried out by each NSO years after the release of the census. However, the timing of the adjustment is different for each country. We have applied the last census projections of the urban and rural populations to the surveys to guarantee comparability at this level.

Third, we exclude some country surveys for certain years in which the parameter of interest included outliers by a simple routine of using as a benchmark the observations for the same country during the period. The parameters used are the proportion of missing labor income among the employed population, average earnings, and the sociodemographic composition of certain groups by education, experience group, sex, and area. This leads to the exclusion of Brazil in 1992 and 2007 and Paraguay in 1990.

Finally, we control for changes in terms of coverage even if these have been minor (similar to previous studies). In addition, in terms of coverage, almost all the surveys are representative at the national level during the last two decades. In the cases where the coverage of the surveys changes during the period of analysis, the surveys were trimmed to the geographical areas that were covered in both decades. This substantially affects Argentina and Uruguay, which thus become representative of the main urban areas, ${ }^{18}$ and excludes less well populated areas in Brazil and Colombia. ${ }^{19}$ The latter rule reduces the share of each of these countries in population-weighted regional averages, but not in the unweighted averages.

The following analysis also offers benchmarking of Latin American countries using a set of middle- and high-income countries and data of the International Labour Organization (ILO) Global Wage Report Gini database (for more than 30 European and middle-income countries). We also conduct our analysis of the changes in returns using data from the World Bank International Income Distribution Dataset (I2D2), consisting of harmonized microdata available for a subset of countries, including the United States and Turkey. Finally, we also incorporate analysis from South Africa built from the Post Apartheid Labor Market Seriesv2.0 and the Russian Federation based on the Russia Longitudinal Monitoring Survey. The trends in labor income inequality found in these countries are similar to those discussed in the literature. ${ }^{20}$ These countries are used as reference points in the study rather than as points of interest. Thus, harmonization, the control of comparability, and the validation of trends over time have been limited to guarantee a rough estimate of differences with respect to relations and trends in the Latin America and Caribbean region (see annex A.2).

The variable of interest is the labor income after taxes associated with the main occupation of workers during the month previous to the survey. The survey question is asked of all employees and of the selfemployed. The objective is to use this variable to approximate the labor earnings structure. As Székely and Hilgert (2007) point out, the cross-country comparison of labor income inequality is meaningful and shows a

\footnotetext{
16 The countries in which the effect was present and in which it was feasible to control for the effect are those on which data exist on two years in the same period, one for the series before the change and the other for the series after the change.

17 This information has been constructed based on a knowledge of the SEDLAC Project and survey metadata and in close contact with the staff of each NSO.

18 This change limited the sample in Argentina to the urban areas covered since 1992, Gran Buenos Aires, and other major urban areas that include around 50 percent of the population. It also limited the sample in Uruguay to the urban population in the metropolitan area of Montevideo (about 70 percent of the population).

${ }_{19}$ Among other trimming procedures, the north rural areas of Brazil were excluded because these were not covered in the 1990s (less than 2 percent of the population); also urban areas in new departments in the Amazon and Oriental regions in Colombia, only recently covered (less than 4 percent of the population).

20 See Bakis and Sezgin (2015) for the case of Turkey, with a fall between 2002 and 2004 and a slight increase in inequality since 2004. See Leibbrandt Arden, and Woolard (2013) for the case of South Africa, with a steady increase since the 1990s and a slight increase during the first decade of the 2000s. See Autor, Katz, and Kearney (2008) for the case of the United States, with a slight increase from the 1990s to the end of 2010. See Calvo, López-Calva, and Posadas (2015) for the case of the Russian Federation, with a slight increase at the end of the 1990s, but a steady fall during the first decade of the 2000s.
} 
relatively lower ratio between noise and signal than the analysis of total income, which is affected by the lower quality of the information on nonlabor incomes. Labor income inequality is the most tractable variable for long periods of time. It is typically constructed using similar questions and recall periods. It also analyzes the same type of income (monetary income after taxes) and suffers from relatively lower underreporting issues than total income inequality across countries. ${ }^{21}$

Monthly labor income is expressed as earnings per hour worked, which is a standard unit value traded in the labor market. Since the objective is to have the most accurate estimates of how the labor market assigns a price to certain skills either observable or unobservable (earnings structure), we limit our analysis to the sample of full-time workers (35+ hours per week) between 15 and 64 years of age. Depending on the country, this accounts for 75 percent to 85 percent of all workers, as has been traditionally done in other countries. ${ }^{22}$ There are several advantages of focusing the analysis on the sample of full-time workers: (a) it reduces the dispersion of hourly earnings that could be caused by measurement error, (b) it allows those workers to be tracked who are strongly attached to the labor force and who are more similar both in observables and unobservables relative to part-time workers, and (c) it isolates the particularities of the demand- and supply-side forces that frame parttime jobs in the estimation of labor market prices, which is the main goal of this study. The main consequence of considering only full-time workers is that labor income inequality may be lower, and the trend may not be necessarily the same if we include part-time workers in the analysis. However, as mentioned above, we are interested in disentangling the trends in labor inequality derived from the inequality of the earnings structure rather than the labor supply decisions of workers.

Finally, the data series are spatially deflated between urban and rural areas using a factor of 15 percent of the differences in the cost of living 23 because the lack of the use of spatial deflators overstates income inequality, although the size of spatial price differences depends on the country, ${ }^{24}$ and the use of a regional factor is a second-best method, but is better than not deflating spatially.

\section{Trends in labor earnings inequality}

Except for Sub-Saharan Africa, Latin America is the most unequal region in the world (Alvaredo and Gasparini 2015; Lakner and Milanovic 2013; Williamson 2015). This holds even after one controls for the fact that inequality in the region is measured through income, while, in the rest of the developing world, it is measured using consumption data. Following a method proposed by Alvaredo and Gasparini (2015) to generate a consumption Gini from income Gini measures, the left panel of figure 1 shows Latin America as the second most unequal region in the world. This position is statistically significant, and it is robust to the exclusion of extreme values.

\footnotetext{
${ }^{21}$ On the other hand, the underreporting of incomes among top earners, a classical drawback in the literature that measures inequality using household surveys, is less pronounced if labor income is considered because a larger share of the incomes of the top of the distribution is derived from capital gains. Moreover, it has been shown that the current underreporting of these income sources is not an important source of variation in the ranking across countries.

22 See Katz and Murphy (1992) and Katz and Autor (1999). Autor et al. (2008) and Acemoglu and Autor (2011) argue for the use of full-time workers, while Lemieux (2006) proposes using all employees.

23 This spatial deflator has been defined within the SEDLAC Project as the average for Latin America. The ideal analysis should not only consider specific price differences by country, but also the differences among regions depending on differences in the size of cities. 24 See Bourguignon, Ferreira, and Lustig (2005) for Brazil; Arndt, Sam, and Vicenzo (2015) for Mozambique; Démurger, Fournier, and Li (2006) for China; and Slesnick (2002) for the United States.
} 
Figure 1. Benchmarking inequality in Latin America with respect to other developing regions, 2013

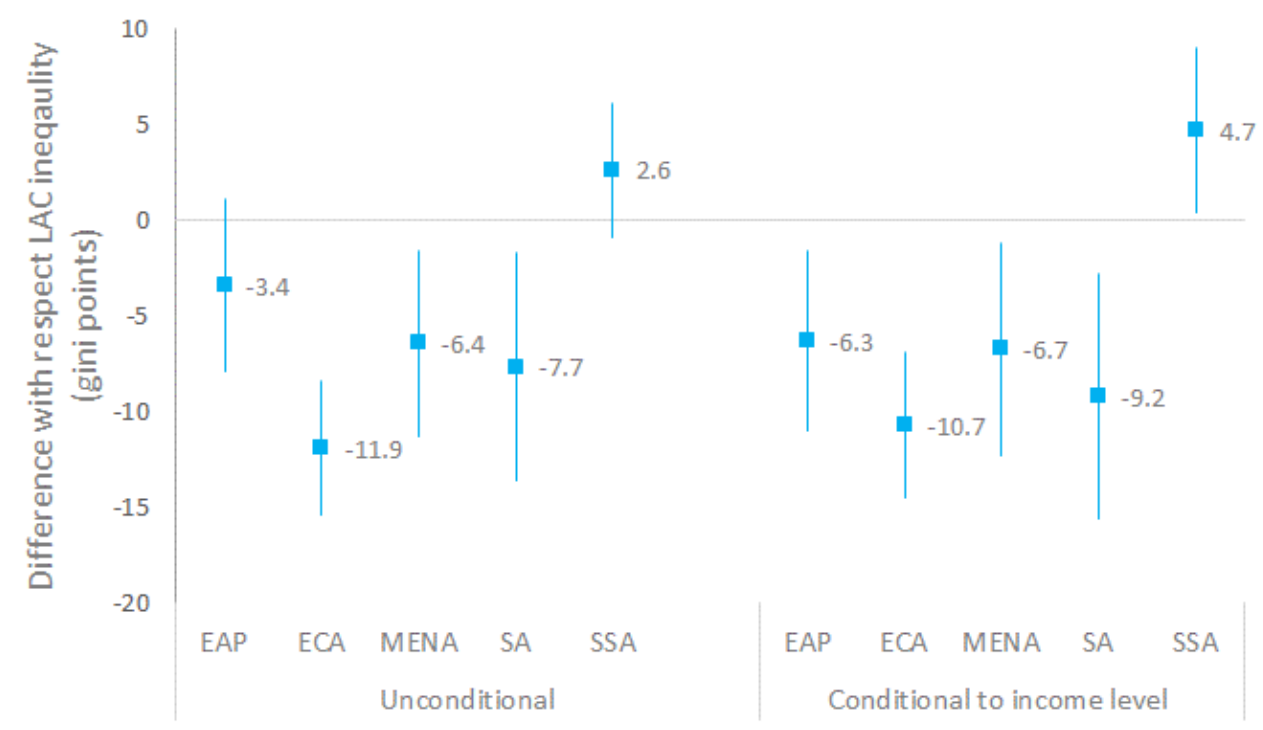

Source: Calculations based on 2015 data in PovcalNet (online analysis tool), World Bank, Washington, DC, http://iresearch.worldbank.org/PovcalNet/.

Note: The unconditional data represent the value of the coefficient of a regional dummy variable of a linear regression model with, as dependent variable, the latest available Gini coefficient for each country. To account for the differences in income level (conditional on the income level), we regress the Gini coefficient on a set of regional dummies and the log of per capita GDP as an independent variable. The calculations utilize data from the most recent year available for each of the 147 countries included in the analysis. Approximately 71 percent of the most recent data points refer to 2008-13. To compare the income Gini and the consumption Gini, the analysis, following Alvaredo and Gasparini (2015), multiplies all Gini coefficients of household per capita income by a factor of 0.86. This factor corresponds to a Latin America-specific average of consumption-income Gini ratios, calculated using data on seven Latin American countries, on which there is frequent information on consumption and income. The analysis follows the World Bank classification into six geographical regions whereby EAP = East Asia and the Pacific, ECA = Eastern Europe and Central Asia, LAC $=$ Latin America and Caribbean, MENA = Middle East and North Africa, SA = South Asia, and SSA = Sub-Saharan Africa.

This result holds after one controls for income level (right panel of figure 1). Moreover, Latin America looks more unequal than what would be expected considering its income level, suggesting that the region suffers from an excess of inequality (Londoño and Székely 2000). In all the less unequal regions (that is, those below the zero line), except the region of Eastern Europe and Central Asia, inequality is even greater if the income level is considered in the analysis.

According to our analysis of unconditional differences (the left panel of figure 1), the mean Gini coefficient among countries in Latin America is approximately 2.6 points lower than the average Gini coefficient among countries in Sub-Saharan Africa, but almost 12.0 Gini points higher than the average Gini among countries in Eastern Europe and Central Asia. The latter is ranked as the most equal region in the world using unconditional measures, but, nonetheless, it is not statistically different from South Asia if income differences are taken into account. Moreover, the average level of total income inequality among the countries of East Asia and the Pacific is 3.4 Gini points below the value for Latin American countries, albeit this difference increases to 6.3 Gini points if income is considered (right panel, figure 1) and becomes statistically no different from the value for the Middle East and North Africa region. In general, the differences conditional on income level reveal a clear gap in inequality between all the regions of the world and Latin America. In addition, an analysis of extreme values rather than a comparison of the regional averages reveals that, among the 20 most unequal countries on which data are available, eight are in Latin America, while the rest are in Sub-Saharan Africa.

Despite its rank as the second most unequal region in the world, Latin America has experienced a steady narrowing in income inequality since the early 2000s that has been observed in every country on which frequent household survey data are available, except Costa Rica. This is at odds with what has happened in other regions across the globe. According to Alvaredo and Gasparini (2015), both the Eastern Europe and Central Asia region 
and the East Asia and the Pacific region experienced widening income inequality over the past decade, while data on the Sub-Saharan Africa region and the South Asia region show almost no change in inequality over the same period. Data on the Middle East and North Africa region reveal a modest decline during the 2000s, but the sample in this region only includes five countries, and data collection there is rather infrequent. The authors conclude, then, that the narrowing in income inequality in Latin America in the 2000s has been remarkable.

To analyze regional trends in several parts of this study, we use unweighted averages of the countryspecific trends for which data are available (unless otherwise indicated). This means that each analysis presented will be the average of the same indicator at the country level. Since not all the countries have information for all the years, a simple linear interpolation is conducted to have balanced panel data. If data are missing at the beginning or at the end of each country series, they are replaced by the value of the nearest year on which information is available. However, excluding these interpolations and extrapolations does not change qualitatively the results of the long-term trends.

Our analysis of the Latin America region (figure 2), which is based on comprehensive harmonized household survey data (the SEDLAC database), reaches a conclusion similar to the conclusions of previous studies, showing that the total income Gini coefficient in the region rose moderately during the 1990s (Londoño and Székely 2000), dropped significantly during the 2000s (Gasparini et al. 2009; López-Calva and Lustig 2010), and experienced a slowdown and possible stagnation during the early 2010s (Cord et al. 2016; Gasparini et al. 2016). Although it may still be too early to claim with any certainty that stagnation has occurred in the regional trends in income inequality, both regional aggregates in figure 2 represent evidence of a slower pace in inequality reduction since 2010, more marked in the case of the weighted average because of the upward inequality in Mexico and the slowdown in the decline in inequality experienced in Brazil (Cord et al. 2016).

The decline in income inequality observed in the region during the period is the most synchronized of these three trends. It is robust to the inequality measure ${ }^{25}$ and to the aggregation method, both weighted and unweighted averages of country values. Moreover, the decline occurred in 16 of 17 countries in the region, ${ }^{26}$ and it holds once the comparability issues of the country-specific trends are taken into account. In contrast, the increase in regional inequality during the 1990s and the slowdown after 2010 hides a certain amount of heterogeneity at the country level. For instance, during the 1990s, Brazil, Mexico, and Chile experienced a slight fall in total income inequality, in contrast with other countries such as Argentina, Uruguay, and Honduras, which witnessed sharp increases. Moreover, the still recent slowdown in the 2010s has meant different trends in some countries such as Bolivia, Costa Rica, and Mexico, where inequality has increased, while other countries experienced a slowdown, such as Chile and Brazil.

25 Our analysis also reaches this conclusion based on the Theil index, the mean log deviation, the Atkinson index, and the $90 / 10$ ratio. 26 Only Costa Rica exhibited an increase in inequality over the first decade of the 2000s (figure C.1, panel b). 
Figure 2. Total income inequality, Latin America, 1993-2013

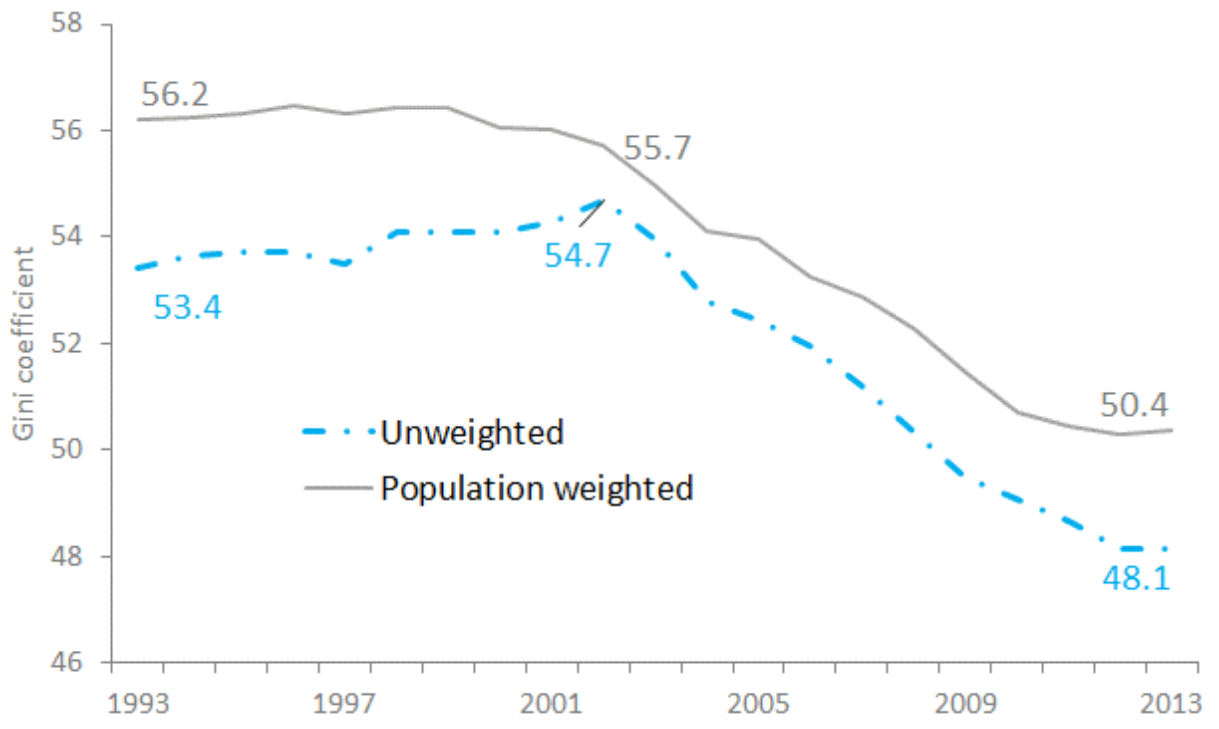

Source: Calculations based on SEDLAC (Socio-Economic Database for Latin America and the Caribbean). See annexes A.1 and A.2 for details.

Note: The underlying data represent household per capita income inequality (Gini) for each country. They have been multiplied by 100 . The regional aggregates are weighted and unweighted averages across the Gini values of the 17 countries on which frequent data are available in the SEDLAC database. If a country-year is missing, an arithmetic linear interpolation is applied. To address missing data at the beginning or at the end of the series, the analysis uses the value of the nearest year for which information is available.

Following a decomposition method proposed by Paes de Barros, Foguel, and Ulyssea (2007) that is based on counterfactual simulations, we identify the factors associated with the changes in income inequality in each country over the aforementioned periods of analysis (see annex C). The method allows us to identify the income source most closely linked to the changes in inequality from among household nonlabor income, labor income per paid worker in the household, and the share of paid workers in the household; the last component may be seen as the joint effect of household composition and employment rates. ${ }^{27}$ Our analysis shows that labor earnings were the main component associated with the moderate widening in income inequality across all the countries in Latin America during the last two decades (figure C.1). In general, we find evidence that labor markets were equalizing in terms of prices (labor income per paid worker in the household) and quantities (the share of working adults in the household) during the last two decades.

Based on the findings across the literature, the apparent long-term relationship between total income inequality (figure 2) and labor inequality, measured using the Gini coefficient of hourly earnings, is not surprising (figure 3). Our analysis allows us to conclude that there was a strong correlation between the distribution of total household income and the distribution of hourly earnings over the past two decades. ${ }^{28}$ In particular, the Gini coefficient of hourly earnings rose by around 2 Gini points between 1993 and 2002, and it dropped thereafter by more than 6 Gini points, to reach 0.410 in 2013 . As in the case of changes in the Gini of

\footnotetext{
${ }^{27}$ The method generates entire counterfactual distributions and can thus capture the heterogeneity of the changes across the distribution. This nonparametric decomposition has typically been used to shed light on the main factors influencing the changes in income inequality. The method should not be relied on to draw conclusions on causal effects because it suffers from problems of equilibrium inconsistency, given that it uses a partial equilibrium framework. Nonetheless, the methodology may be used as an informed approximation of the main factors that may be associated with changes in the income distribution.

${ }^{28}$ Figure C2.1 shows the coefficient of a regression between the total income Gini and the labor income Gini at the country level. The significance of the coefficient is evidence of the strong relationship between both variables and how this relationship grew during the fall of total income inequality after 2003.
} 
total income inequality, the fall of labor income during the 2000s is robust to the choice of aggregation method, the measures of inequality, ${ }^{29}$ the selection of countries to define the regional aggregate, and the time period.

Figure 3. Trends in labor income inequality, Latin America, 1993-2013

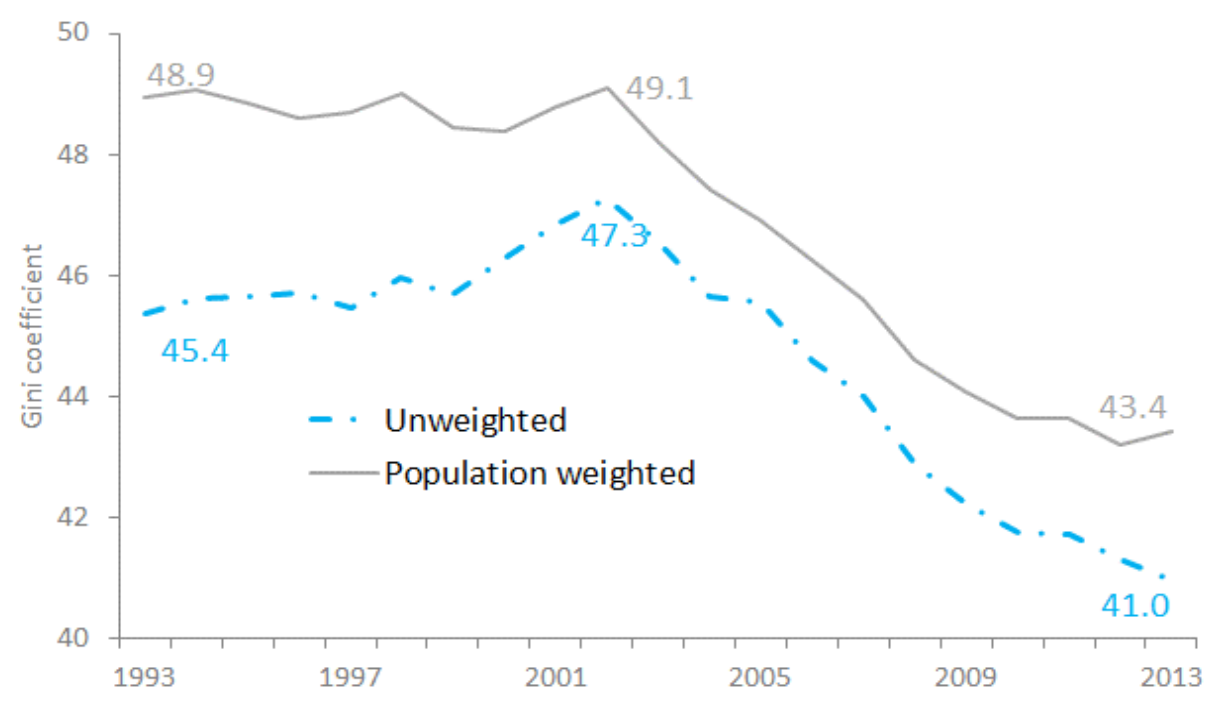

Source: Calculations based on the SEDLAC database. See annexes A.1 and A.2 for details.

Note: The underlying data represent the hourly wage Gini for each country and year. They have been multiplied by 100 . The sample covers full-time, wage, and self-employed workers 15-64 years of age. The values of the 1st and 100th percentiles of the earnings distribution were trimmed by each gender-education cell. The regional aggregates are weighted and unweighted averages across the Gini values of the 17 countries on which frequent data are available in the SEDLAC database. If a country-year is missing, an arithmetic linear interpolation is applied. To address missing data at the beginning or at the end of the series, the analysis uses the value of the nearest year for which information is available.

Moreover, the trend reversal of earnings inequality in Latin America was a unique phenomenon relative to other countries in the world. ${ }^{30}$ Figure 4 shows the differences in labor earnings inequality in any year between 1993 and 2013 with respect to labor earnings inequality in 2002 estimated from a country-level panel data analysis. While Latin America shows a slight increase during the 1990s, followed by a strong and fully synchronized trend reversal after 2002, the rest of the world, mostly the developed world, showed a slight increase during the 1990s and the 2000s. In 1995, a country in Latin America exhibited lower labor earnings inequality, on average 2.6 Gini points lower, with respect to the value in 2002, while a country outside Latin America, mostly in the developed world, had labor earnings at about 0.9 Gini points below the value in 2002 (and not statistically different from zero). After 2002, Latin America experienced a steady decline in earnings inequality, and, in 2013, a country in the region showed labor earnings inequality of about 6 Gini points below the value in 2002, while countries outside the region had a Gini about 1.3 Gini points above the value in 2002.

${ }_{29}$ The same trends are observed in the Theil index, the mean log deviation, the Atkinson index, and the 90/10 ratio.

30 See annex A.3 for information on the data sources and the selection of countries outside Latin America and the Caribbean. 
Figure 4. Difference in the labor earnings Gini with respect to the value in 2002, Latin America and selected countries, 1993-2013
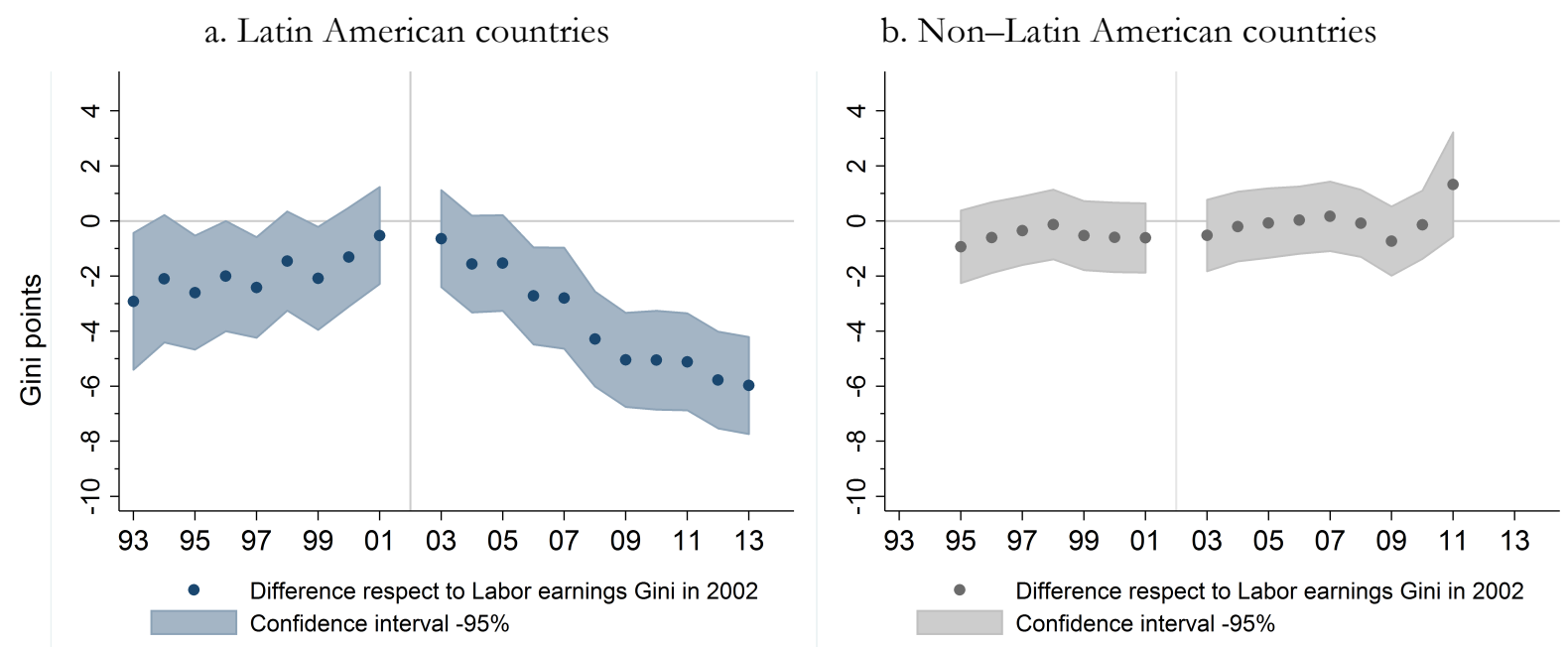

Source: Venezuela, RB and the non-Latin American countries: Global Wage Report, International Labour Organization. Seventeen Latin American countries: SEDLAC database. See annex A.3 for details.

Note: The underlying data represent the hourly wage Gini among paid workers 15-64 years of age for each country and year. They have been multiplied by 100 . The values of the 1 st and 100th percentiles of the earnings distribution were trimmed by each gendereducation cell. This figure uses only the information (noninterpolated) available for each country. It shows the average difference between the labor income Ginis in any year with respect to the value in 2002. Each average value and its standard errors are estimated as part of a simple panel data specification with country fixed effects. The Global Wage Report data are not strictly comparable with SEDLAC data. In some countries, different types of surveys were used, and the sample and trimming criteria are different.

Most Latin American countries experienced an increase in labor earnings inequality over the 1990s (with the exception of Bolivia, Brazil, El Salvador, and Nicaragua), but this phenomenon reverted during the 2000s, when all countries in the region, except Costa Rica, experienced a significant narrowing in labor income inequality (figure 5). In addition, such a homogenous trend reversal in labor income inequality contrasts with the increase or modest decline in labor income inequality in countries on which data are available in the 1990s and 2000s. ${ }^{31}$

\footnotetext{
${ }^{31}$ Despite the wealth of literature and the availability of new harmonized datasets with comparable data on total income inequality, the literature and harmonized data on labor earnings inequality are deficient. We have been able to identify only one source of harmonized data on labor earnings inequality: Global Wage Report (database) International Labour Organization, Geneva, http://www.ilo.org/ilostat/GWR?_afrLoop=778317871631331\#\%40\%3F_afrLoop\%3D778317871631331\%26_adf.ctrl-

state\%3D5ldkmifc_319. Combined with the data of the SEDLAC database, this dataset is useful in illustrating the trend reversal in labor earnings inequality experienced across Latin America relative to other regions during the 2000s. After sorting countries according to the largest average decline in income inequality during the 2000 s, we may observe that Latin American countries rank among the countries with the largest reductions in labor earnings inequality.
} 
Figure 5. Annual changes in the labor income Gini, Latin America and selected countries, ca. 1993-2003 and ca. 2003-13
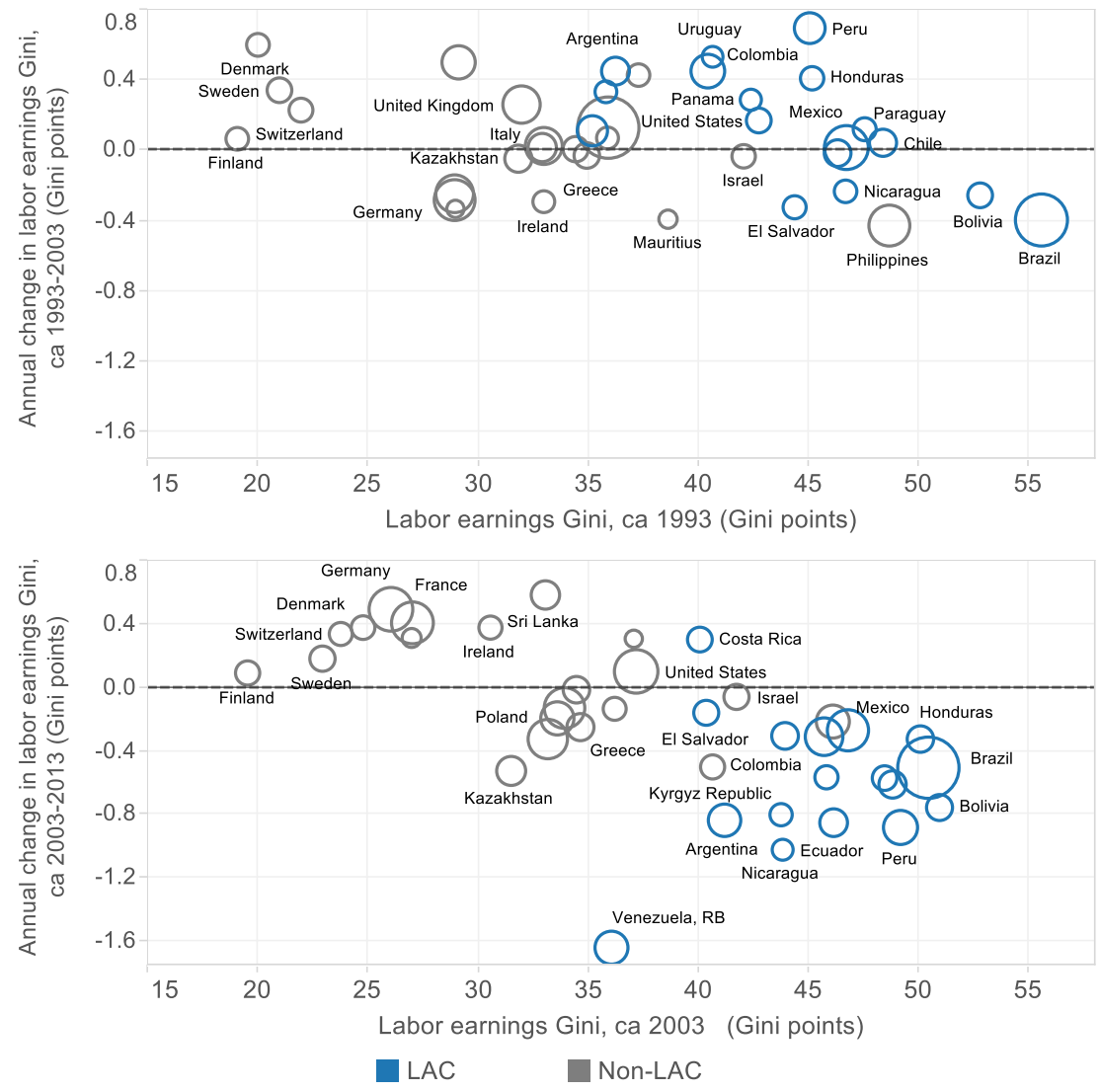

Source: Venezuela, RB and the non-Latin American countries: Global Wage Report, International Labour Organization. Seventeen Latin American countries: SEDLAC database. See annex A.3 for details about the underlying data and Annex B for circa periods.

Note: The data have been multiplied by 100. For SEDLAC countries, the sample covers full-time, wage, and self-employed workers $15-$ 64 years of age. The values of the 1st and 100th percentiles of the earnings distribution were trimmed by each gender-education cell. The Global Wage Report data are not strictly comparable with SEDLAC data. In some countries, different types of surveys were used, and the sample and trimming criteria are different. The size of the bubbles represent the population of the country.

The most pronounced drop in earnings inequality since 2003 was observed in República Bolivariana de Venezuela, although the relevant data are not strictly comparable because they are provided through a harmonization process that differs relative to the process in the rest of Latin America (an International Labour Organization method instead of the SEDLAC method). República Bolivariana de Venezuela is followed by Uruguay (urban), Nicaragua, Peru, Ecuador, and Argentina (urban). The sharp contrast among the trends in labor income inequality in Argentina, Nicaragua, and Peru, which experienced large increases in labor income inequality over the 1990s, are of particular interest. In contrast, Costa Rica was the only country in Latin America on which data are available that experienced a widening in labor income inequality in the 2000s and, thus, across two consecutive decades.

The trend reversal in labor inequality can be illustrated through a graphic on the growth of real hourly earnings in Latin America. Thus, figure 6 shows that average earnings in Latin America rose at the bottom, the middle, and the top of the labor income distribution over 2002-13, after experiencing no change or even a slight reductions between the 1990s and early 2000s. The largest increase occurred among workers at the bottom of the earnings distribution, who experienced a rise of more 50 percent in real earnings in 2002-13. In contrast, the most well paid workers - those at the top of the labor income distribution-experienced a modest average earnings increase of 16 percent over the decade. Moreover, workers at the median of the earnings 
distribution experienced greater growth in labor incomes relative to workers at the top of the distribution, but at a lower rate relative to workers at the bottom of the distribution. Overall, this suggests that the rise in labor inequality occurred during a plateau in terms of growth, while the decline in labor inequality occurred during an undoubted expansion in real earnings.

Figure 6. Growth in real hourly earnings along different points of the labor income distribution, Latin America, 1993-2013

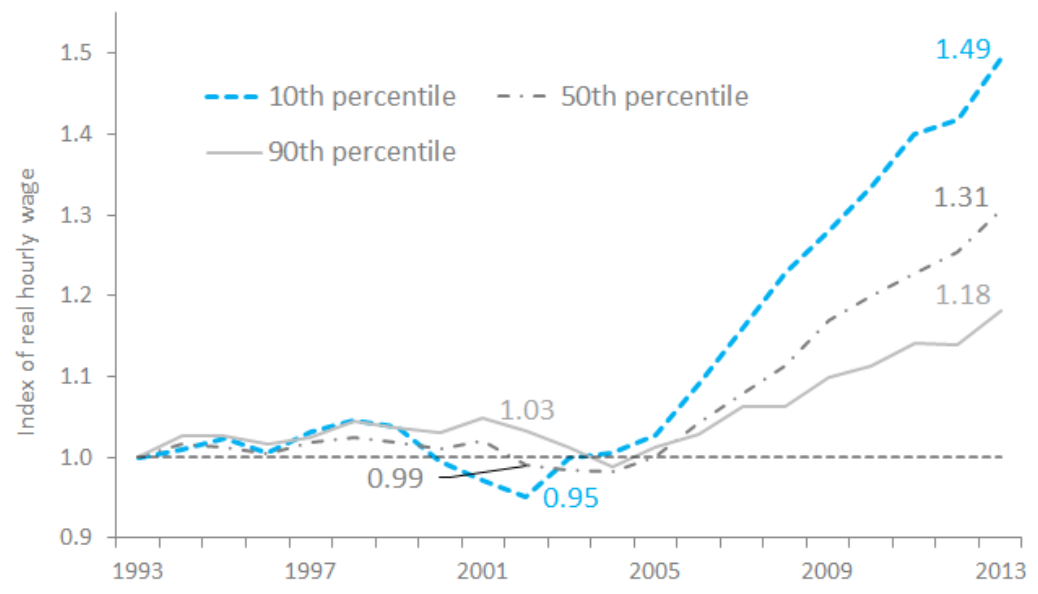

Source: Calculations based on the SEDLAC database. See annexes A.1 and A.2 for details.

Note: The data were indexed to the 1993 values. The underlying data represent the index of hourly earnings for each percentile in the distribution in each country. The sample covers full-time, wage, and self-employed workers 15-64 years of age. The values of the 1st and 100th percentiles of the earnings distribution were trimmed by each gender-education cell. The regional aggregate is the unweighted average across the index of hourly earnings values of the 17 countries on which frequent data are available in the SEDLAC database. If a country-year is missing, an arithmetic linear interpolation has been applied. To address missing data at the beginning or at the end of the series, the analysis uses the value of the nearest year for which information is available.

In analyzing the distributional differences in earnings growth (presented in figure 6), we observe that the rise of inequality was the result of a dramatic reduction in real earnings at the bottom of the distribution, while the earnings at the middle and the top showed a parallel trend: moderate gains in real terms at the top of the distribution and almost null growth in the middle. In contrast, during the period of decline, a negative and monotone relationship between earnings growth and the position in the earnings distribution took place. This is confirmed in figure D.1 (panel b), which shows how, during the period of decline, both the lower and upper tail distribution narrowed, while, during the 1990s, the lower tail inequality was the one that suffered from relatively high increases, while the upper tail rose to a lesser extent.

To test for monotonicity in the relationship between earnings growth and its position in the earnings distribution, we plot the annualized growth at each percentile of the hourly wage distribution for the rise period (1993-2002) and the decline period (2002-13) (figure 7). Earnings growth had a monotonic relation with the percentiles of the earnings distribution in both periods. However, during the period of the rise in labor earnings inequality (1990s), this relationship was monotonically increasing, while, during the period of fall of labor earnings inequality (2000s), it was monotonically decreasing.

On the other hand, during the 1990s, real growth was mostly negative or neutral, except for the upper tail of the earnings distribution. In contrast, during the 2000s, real growth was positive across all percentiles of the earnings distribution. Indeed, the redistribution momentum of labor income led to gains in real terms for almost all parts of the distribution except the top, in particular those above the 97 th percentile. ${ }^{32}$

32 Our analysis does not includes changes in the top 2 percent of the distribution because the household surveys suffer from underreporting and inadequate coverage among top earners. 
Figure 7. Growth incidence curve, real hourly earnings, Latin America, 1993-2002 and 2002-2013

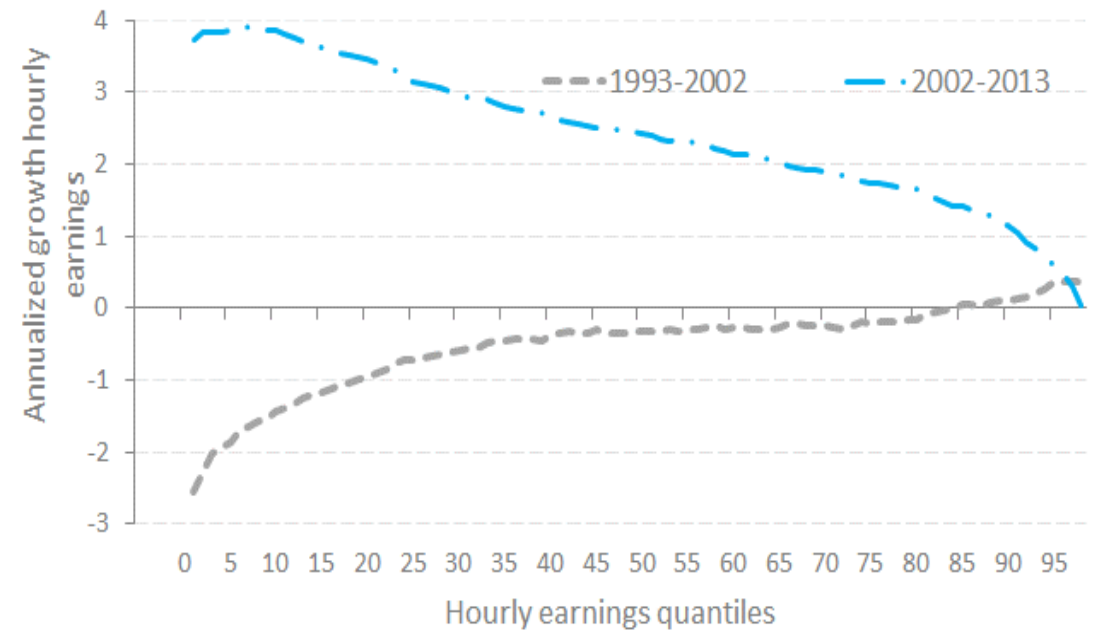

Source: Calculations based on the SEDLAC database. See annex A.1 and A.2 for details.

Note: The underlying data represent the annualized growth of earnings for each percentile of the earnings distribution in each country during the specified period. They have been aggregated at the regional level as an unweighted average across the values of the earnings distribution in the 17 countries on which frequent data are available in the SEDLAC database. The sample covers full time, wage, and self-employed workers 15-64 years of age. The values of the 1st and 100th percentiles of the earnings distribution were trimmed by each gender-education cell. If a country-year is missing, an arithmetic linear interpolation is applied. To address missing data at the beginning or at the end of the series, the analysis uses the value of the nearest year on which information is available.

Although the explanation for such dynamic performance in less well paid jobs is unclear, institutional factors may have benefited workers at the bottom of the earnings distribution through, for example, policies to raise the minimum wage above the inflation rate, fiscal incentives to hire young workers with little experience, or reductions in payroll taxes that stimulated the mobility of workers from the informal sector to the formal sector. These potential explanations should be evaluated considering not only the isolated effect of each channel, but also how these effects interacted with simultaneous changes in labor supply and the skill demands associated with these jobs. For instance, raising the minimum wage could have different effects on inequality during boom periods when labor demand is growing and during periods of recession.

Other plausible factors involved in the better performance among less well paid jobs may have been the interaction between demand and supply, particularly a greater demand for commodities, which may have produced an expansion in the demand in sectors intensive in unskilled and low-skilled workers (measured through education) in both the tradable and nontradable sectors (World Bank 2015). This relationship between a commodity boom and earnings growth among less well educated workers is linked to the pecuniary externalities that the boom generates in nontradable sectors, which are intensive in unskilled labor in developing countries (Goderis and Malone 2011). The phenomenon cataloged as a commodity boom observed in Latin America during the 2000s particularly benefited countries in South America and, coupled with supply-side factors such as skill upgrading among the labor force, could have fostered a relative scarcity of workers with primary or secondary educational attainment and, in turn, raised their earnings, as in the case of Argentina and Chile (Gasparini and Cruces 2010; Pellandra 2014).

Now that we have documented the significant inverted U-shaped trend of labor earnings inequality in Latin America since the early 2000s, we turn our attention to the factors that may have played a role in the narrowing in labor earnings inequality across the region. Next, we focus on the underlying changes generated in the labor market by the different characteristics that affect overall labor returns and that can be examined through the microdata used in this study.

\section{The dynamics of labor market returns}

The inequality in the value paid in the labor market to each worker may be seen as a result of differences 
in the productivity of workers, which is closely related with the differences in the attributes of workers, plus discrepancies that are usually called an error term. Some of these attributes can be easily observed (such as education and experience), while others are more difficult to observe or measure (such as ability and soft skills). Using the framework of Autor and Katz (1999), Lemieux (2006), and Autor, Katz, and Kearney (2008), this section analyzes overall inequality by separating the range in the earnings of workers with different observed attributes and the range in the earnings of workers with similar observed attributes. The latter term-residual earnings inequality - may be a product of differences in the unobserved skills among otherwise equal observable workers, an idiosyncratic variance in certain types of workers, asymmetries in the information about human capital prices across firms, or a kind of measurement error. For our analysis, we estimate standard Mincer equations (Mincer 1974), but in a semiparametric way using a multiple dummy specification, as follows:

$$
\log (W)=f(\text { education, experience, gender, region, e), }
$$

where $W$ corresponds to the real hourly earnings of full-time workers to minimize the potential impact that measurement errors in hours or salary can have on the hourly wages of part-time workers. In addition, considering only full-time workers allows us to control partially by the unobservables of those who are not fully attached to the labor market. Education is measured through three educational categories: college, high school, and primary education. Experience refers to potential experience and is divided into five groups: $0-5$ years, $6-$ 10 years, 11-20 years, 21-30 years, and 31+ years. Gender and urban are dummies for men and for urban residence. Regarding the definition of the education categories mentioned above, we follow country-specific definitions rather than homogenous cutoffs based on years of education as was proposed by Gasparini et al. (2011). ${ }^{33}$ Under this country-specific definition, college refers to university degrees or completed official postsecondary education; high school refers to upper-secondary education, incomplete college education, or no formal education; and primary refers to no education, incomplete or complete primary education, and incomplete secondary education. Experience refers to potential experience, which is age in years, minus years of education, minus 6; it assumes short spells of unemployment during the average adult life.

For simplicity, we assume $f\left({ }^{*}\right)$ is a linear function so that the parameters associated with each covariate can be interpreted as the returns to worker characteristics. We note that the mechanisms through which returns to human capital (education and experience) and other worker characteristics change are the result of interactions among demand, supply, and institutional factors. For instance, an observed reduction in the returns to college may arise because of either a less well educated labor force or a higher demand for workers with higher educational attainment.

\section{The trends in explained and unexplained earnings inequality}

Figure 8 plots inequality measured through the variance in the log of the hourly wage and residual earnings inequality, which is defined as the part of inequality that is not fully explained by worker attributes. The first finding that arises from a comparison between overall and residual earnings inequality, according to figure 8 , is that the inequality in labor earnings in the average country is mostly a result of the inequality across workers with similar observable attributes. About 70 percent of the overall inequality, the dark line in figure 8 , in a particular year arises from the residual component, the blue line in figure 8 , rather than from differences in the earnings between workers with different attributes. This result is not surprising, since the literature on labor market returns find that the Mincer model has limited explanatory power on the variance in wages. Even with a fully specified model with interactions between all variables and using sector and occupation, which are highly correlated with education, the size of the residual explains at least half the total variance (Silva et al. 2016).

\footnotetext{
33 The reason to change this tradition is that a country's labor market may offer pay based on educational attainment according to the structure of the country's educational system rather than international standards in the description of primary or secondary education.
} 
Figure 8. Overall and residual earnings inequality, Latin America, 1993-2013

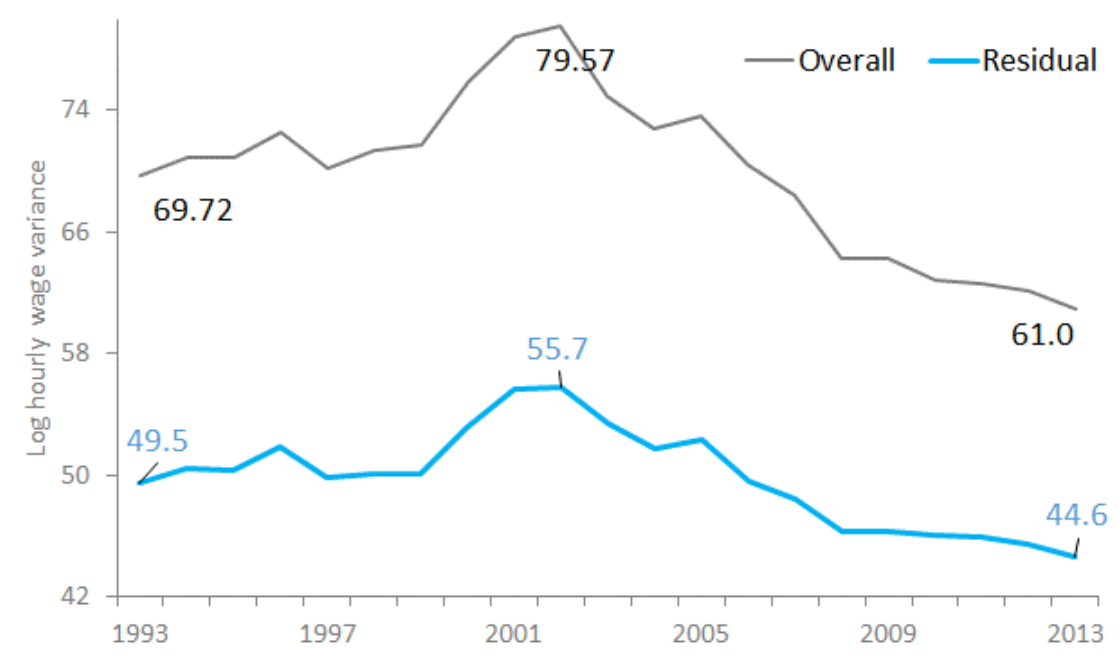

Source: Calculations based on the SEDLAC database. See annexes A.1 and A.2 for details.

Note: The underlying data represent the log variance of the hourly earnings in each country. The residual component is the variance that is not explained by the Mincer model specified in equation 1 . The data are aggregated at the regional level as unweighted averages across the $\log$ variance of the 17 countries on which frequent data are available in the SEDLAC database. The data have been multiplied by 100 . The sample covers full time, wage, and self-employed workers 15-64 years of age. The values of the 1st and 100th percentiles of the earnings distribution have been trimmed by each gender-education cell. If a country-year is missing, an arithmetic linear interpolation is applied. To address missing data at the beginning or at the end of the series, the analysis uses the value of the nearest year for which information is available.

The second and most important finding of this analysis is an explanation for the variations in overall inequality and in the residual component during the last two decades. Between 1993 and 2002, the total variance in $\log$ wages increased from 69.7 to $79.6 \log$ points. Most of this increase, about 6.1 of $9.8 \log$ points, occurred in residual wage inequality, which means that about 60 percent of the increase in inequality was the result of a widening in the inequality in the earnings of workers with similar observable attributes. Similar results were found on the decline in labor inequality in the $2000 \mathrm{~s}$, when 10.7 of $18.6 \mathrm{log}$ points were explained by a reduction in the residual component. Although, in absolute terms, the contribution of the observable component to the rise or decline in labor inequality seems to have been relatively modest, this is not the case if the size of the contribution is taken into account, considering that it explains only 30 percent of the total inequality in a particular year, but still explains 37 percent of the rise and 42 percent of the decline. Thus, it is valid to conclude that observable inequality was an important component of the rise in earnings inequality in the 1990s and of the decline in earnings inequality in the 2000s, though more important in the latter case. Thus, for instance, during the 2000s, the observable component was reduced by a third, while residuals inequality was reduced by less than a fifth.

In sum, most of the inequality—about 70 percent—in earnings is associated with attributes that are beyond the observable human capital characteristics of workers. However, the rise and decline in labor income inequality were a product of the rise and decline in the inequality between workers with different characteristics and the residual earnings inequality. Even if most of the reduction-about 60 percent-is explained by the decline in residual inequality, offsetting the increase during the 1990s, the pace of this decline was slower than the pace of the decline in observed inequality.

\section{The trends in labor market returns}

This subsection attempts to disentangle the price for each observable attribute that a worker offered on the labor market across Latin America over the last two decades. Examining the trend in labor market returns will allow us to determine the correlation between the decline in total earnings inequality and changes in the education or experience premium. Based on the results of the earnings Mincer equations, we aim to provide 
evidence for the hypothesis that the trend reversal in labor income inequality has been associated with a decline in the education and experience premiums. In addition, we also use the estimation of the gender and urban earnings gap, because they are exogenous to decisions on education and experience and allow us to identify whether changes in earnings differentials that previously existed — the gender earnings gap and the urban-rural earnings gap-may be correlated with the trend reversal observed in labor income inequality.

\section{Trends in the education premia}

According to the Mincer equation, the decline in the returns to education observed during the early 2000s is linked to the trend reversal in labor income inequality. We find strong evidence of a parallel movement among the Gini coefficients of labor income inequality and the education premium in the region. ${ }^{34}$ Labor income inequality declined from 0.473 in 2002 to 0.410 in 2013 . According to our analysis, which relies on a standard Mincer framework, the average gap between college-educated workers and workers with primary schooling increased slightly (around 10 percent) during the 1990s and narrowed by 25 percent after 2003 (figure 9).

Figure 9. The earnings gap between workers with greater educational attainment and workers with primary education or less, Latin America, 1993-2013

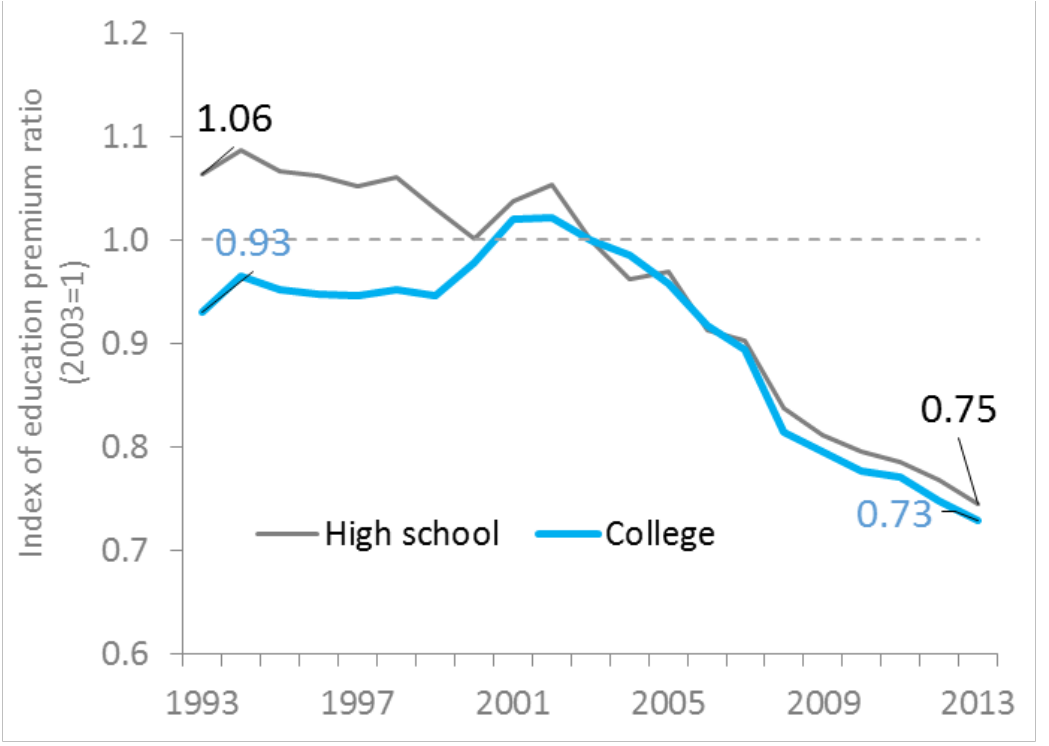

Source: Calculations based on the SEDLAC database. See annexes A.1 and A.2 for details.

Note: The underlying data represent the returns to education by country and year. The figure shows the ratio of the expected returns for workers with the indicated educational attainment with respect to workers with primary education or less. The educational categories — college, high school, and primary education or less (reference category)—follow country-specific education systems; see section 3 and equation 1 for details. The sample covers full-time, wage, self-employed, and paid workers 15-64 years of age. The values of the 1st and 100th percentiles of the earnings distribution were trimmed by each gender-education cell. The regional aggregate is an unweighted average across the returns to education of the 17 countries on which frequent data are available in the SEDLAC database. If a country-year is missing, an arithmetic linear interpolation is applied. To address missing data at the beginning or at the end of the series, the analysis uses the value of the nearest year for which information is available.

Moreover, after being almost constant for most of the 1990s, the average premium associated with workers with secondary educational attainment relative to workers with primary education or less also declined by about 25 percent. Thus, we may conclude that, although the educational premiums have declined since the early 2000s, the earnings gap between college-educated workers and workers with primary education widened slightly during the 1990s (as did labor income inequality), which contrasts with what happened to the earnings gap between

\footnotetext{
${ }^{34}$ Figure C2.2 in annex C shows the coefficient of a regression between the labor income Gini and the education premium (college relative to primary or less educational attainment). The results plotted in the figure reveal a significant and strong relationship among the variables that increased after 2007.
} 
workers with secondary education and workers with primary education, which was stable during the 1990s and then narrowed after 2002.

Both panels of figure 10 plot the estimated variations in the returns to schooling for the 17 countries in Latin America, plus Russia, South Africa, Turkey, and the United States. In particular, the left panel shows the annual changes in the country-specific labor earnings premiums of workers with secondary education relative to workers with primary or less education, and the right panel shows the annual changes in the country-specific labor earnings premiums of college-educated workers relative to workers with primary or less education. The variations have been truncated at 20 percent in absolute terms to control for outliers.

Figure 10 Annual growth rate of the education premium and labor income inequality, selected countries,

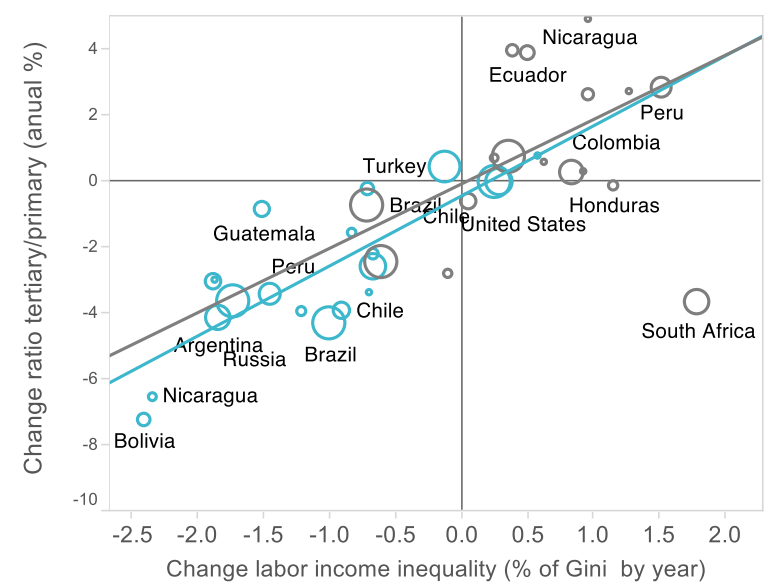

1993-03

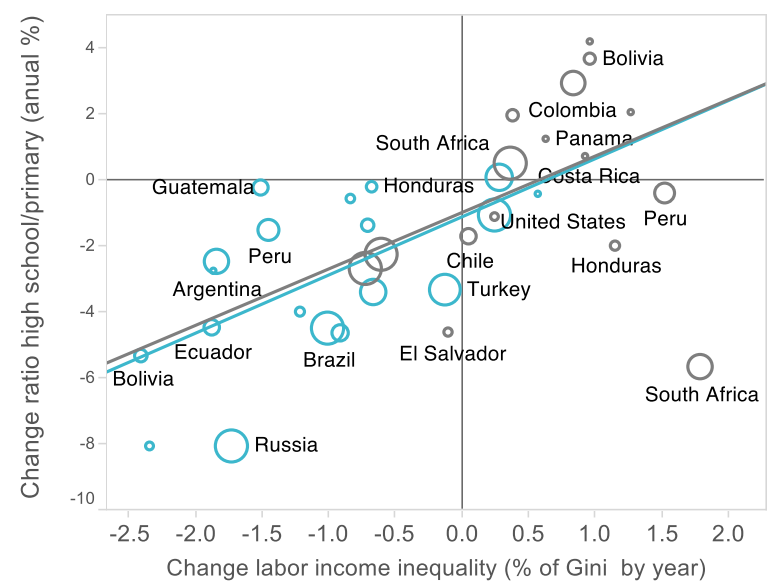

2003-13

Sources: Seventeen Latin American countries: SEDLAC database; Russia: the Russia Longitudinal Monitoring Survey; Post Apartheid Labor Market Series: South Africa; Turkey: I2D2-LFS; the United States: I2D2-IPUMS. See annexes A.1 and A.2 for details.

Note: The underlying data represent the change in wage inequality and the change in the earnings premiums for each country and circa period. The years selected for each country-circa combination may be different depending on survey availability and to assure, to the extent possible, within-country comparability for each period; see annex B.1 for details. In the case of the y-axis, the growth rate of the education premium is plotted. For the x-axis, the growth rate of the labor income Gini is plotted. The educational categories-college, high school, and primary education or less (reference category) — follow country-specific education systems; see section 3 and equation 1 for details. The sample covers full time, wage, and self-employed workers 15-64 years of age. The values of the 1st and 100th percentiles of the earnings distribution were trimmed by each gender-education cell. The size of the bubbles represent the population of the country.

Our results show that countries with the most substantial decline in labor income inequality during the past decade (the countries on the left side of the $\mathrm{x}$-axes) are also the countries that experienced negative expansion in the earnings gap (the blue bars). This pattern is more consistent in the declines in the earnings premiums of workers with college education, with the notable exception of South Africa, Russia, and some Latin American economies during the 1990s: Ecuador and, to a lesser extent, Chile and Uruguay (figure 10, panel b). The case of Costa Rica is also noteworthy because Costa Rica is the only country in which labor earnings inequality did not narrow during the last decade. In Costa Rica, the earnings premium of workers with secondary education widened relative to workers with primary education, although the earnings gap between workers with college education and workers with primary education narrowed. Russia and Bolivia, the countries exhibiting the largest decline in earnings inequality during the 2000s, showed a significant reduction in both education premiums. Earnings gaps-both between workers with secondary education and workers with primary education and between workers with college education and workers with primary education-were heterogeneous and less volatile between 1990 and 2003, although there was no clear pattern. 


\section{Trends in the experience premium}

Next, we turn our attention to trends in the experience premium. We approximate the variable of experience through the difference between age and years of education, minus 6 . This is a standard measure in the literature and assumes that the full-time years of adulthood not involving study were spent working. For our analysis, we consider five intervals of experience: $0-5$ (entrants, the reference category), $6-10,11-20,21-$ 30 , and more than 31 years of experience.

We find evidence that work experience premiums may be related to the decline in labor earnings inequality. The experience premium declined at a more rapid pace beginning in the early 2000s (figure 11). The apparent decrease in labor earnings among the most experienced workers relative to less-experienced workers suggests that the skills gained through years of work in the labor market may be losing value, and this may represent lower earnings among older age-groups as time passes. For instance, the experience premium among the groups showing the largest difference in years of experience (31+ years of experience) relative to labor market entrants ( 0 to 5 years of experience) was reduced by almost 18 percent between 1993 and 2003. After 2004, it declined at a significantly more rapid pace, reaching a reduction of almost 40 percent in 2013. By comparison, the experience premium among the group with 6 to 10 years of experience relative to the group of labor market entrants ( 0 to 5 years of experience) showed the least dramatic decrease during the two decades, although this premium started to decline more rapidly in 2005. These results are not affected by the compositional changes of the labor force, which is aging, since these measures represent the relative differences between older (experienced) workers and younger (unexperienced) workers, independent of their relative size in the workforce.

Figure 11. The earnings gap at different ratios of potential experience, Latin America, 1993-2013

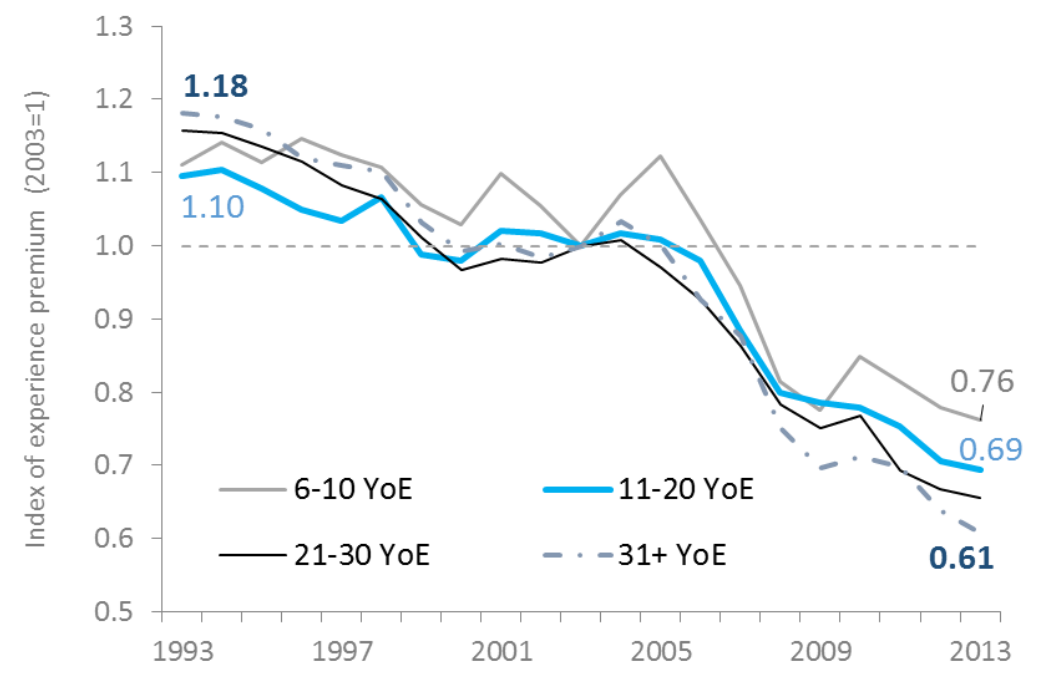

Source: Calculations based on the SEDLAC database. See annexes A.1 and A.2 for details.

Note: The underlying data represent the returns to experience by country and year. The figure shows the ratio of the expected returns for workers with the indicated years of experience ( $\mathrm{YoE}$ ) with respect to workers with $0-5$ years of experience. Experience is measured through potential experience using age and education. According to the potential experience, five groups were defined: $0-5$ (reference category), 6-10, 11-20, 21-30, and more than 31 years of experience. See section 3 and equation 1 for details. The sample covers fulltime, wage and self-employed, paid workers 15-64 years of age. The values of the 1 st and 100th percentiles of the earnings distribution were trimmed by each gender-education cell. The regional aggregate is an unweighted average across returns to experience of the 17 countries with frequent data available in the SEDLAC database. If a country-year is missing an arithmetic linear interpolation is applied. To address missing data at the beginning or at the end of the series, the analysis uses the value of the nearest year for which information is available.

We have also conducted a country-by-country analysis of changes in the premium associated with potential experience. This analysis includes the benchmarking exercise involving Russia, South Africa, Turkey, and the United States. Our results show that the growth rate of the experience premium-measured by the ratio of the group with $31+$ years of experience relative to the group with 0 to 5 years of experience and by the ratio of the 
group with 6 to 10 years of experience relative to the group with 0 to 5 years of experience-was negative in 2003-10, particularly in those countries that experienced the largest decline in labor income inequality over the period (figure 12). These countries include Bolivia, Ecuador, Nicaragua, Panama, Peru, and Russia. In contrast, the experience premium increased in Costa Rica, the only country that observed a widening in income inequality in the 2000s. The variation in the premiums across counties in the earlier period, 1990-2003, was not systematic.

Figure 12. Growth in the experience premium, the group with 6-10 years of experience relative to the group with $0-5$ years of experience, selected countries, 1990-2010

a. Low (6-10) and lower middle (11-20) experience groups

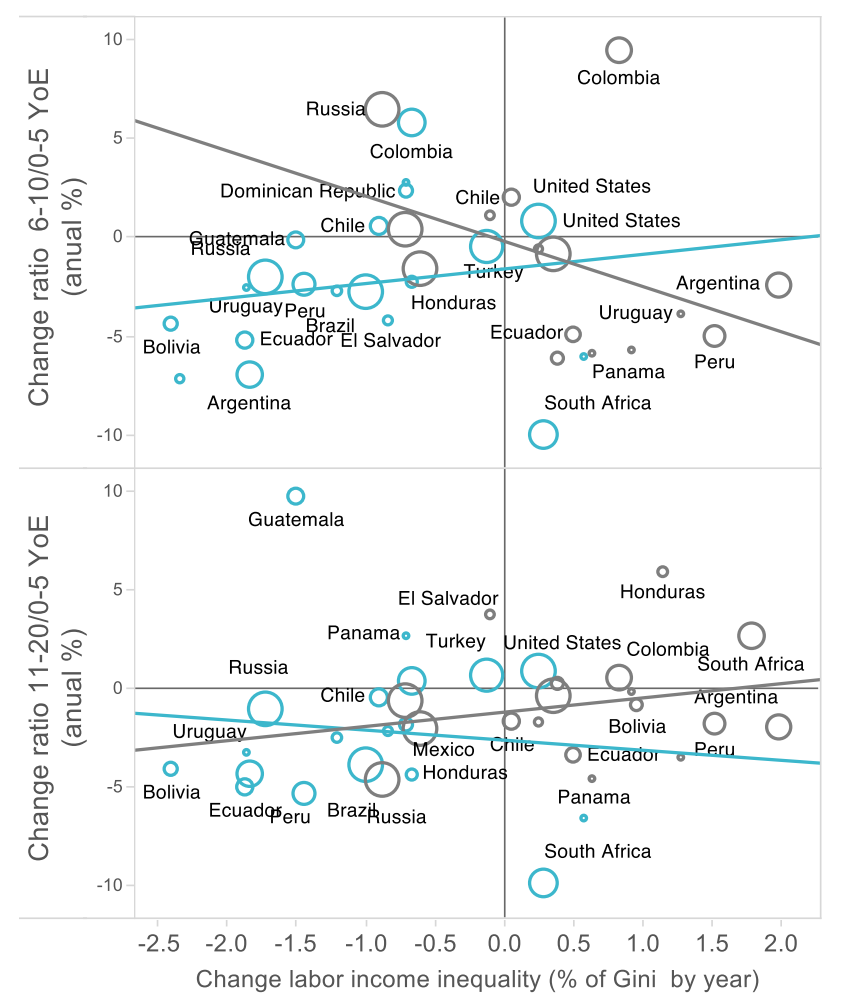

1993-03 b. Upper middle (21-30) and high (31+) experience groups

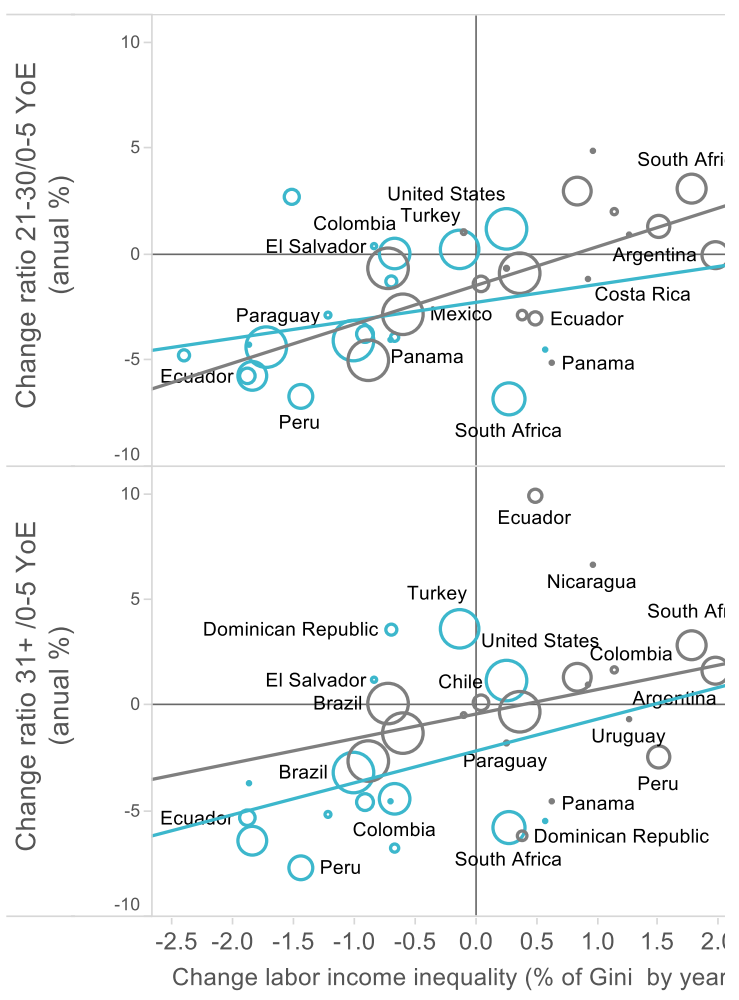

2003-13

Source: Seventeen Latin American countries: the SEDLAC database; Russia: the Russia Longitudinal Monitoring Survey; Post Apartheid Labor Market Series: South Africa; Turkey: I2D2-LFS; the United States: I2D2-IPUMS. See annexes A.1 and A.2 for details.

Note: The underlying data represent the change in wage inequality and the change in the earnings premiums for each country and circa period. The years selected for each country-circa combination may be different depending on the survey availability and to assure, to the extent possible, within country comparability for each period; see annex B.1 for details. In the case of the y-axis, the growth rate of the experience premium is plotted. For the x-axis, the growth rate of the labor income Gini is plotted. Experience is measured trough potential experience using age and education. According to the potential experience, five groups were defined: $0-5$ (reference category), 6-10, 11-20, 21-30, and more than 31 years of experience, See Section 3 and equation 1 for details. The sample covers full-time, wage, and self-employed workers 15-64 years of age. The values of the 1st and 100th percentiles of the earnings distribution were trimmed by each gender-education cell. The size of the bubbles represents the populations of the countries.

\section{Trends in gender and urban-rural earnings gaps}

Although gender and location are not skills, they are stylized factors that facilitate an explanation of earnings variations. Segregation and discrimination among groups in the labor market have been traditionally linked to broadening earnings inequality, particularly in the empirical literature on Latin America. Our results are consistent with this literature and show that the decline in both the returns to schooling and the experience premiums analyzed above were accompanied by a substantial narrowing in the urban-rural labor earnings gap and by a slight decline in the gender wage gap that occurred earlier in the 2000s (figure 13). We thus conjecture 
that the decline in labor income inequality observed across the region since the early 2000s does not seem to be related with a decline in the gender gap, but seems closely related to the large drop in the urban-rural wage gap experienced after 2002 .

Figure 13. The gender and urban/rural earnings gap, Latin America, 1993-2013

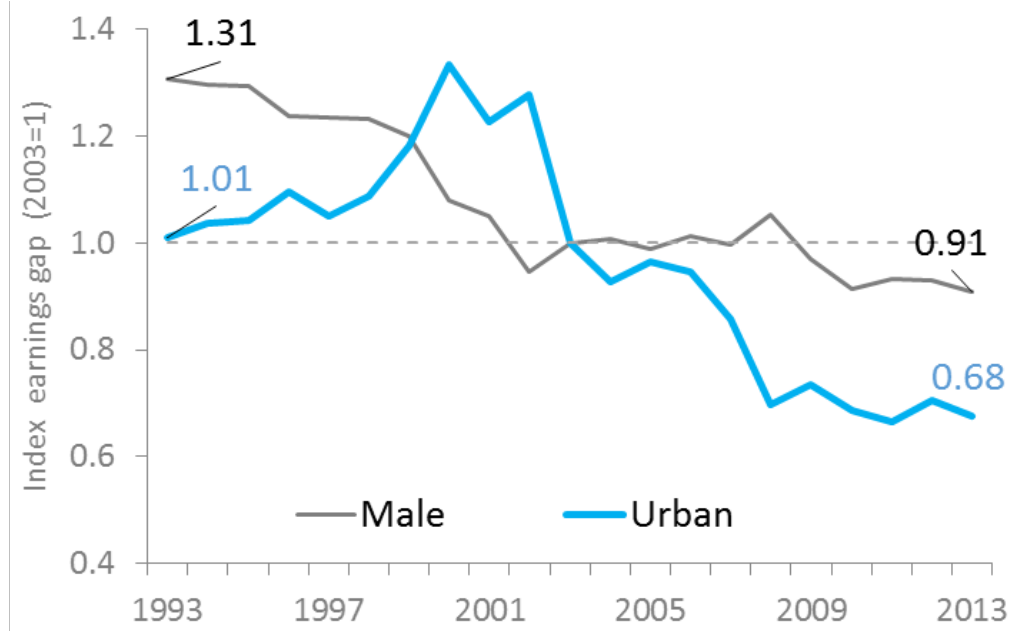

Source: Calculations based on the SEDLAC database. See annexes A.1 and A.2 for details.

Note: The underlying data represent the earnings gap and the area of residence earnings gap by country and year. The data show the ratio of the expected earnings for male (urban) workers with respect to female (rural) workers. The reference category of the gender gap is a woman, and the reference category of the residence earnings gap is rural areas. See section 3 and equation 1 for details. The sample covers full-time, wage, and self-employed workers 15-64 years of age. The values of the 1st and 100th percentiles of the earnings distribution were trimmed by each gender-education cell. The regional aggregate is an unweighted average across the gender and area of residence gap of the 17 countries with frequent data available in the SEDLAC database. If a country-year is missing an arithmetic linear interpolation is applied. To address missing data at the beginning or at the end of the series, the analysis uses the value of the nearest year for which information is available.

The substantial compression in the urban-rural earnings distribution, which first expanded from 36 percent in 1993 to 46 percent in 2002 and thereafter narrowed to 25 percent in 2013, may suggest there is a strong association between higher earnings in rural markets and less labor income inequality across Latin America. Despite the evidence of a modest compression in the labor income distribution between men and women in the region over the past two decades, the timing before the 2000 s does not match the timing of earnings compression at the regional level. Figure 13 shows that the gender wage gap remained relatively stable in 1993-99 and then narrowed between 1999 and 2003, remaining flat thereafter.

Our country-specific benchmark analysis of the gender earnings gap offers no sign of a clear trend in 1990-2013. However, in most countries, the gender wage gap showed a negative growth rate in the 1990s. In our sample of 22 countries, only Argentina, Costa Rica, the Dominican Republic, Peru, and the United States experienced a widening labor earnings gap between men and women (figure 14, panel a). In 2003-13, four of the five countries with the largest decline in labor income inequality also showed a large decline in the gender wage gap: Bolivia, Ecuador, Guatemala, and Russia, suggesting the validity of an effect at the country level.

Through our country-by-country analysis of the urban-rural labor earnings gap, we find that changes in wage compression were rather small in 1990-2003 (figure 14, panel b). Only Colombia, El Salvador, and Paraguay showed a negative annual growth rate larger than 5 percent. However, during the second period, 2003-10, half our sample countries experienced larger declines in the urban-rural wage gap. This substantial compression in the urban-rural earnings distribution occurred especially in countries that were exposed to the commodity boom of the 2000s, such as Argentina, Bolivia, Brazil, Chile, Colombia, Ecuador, and Peru, ${ }^{35}$ which

35 According to World Bank (2015), Argentina, Bolivia, Brazil, Chile, Colombia, Ecuador, and Peru were directly impacted by the commodity boom because they registered annualized growth in the terms of trade above 2 percent in 2003-13. The World Bank study 
suggests that the commodity boom may have translated into earnings growth among workers in rural areas who were specialized in the tradable sectors (including primary activities, mining, and manufacturing). These countries, plus Costa Rica, El Salvador, Nicaragua, and Panama, showed the largest narrowing in the urbanrural wage gap after 2003 (figure 12, panel b).

Figure 14. The average gender and urban-rural wage gaps, Latin America, 1993-2013

a. Gender labor earnings gap

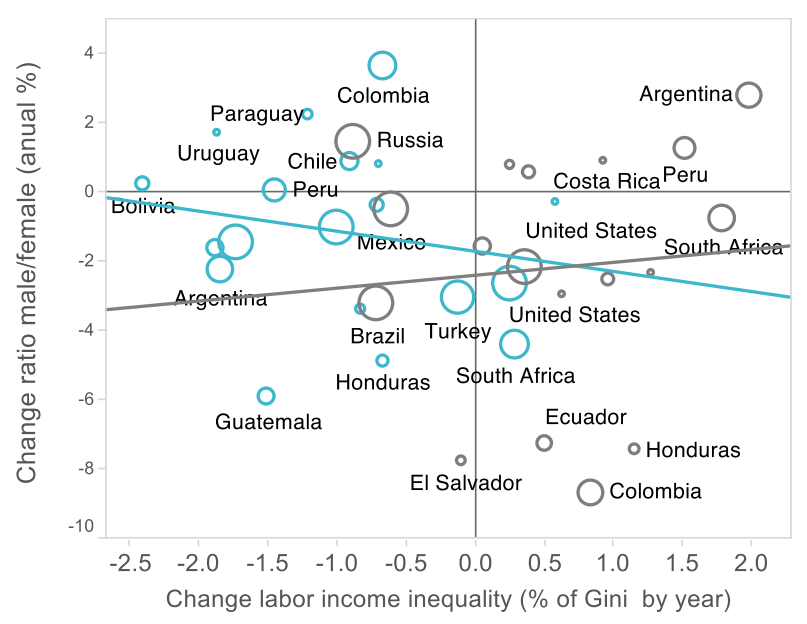

1993-03 b. Urban-rural labor earnings gap

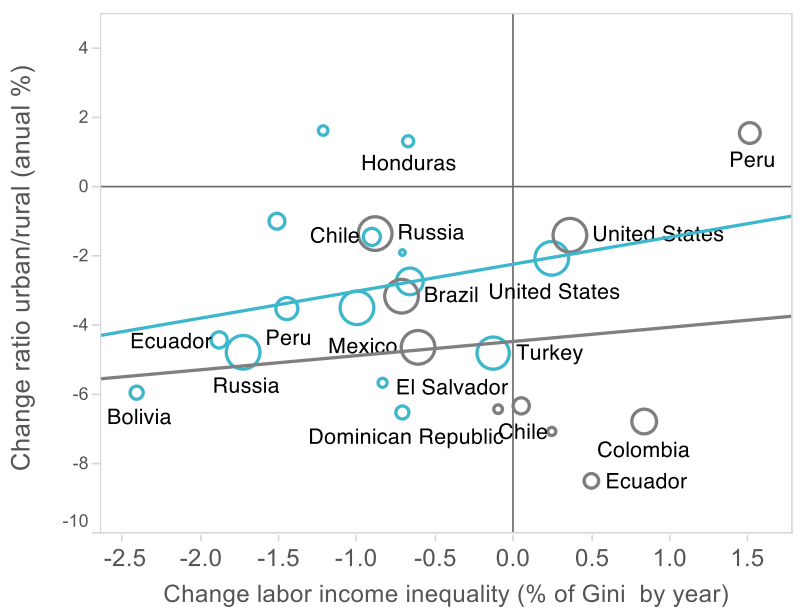

$2003-13$

Source: Seventeen Latin American countries: SEDLAC database; Russia: the Russia Longitudinal Monitoring Survey; Post Apartheid Labor Market Series: South Africa; Turkey: I2D2-LFS; the United States: I2D2-IPUMS. See annexes A.1 and A.2 for details.

Note: The underlying data represent the change in wage inequality and the change in the earnings premiums for each country and circa period. The years selected for each country-circa combination may be different depending on the survey availability and to assure, to the extent possible, within country comparability for each period; see annex B.1 for details. In the case of the y-axis, the growth rate of the gender and area of residence gap is plotted. For the x-axis, the growth rate of the labor income Gini is plotted. The reference category of the gender gap is a woman, and the reference category of the residence earnings gap is rural areas. See section 3 and equation 1 for details. The sample covers full-time, wage, and self-employed workers 15-64 years of age. The values of the 1st and 100th percentiles of the earnings distribution were trimmed by each gender-education cell. The size of the bubbles represent the population of the country.

\section{Summary and correlations: earnings inequality and observed labor market structure}

Table 1 presents a summary of the main findings on the dynamics of labor market returns in Latin America over the last two decades. We can conclude that the four measures of earnings gaps that we have analyzedthe education premium, the experience premium, the gender earnings gap, and the urban-rural earnings gaphave exhibited significant declines since the early 2000s (with the exception of the gender wage gap in 201013) relative to the changes observed in 1993-2003. Moreover, if we split the later period into 2003-2010 and 2010-13, we are able to uncover additional dynamics across the various measures of labor market returns. First, both measures of the education premium analyzed in this study-college relative to primary educational attainment and secondary relative to primary educational attainment-registered a more rapid reduction during 2003-10 than during 2010-13. Second, the same dynamics occurred in the urban-rural labor earnings gap. Indeed, this gap remained steady during the more recent years after a substantive compression during the commodity boom (2003-10). Third, all four measures of the experience premium showed a significant decline in 2003 that accelerated in 2010. One plausible factor in the dynamics of this phenomenon is skills obsolescence among older age-groups because of the rapid developments in information and communication technology in labor markets and the increasing mechanization and automation in sectors that have traditionally been intensive

classified the Dominican Republic, El Salvador, Guatemala, Honduras, Mexico, Paraguay, and Uruguay as noncommodity boom countries, while excluding Costa Rica, Nicaragua, and Panama from the analysis because of data limitations. 
in the use of labor (manufacturing and services). Likewise, the rate of decline in the experience premium has been larger at the high end of years of experience relative to the low end $(0-5$ years of experience). Finally, the gender earnings gap showed the largest decline in the earlier period, 1993-2003, but this was partially reverted in 2010-13. More research is definitely needed in this area.

Table 1. Average changes, measures of the earnings gaps, Latin America, 1993-2013

\begin{tabular}{lcccccc}
\hline \multirow{2}{*}{ Relative returns } & \multicolumn{6}{c}{ Average growth rate by year (percentage) } \\
\cline { 2 - 6 } & $1993-99$ & $1999-03$ & $2003-10$ & $2010-13$ & $1993-03$ & $2003-13$ \\
\hline Education & -0.5 & -0.7 & -2.9 & -2.1 & -0.6 & -2.5 \\
High school & 0.3 & 1.4 & -2.8 & -2.1 & 0.8 & -2.7 \\
$\begin{array}{l}\text { Tertiary } \\
\text { Potential experience }\end{array}$ & & & & & & \\
6-10 YoE & -0.8 & -1.3 & -1.9 & -3.4 & -1.0 & -2.4 \\
11-20 YoE & -1.6 & 0.3 & -2.8 & -3.7 & -0.9 & -3.1 \\
21-30 YoE & -2.1 & -0.3 & -2.9 & -4.9 & -1.4 & -3.4 \\
31+ YoE & -2.1 & -0.8 & -3.6 & -4.9 & -1.5 & -3.9 \\
Gender and area of residence & & & & & & \\
Male/Female & -1.4 & -4.2 & -1.1 & -0.2 & -2.3 & -0.9 \\
Urban/Rural & 2.8 & -3.8 & -3.9 & -0.5 & -0.1 & -3.2 \\
\hline
\end{tabular}

Source: Calculations based on the SEDLAC database. See annexes A.1 and A.2 for details.

Note: The underlying data represent the differences in the trends plotted in figures 9,11 , and 13 . The bases for each category are primary or less in education, between 0 and 5 years of age for the potential experience, females for gender, and rural areas for area of residence. YoE $=$ years of experience.

\section{Conclusions}

In this paper, we examine trends in labor income inequality in Latin America during the last 20 years. To estimate the inequality derived from the way the labor market values the different skills and demographic characteristics, we focus on the hourly earnings inequality of the main occupation of full-time workers between 15 and 65 years of age.

We identify a trend reversal in labor income inequality beginning in the early 2000 s that followed a slight increase during the early 1990s. The increase of labor income inequality during the 1990s was associated with a reduction in real wages, most severe for the workers on less well paid jobs, particularly for those in the left half of the earnings distribution. On the other hand, we find evidence that this decline in labor income inequality in the 2000s was associated with more rapid growth rates in the earnings of less well paid jobs relative to labor incomes among the more well paid earners. This expansion at the bottom of the wage distribution that narrowed the inequality in the lower tail of the earnings distribution was accompanied by a smaller, but still significant expansion in the middle part of the wage distribution that also helped narrow the inequality at the upper tail of the labor income distribution. In contrast to the increase in labor income inequality in the 1990s, the trend reversal in labor income inequality observed during the 2000 's is robust to the selection of inequality measure, the aggregation method of country indicators (population weighted or unweighted), the countries selected to define the regional trend, and the definition of the time interval.

We also find that the trend reversal in labor income inequality is correlated with a steady compositional change in labor force attributes along the two decades of analysis: workers are becoming generally more educated, more highly experienced, and more urbanized, and more women are participating in the workforce. Because this compositional change has been fairly constant during the two decades, it does not explain alone the trend reversal in earnings inequality, suggesting that the influence of demand and institutional factors are among the forces behind the regional trend. 
The increase and subsequent reduction of the variance in labor earnings occurred in the variance of the earnings between workers with different observed attributes as well as in the variance of the residual earnings inequality. The latter explains at least half of the increase and the reduction, a phenomenon that calls for further investigation.

Our main conclusion is that the drop in the college/primary education premium and the acceleration in the decline of the high school/primary education premium are part of the story in the reversal of labor income inequality. Also a noticeable decline in the experience premium across all age-groups, observed beginning in the early 2000s, is part of the main observable factors associated with the trend reversal in income inequality in Latin America. Finally, we find strong evidence that the urban-rural earnings gap may have also influenced the decline in earnings inequality in the region. Since the gender gap fell mostly during the 1990s, it is probably not directly related with the regional trend reversal, although it could explain the reduction of inequality in some countries in the region.

More research is needed to test the demand, supply, and institutional factors that may help explain the trend reversal in earnings inequality in Latin America. However, although our main findings should not be understood to imply causality, they represent a fundamental result that focuses attention on the importance of relative returns of different attributes in explaining regional patterns in labor income inequality, which goes beyond country-specific explanations. 


\section{References}

Alvaredo, Facundo, and Leonardo Gasparini. 2015. "Recent Trends in Inequality and Poverty in Developing Countries." In Handbook of Income Distribution, vol. 2, edited by Anthony B. Atkinson and François Bourguignon, 697-805. Handbooks in Economics. Amsterdam: North-Holland.

Autor, David H., Lawrence F. Katz, and Melissa S. Kearney. 2008. "Trends in U.S. Wage Inequality: Revising the Revisionists." Review of Economics and Statistics 90 (2): 300-23.

Arndt, Channing, Sam Jones, and Vincenzo Salvucci. 2015. "When Do Relative Prices Matter for Measuring Income Inequality? The Case of Food Prices in Mozambique." Journal of Economic Inequality 13 (3): 449-64.

Attanasio, Orazio, Pinelopi K. Goldberg, and Nina Pavcnik. 2004. "Trade Reforms and Wage Inequality in Colombia." Journal of development Economics 74 (2): 331-66.

Azevedo, João Pedro, María Eugenia Dávalos, Carolina Díaz-Bonilla, Bernardo Atuesta, and Raul Andres Castañeda. 2013. "Fifteen Years of Inequality in Latin America: How Have Labor Markets Helped?" Policy Research Working Paper 6384, World Bank, Washington, DC.

Bakis, Ozan, and Sezgin Polat. 2015. "Wage Inequality in Turkey, 2002-10.” Economics of Transition 23 (1): 169-212.

Bastos, Paulo, and Joana Silva. 2008. "The Wage and Unemployment Impacts of Trade Adjustment." In Globalisation and Labour Market Adjustment, edited by David Greenaway, Richard Upward, and Peter W. Wright, 31-53. London: Palgrave Macmillan.

Bourguignon, François, Francisco H. G. Ferreira, and Nora Lustig, eds. 2005. The Microeconomics of Income Distribution Dynamics in East Asia and Latin America. Washington, DC: World Bank; New York: Oxford University Press.

Calvo, Paula Andrea, Luis F. López-Calva, and Josefina Posadas. 2015. "A Decade of Declining Earnings Inequality in the Russian Federation." Policy Research Working Paper 7392, World Bank, Washington, DC.

Campos Vázquez, Raymundo M., Luis F. López-Calva, and Nora Lustig. 2016. "Declining Wages for College-Educated Workers in Mexico: Are Younger or Older Cohorts Hurt the Most?" Policy Research Working Paper 7546, World Bank, Washington, DC.

Cord, Louise, Oscar Barriga-Cabanillas, Leonardo Lucchetti, Carlos Rodríguez-Castelán, Liliana D. Sousa, and Daniel Valderrama. 2016. "Inequality Stagnation in Latin America in the Aftermath of the Global Financial Crisis." Review of Development Economics.

Cord, Louise, María Eugenia Genoni, and Carlos Rodríguez-Castelán. 2015. Shared Prosperity and Poverty Eradication in Latin America and the Caribbean. Washington, DC: World Bank.

Cornia, Giovanni Andrea. 2014. "Inequality Trends and Their Determinants: Latin America over 1990-2010.” In Falling Inequality in Latin America: Policy Changes and Lessons, edited by Giovanni Andrea Cornia, 23-48. UNU-WIDER Studies in Development Economics. Oxford: Oxford University Press.

de la Torre, Augusto, Alain Ize, Guillermo Beylis, and Daniel Lederman. 2015. "Jobs, Wages, and the Latin American Slowdown." LAC Semiannual Report (October), Office of the Chief Economist, Latin America and Caribbean Region, World Bank, Washington, DC.

de la Torre, Augusto, Eduardo Levy Yeyati, Guillermo Beylis, Tatiana Didier, Carlos RodríguezCastelán, and Sergio Schmukler. 2014. "Inequality in a Lower Growth Latin America." Semiannual Report (October), Latin America and Caribbean Region, World Bank, Washington, DC.

Démurger, Sylvie, Martin Fournier, and Shi Li. 2006. "Urban Income Inequality in China Revisited, 1988-2002." Economics Letters 93 (3): 354-59.

Esquivel, Gerardo, and José Antonio Rodríguez-López. 2003. "Technology, Trade, and Wage Inequality in Mexico before and after NAFTA." Journal of Development Economics 72 (2): 543-65.

Fairris, David. 2003. "Unions and Wage Inequality in Mexico.” Industrial and Labor Relations Review 56 
(3): 481-97.

Ferreira, Francisco H. G., and Norbert Schady. 2009. "Social Consequences of the Global Financial Crisis in Latin America: Some Preliminary, and Surprisingly Optimistic, Conjectures." LCR Crisis Brief 53546, Latin America and Caribbean Region, World Bank, Washington, DC.

Gasparini, Leonardo, and Guillermo Cruces. 2010. "A Distribution in Motion: The Case of Argentina." In Declining Inequality in Latin America: A Decade of Progress?, edited by Luis F. López-Calva and Nora Lustig, 100-33. New York: United Nations Development Programme; Baltimore: Brookings Institution Press.

Gasparini, Leonardo, Guillermo Cruces, Leopoldo Tornarolli, and Mariana Marchionni. 2008. “A Turning Point? Recent Developments on Inequality in Latin America and the Caribbean.” Working Paper 81, Center for Distributive, Labor, and Social Studies, Facultad de Ciencias Económicas, Universidad Nacional de La Plata, La Plata, Argentina.

Gasparini, Leonardo, Sebastián Galiani, Guillermo Cruces, and Pablo Acosta. 2011. "Educational Upgrading and Returns to Skills in Latin America: Evidence from a Supply-Demand Framework, 1990_ 2010." Working Paper 127, Center for Distributive, Labor, and Social Studies, Facultad de Ciencias Económicas, Universidad Nacional de La Plata, La Plata, Argentina.

Gasparini, Leonardo, and Nora Lustig. 2011. "The Rise and Fall of Income Inequality in Latin America.” Working Paper 1110, Tulane University, New Orleans.

Global Wage Report (database), International Labour Organization, Geneva. http://www.ilo.org/ilostat/GWR?_afrLoop=778317871631331\#\%40\%3F_afrLoop\%3D778317871631 331\%26_adf.ctrl-state\%3D5ldkmifc_319.

Goderis, Benedikt, and Samuel W. Malone. 2011. "Natural Resource Booms and Inequality: Theory and Evidence." Scandinavian Journal of Economics 113 (6): 388-417.

Gonzaga, Gustavo, Naércio Menezes Filho, and Cristina Terra. 2006. "Trade Liberalization and the Evolution of Skill Earnings Differentials in Brazil.” Journal of International Economics 68 (2): 345-67.

Higgins, Sean, and Claudiney Pereira. 2014. "The Effects of Brazil's Taxation and Social Spending on the Distribution of Household Income." In "Analyzing the Redistributive Impact of Taxes and Transfers in Latin America," edited by Nora Lustig, Carola Pessino, and John Scott, special issue, Public Finance Review 42 (3): 346-67.

Jaramillo, Miguel. 2014. "The Incidence of Social Spending and Taxes in Peru." In "Analyzing the Redistributive Impact of Taxes and Transfers in Latin America," edited by Nora Lustig, Carola Pessino, and John Scott, special issue, Public Finance Review 42 (3): 391-412.

Lakner, Christoph, and Branko Milanovic. 2013. "Global Income Distribution: From the Fall of the Berlin Wall to the Great Recession.” Policy Research Working Paper 6719, World Bank, Washington, DC.

Leibbrandt, Murray, Arden Finn, and Woolard Ingrid. 2012. "Describing and Decomposing PostApartheid Income Inequality in South Africa." Development Southern Africa 29 (1): 19-34.

Lemieux, Thomas. 2006. "Increasing residual wage inequality: Composition effects, noisy data, or rising demand for skill?.” The American Economic Review, 96(3): 461-498.

Levy, Santiago, and Luis F. López-Calva. 2016. "Labor Earnings, Misallocation, and the Returns to Education in Mexico.” IDB Working Paper 671, Inter-American Development Bank, Washington, DC.

López-Calva, Luis F., and Nora Lustig. 2010. "Explaining the Decline in Inequality in Latin America: Technological Change, Educational Upgrading, and Democracy." In Declining Inequality in Latin America: A Decade of Progress?, edited by Luis F. López-Calva and Nora Lustig, 1-24. New York: United Nations Development Programme; Baltimore: Brookings Institution Press.

Londoño, Juan Luis, and Miguel Székely. 2000. "Persistent Poverty and Excess Inequality: Latin America, 1970-1995." Journal of Applied Economics 3 (May): 93-134.

López-Calva, Luis F., Nora Lustig, and Eduardo Ortiz-Juárez. 2015. “A Long- Term Perspective on Inequality and Human Development in Latin America." Journal of Human Development and Capabilities 16 (3): 
$319-23$.

Lustig, Nora, Luis F. López-Calva, and Eduardo Ortiz-Juárez. 2013. "Declining Inequality in Latin America in the 2000s: The Cases of Argentina, Brazil, and Mexico." World Development 44 (C): 129-41.

Lustig, Nora, and Carola Pessino. 2014. "Social Spending and Income Redistribution in Argentina in the 2000s: The Rising Role of Noncontributory Pensions." In "Analyzing the Redistributive Impact of Taxes and Transfers in Latin America," edited by Nora Lustig, Carola Pessino, and John Scott, special issue, Public Finance Review 42 (3): 304-25.

Manacorda, Marco, Carolina Sánchez-Páramo, and Norbert Schady. 2010. "Changes in Returns to Education in Latin America: The Role of Demand and Supply of Skills." Industrial and Labor Relations Review 63 (2): 307-26.

Maurizio, Roxanna. 2014. "Labour Formalization and Declining Inequality in Argentina and Brazil in 2000s: A Dynamic Approach.” ILO Research Paper 9, International Labour Office, Geneva.

Messina, Julián and Fernandez Manuel 2016. "Changes in the Structure of Wages in South America" Unpublished background paper for a study on wage inequality, Office of the Chief Economist, Latin America and Caribbean Region, World Bank, Washington, DC.

Mincer, Jacob A. 1974. "Age and Experience Profiles of Earnings." In Schooling, Experience, and Earnings, edited by Jacob A. Mincer, 64-82. Cambridge, MA: National Bureau of Economic Research. 33.

Ocampo, José Antonio. 2008. "El auge económico latinoamericano.” Revista de ciencia política 28 (1): 7-

Paes de Barros, Ricardo, Miguel Nathan Foguel, and Gabriel Ulyssea. 2007. Desigualdade de renda no Brasil: uma análise da queda recente. Vol. 1. Brasília: Institute for Applied Economic Research.

Pellandra, Andrea. 2014. "The Commodity Price Boom and Regional Workers in Chile: A Natural Resources Blessing?” Draft working paper, Heinz College, Carnegie Mellon University, Pittsburgh.

Revenga, Ana. 1997. "Employment and Wage Effects of Trade Liberalization: The Case of Mexican Manufacturing." Journal of Labour Economics 15 (3): 20-43.

Silva, Joana, Julian Messina, and Luis F. López-Calva. 2016. "Wage Inequality in Latin America: Trends and Puzzles." Unpublished regional study, Office of the Chief Economist, Latin America and Caribbean Region, World Bank, Washington, DC.

Scott, John. 2014. "Redistributive Impact and Efficiency of Mexico’s Fiscal System.” In "Analyzing the Redistributive Impact of Taxes and Transfers in Latin America," edited by Nora Lustig, Carola Pessino, and John Scott, special issue, Public Finance Review 42 (3): 368-90.

SEDLAC (Socio-Economic Database for Latin America and the Caribbean), Center for Distributive, Labor, and Social Studies, Universidad de La Plata, La Plata, Argentina; World Bank, Washington, DC. http://sedlac.econo.unlp.edu.ar/eng/index.php.

Slesnick, Daniel T. 2002. "Prices and Regional Variation in Welfare." Journal of Urban Economics 51 (3): 446-68.

Székely, Miguel, and Marianne Hilgert. 2007. "What's Behind the Inequality We Measure? An Investigation Using Latin American Data." Oxford Development Studies 35 (2): 197-217.

Székely, Miguel, and Pamela Mendoza. 2015. "Is the Decline in Inequality in Latin America Here to Stay?" Journal of Human Development and Capabilities 16 (3): 397-419.

Verhoogen, Eric A. 2008. "Trade, Quality Upgrading, and Wage Inequality in the Mexican Manufacturing Sector." Quarterly Journal of Economics 123 (2): 489-530.

Williamson, Jeffrey G. 2015. "Latin American Inequality: Colonial Origins, Commodity Booms, or a Missed 20th Century Leveling?" NBER Working Paper 20915, National Bureau of Economic Research, Cambridge, MA.

World Bank. 2011. "A Break with History: Fifteen Years of Inequality Reduction in Latin America." LAC Poverty and Labor Brief 2, Latin America and Caribbean Region, World Bank, Washington, DC. 
. 2012. "The Labor Market Story behind Latin America's Transformation.” October, Office of the Chief Economist, Latin America and Caribbean Region, World Bank, Washington, DC.

. 2013. "Shifting Gears to Accelerate Shared Prosperity in Latin America and the Caribbean." LAC Poverty and Labor Brief 5, Latin America and Caribbean Region, World Bank, Washington, DC.

. 2015. "Working to End Poverty in Latin America and the Caribbean: Workers, Jobs and Wages." LAC Poverty and Labor Brief 7, Latin America and Caribbean Region, World Bank, Washington, DC. 


\section{Annex A. Data sources}

\section{A.1 Countries and years with microdata available}

The household surveys used in this study have been carried out through various harmonization projects, except for the case of Latin America. The countries outside the region have been selected based on data availability, consistency in the sociodemographic characteristics, and analysis of missing data on labor income. There is no information available on household per capita income for microdata available for countries outside the Latin America and Caribbean region. Data on the Latin American countries are taken from SEDLAC (World Bank and CEDLAS), South African data are taken from the Post Apartheid Labor Market Series-v2.0. The data on Turkey are taken from the I2D2-LFS surveys (World Bank). The data on Russia are provided through Russia Longitudinal Monitoring Survey of the University of North Carolina-Chapel Hill. The data on the United States are taken from the I2D2-IPUMS surveys. Table A.1 illustrates the comparability of the data. The blue points means that the data is comparable to the latest survey available. For example, Costa Rica 2013 is comparable with Costa Rica 2010, but it is not comparable with surveys carried out before 2010. There is no information about the comparability of the surveys indicated by the gray circles.

Table A.1. Microdata datasets available and comparability with the most recent survey
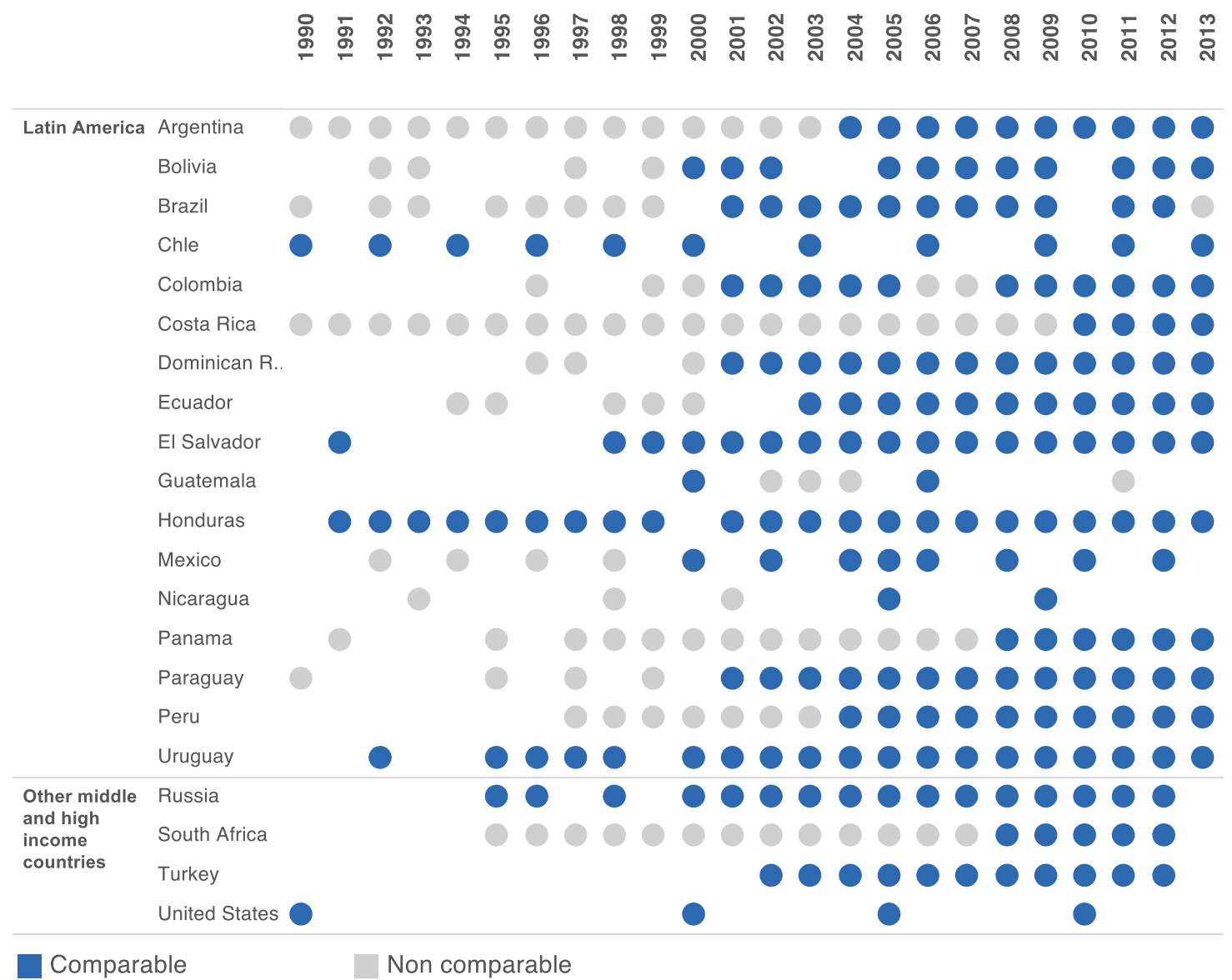

Sources: Latin American countries: tabulations of Equity Lab, Team for Statistical Development, World Bank. Other countries: World Bank compilation. 


\section{A.2 Microdata sources and harmonization}

\section{Table A.1.2.1 Socio-Economic Data for Latin America and the Caribbean (SEDLAC)}

\begin{tabular}{|c|c|}
\hline Variable & Description \\
\hline Wage & $\begin{array}{l}\text { Remuneration from the primary place of work after taxes. For nonsalaried workers, the } \\
\text { variable is the monthly earnings from other paid activities such as apartment or car repairs, } \\
\text { food delivery, selling goods in the street, and related activities. }\end{array}$ \\
\hline Hours worked & $\begin{array}{l}\text { Hours worked in the last } 30 \text { days in the primary place of employment or other informal } \\
\text { activities. }\end{array}$ \\
\hline Education & $\begin{array}{l}\text { Sum of years at school or in other education programs, including years in technical career } \\
\text { training and university and graduate education. }\end{array}$ \\
\hline Age & Individual's age in years. \\
\hline Sex & Dummy variable that indicates the gender $(\operatorname{men}=1)$ \\
\hline Region & Dummy variable that indicates residency area $($ urban $=1)$. \\
\hline Years & 2000 and 2010. \\
\hline
\end{tabular}

Source: SEDLAC (World Bank and CEDLAS).

Note: The main survey sources for the relevant data in the database are Argentina: Encuesta Permanente de Hogares-Continua; Bolivia: Encuesta Continua de Hogares; Brazil: Pesquisa Nacional por Amostra de Domicilios; Chile: Encuesta de Caracterización Socioeconómica Nacional; Colombia: Gran Encuesta Integrada de Hogares; Costa Rica: Encuesta Nacional de Hogares; Dominican Republic: Encuesta Nacional de Fuerza de Trabajo; Ecuador: Encuesta de Empleo, Desempleo y Subempleo; El Salvador: Encuesta de Hogares de Propósitos Múltiples; Guatemala: Encuesta Nacional de Condiciones de Vida; Honduras: Encuesta Permanente de Hogares de Propósitos Múltiples; Mexico: Encuesta Nacional de Ingresos y Gastos de los Hogares; Nicaragua: Encuesta Nacional de Hogares sobre Medición de Niveles de Vida; Panama: Encuesta de Hogares; Paraguay: Encuesta Permanente de Hogares; Peru: Encuesta Nacional de Hogares; and Uruguay: Encuesta Continua de Hogares.

Table A.1.2.2 The Longitudinal Monitoring Survey (RLMS), Russian Federation

\begin{tabular}{|c|c|}
\hline Variable & Description \\
\hline Wage & $\begin{array}{l}\text { Remuneration from the primary place of work after taxes. For nonsalaried workers, the } \\
\text { variable is the monthly earnings from other paid activities such as apartment or car repairs, } \\
\text { food delivery, selling goods in the street, and related activities. }\end{array}$ \\
\hline Hours worked & $\begin{array}{l}\text { Hours worked in the last } 30 \text { days in the primary place of employment or other informal } \\
\text { activities. }\end{array}$ \\
\hline Education & $\begin{array}{l}\text { Sum of years at school or in other education programs, including years in technical career } \\
\text { training and university and graduate education. }\end{array}$ \\
\hline Age & Individual's age in years. \\
\hline Sex & Dummy variable that indicates the gender $(\mathrm{men}=1)$ \\
\hline Region & Dummy variable that indicates residency area $($ urban $=1)$. \\
\hline Years & 2000 and 2010. \\
\hline
\end{tabular}


Table A.1.2.3 Post Apartheid Labor Market Series (PALMS), South Africa

\begin{tabular}{ll}
\hline Variable & \multicolumn{1}{c}{ Description } \\
\hline Wage & Monthly salary estimated based on hours worked. \\
Hours worked & Hours worked in the last week. \\
Education & Number of years of education. \\
Age & Individual's age in years. \\
Sex & Dummy variable that indicates the gender $($ men $=1)$. \\
Region & Dummy variable that indicates residency area $($ urban $=1)$. Only available for 2000. \\
Years & 2000 and 2010. \\
\hline
\end{tabular}

Table A.1.2.4 Household Labor Force Survey (LFS), Turkey

\begin{tabular}{|c|c|}
\hline Variable & Description \\
\hline Wage & $\begin{array}{l}\text { Total net income in cash earned in the form of wages, salaries, or daily wages in the last } \\
\text { month. }\end{array}$ \\
\hline Hours worked & Hours usually worked per week. \\
\hline \multirow[t]{11}{*}{ Education } & Year imputed according to achieved educational level: \\
\hline & 0 if illiterate \\
\hline & 3 if literate \\
\hline & 5 if primary \\
\hline & 8 if junior high school \\
\hline & 9 if vocational training at junior high school \\
\hline & 12 high school \\
\hline & 13 vocational training at high school \\
\hline & 14 if 2 years of higher education \\
\hline & 16 if 4 years of higher education \\
\hline & 18 if master's or doctorate \\
\hline Age & Individual's age in years. \\
\hline Sex & Dummy variable that indicates the gender $(\operatorname{men}=1)$. \\
\hline Region & Not available. \\
\hline Years & 2002 and 2011. \\
\hline
\end{tabular}




\section{A.3 Earnings inequality in Latin America and the world}

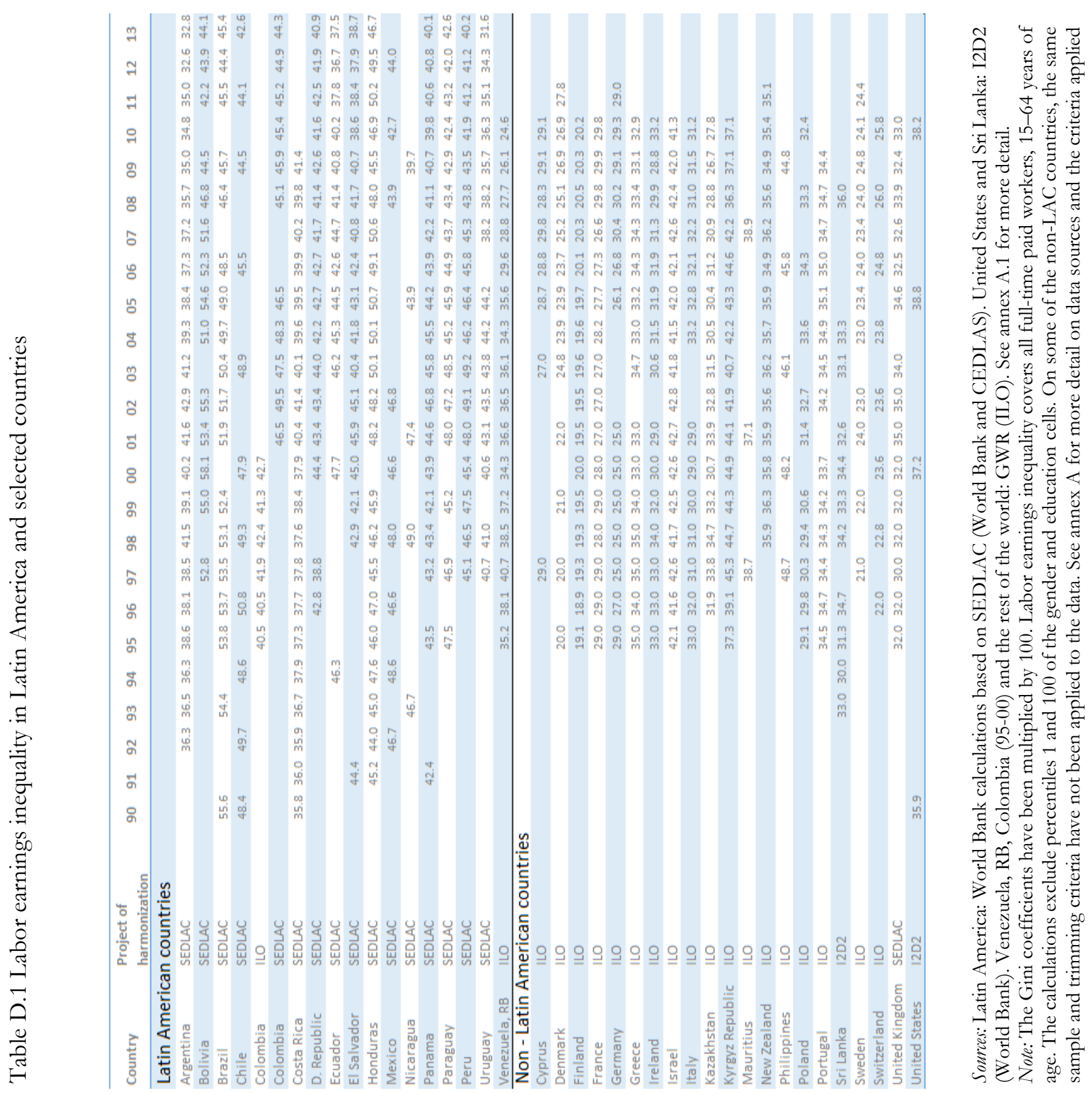




\section{Annex B Sample selection and comparability criteria}

\section{Annex B.1 Selected years for circa analysis in total and wage inequality}

For the study, four circa periods were selected for a varied analysis on the 1990s and on the 2000s. Because the surveys are not fully comparable within countries and considering the differences in terms of availability for each country, the year used for each circa may differ by country. The rule of thumb was to select, for each circa, the closest year with information available as long as the surveys are fully comparable and do not show sociodemographic inconsistencies. The distance searching algorithm stop whenever the absolute distance between the circa year and the year selected is greater than four.

Table B.1 Circa periods for each country

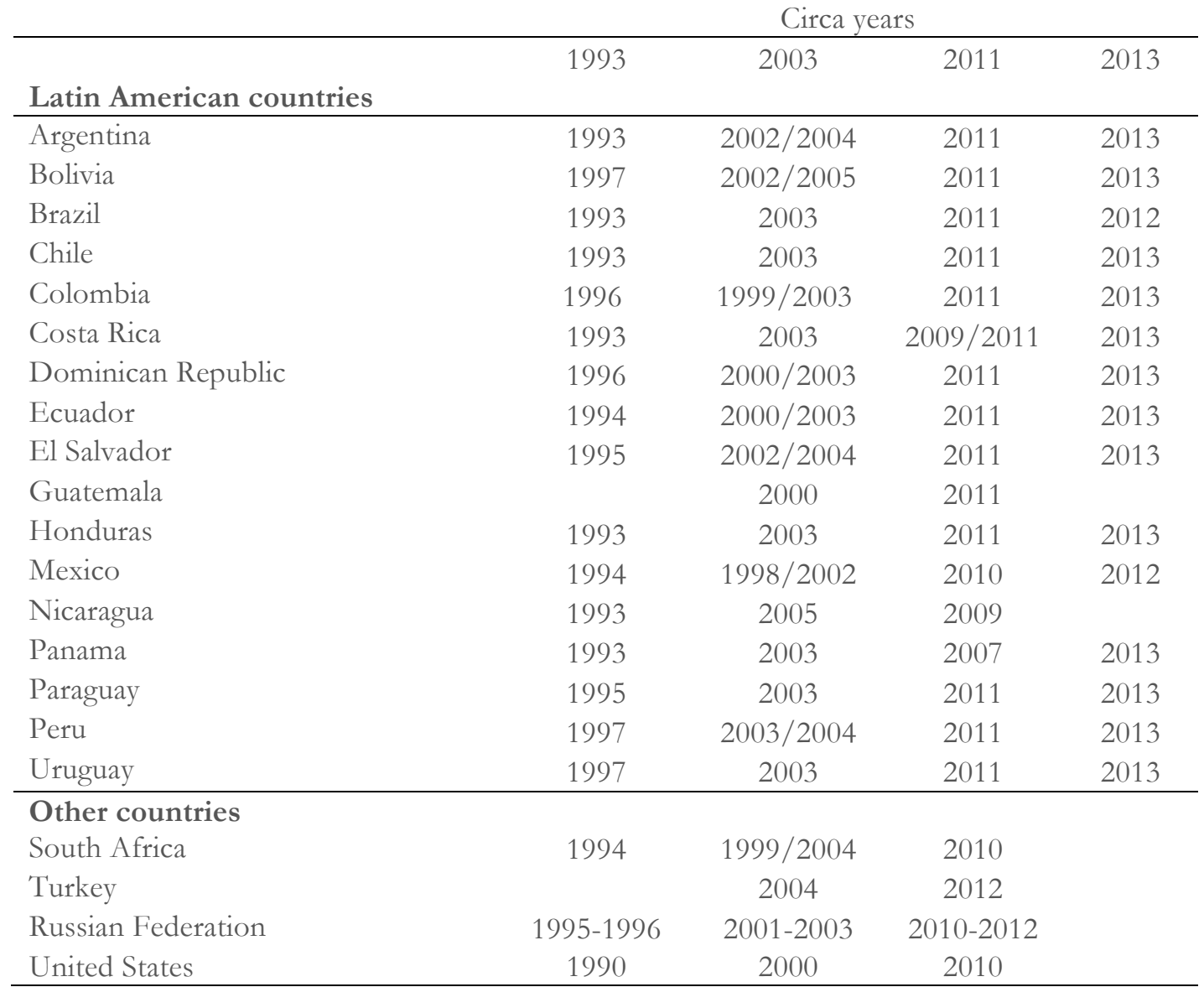

Sources: Latin American countries: calculations based on tabulations of Equity Lab, Team for Statistical Development, World Bank. Other countries: World Bank calculations based on country-specific trends and data sources on each year.

Note: Columns with more than one year indicate that, depending on the circa period, a specific year was selected. 


\section{Annex C. Labor income inequality and total income inequality}

\section{C.1. Decomposition of the slightly rise, the fall and the slowdown of total income inequality}

The change in the total income Gini can be decomposed by changes in income sources using a nonparametric decomposition technique developed by Paes de Barros, Foguel, and Ulyssea (2007). It is based on the property that changes in inequality can be expressed as a function of changes in each income source along the distribution of total income. The method allows us to identify the income source that is more closely linked to the changes in inequality from households' nonlabor income, labor income per paid worker in the household, and the share of paid workers in the household. The last component may be seen as the join effect of household composition and employment rates. ${ }^{36}$ Even if the regional trend hides a certain heterogeneity across countries, we selected the same periods for all the countries to test the robustness of the regional trends at the country level. Thus, for each country on which data are available, we decomposed the change in inequality into the three components mentioned above for three circa periods: the moderate rise (ca 1993-2003), the turning point (ca 2003-11), and the slowdown (ca 2011-13). ${ }^{37}$ The years selected for each country are different and follow certain parameters: (a) the distance to the years that define the regional breakpoints, (b) maximization in the number of surveys available for the region in a specific year, and (c) maximization in the comparability within countries for each period. ${ }^{38}$

The changes are expressed in average Gini points by year to control for the different spans in years that result from the varying availability of surveys for each country in the circa 1993, circa 2003, and circa 2013 time frame. For each country in each period, the figures show the contribution of three factors to changes in the Gini of household per capita income: household nonlabor income, labor income per paid worker in the household, and the share of working adults in the household. The last component is affected by the changes in the employment rates and the demographic composition along the distribution.

Our analysis shows that labor earnings were the main component associated with the moderate widening in income inequality in Latin America during the 1990s (figure C.1, panel a). This is especially the case in those countries experiencing a rise in income inequality between 1993 and 2002, including Argentina (urban), Bolivia, Costa Rica, the Dominican Republic, Ecuador, Honduras, Nicaragua, and Uruguay (urban). During the 1990s, labor earnings were an equalizing force only in Chile, Mexico, and Paraguay. In 2003-11, similar to earlier studies, such as Cord et al. (2016) and World Bank (2011), we find that labor income was the most important factor linked to the turning point in income inequality across Latin America (figure C.1, panel b). In general, we find evidence that labor markets were equalizing in terms of prices (labor income per paid worker in the household) and quantities (the share of working adults in the household). Finally, like Cord et al. (2016), we find that the slowdown in the regional trend is a product of countries in which inequality was starting to increase (such as Bolivia, Ecuador, and Mexico) and countries in which the pace of inequality reduction slowed by half

\footnotetext{
${ }^{36}$ The method generates entire counterfactual distributions and can thus capture the heterogeneity of the changes across the distribution. This nonparametric decomposition has typically been used to shed light on the main factors influencing the changes in income inequality. The method should not be relied on to draw conclusions on causal effects because it suffers from problems of equilibrium inconsistency, given that it uses a partial equilibrium framework. Nonetheless, the methodology may be used as an informed approximation of the main factors that may be associated with changes in the income distribution.

${ }^{37}$ The main reason to select 2003 as the circa year for the reversal point at the country level is the fact that most of the countries experienced economic drawbacks during the lost half-decade (Ocampo 2008). Therefore, selecting 2002 could overestimate the narrowing in inequality as the economies were recovering from the recent financial crisis in Latin America. On the other hand, Argentina, Bolivia, Ecuador, El Salvador, and Peru underwent methodological changes in surveys after 2002, making 2003 a better midpoint of countryspecific years. The selection of 2011 increases considerably the number of countries with surveys available with respect to 2010. Moreover, the need to control for the recovery from the global financial crisis of 2008-09 also supports this decision.

38 Considering the three parameters mentioned above, the circa values for cross-country analysis were not strictly the regional breakpoints, since we selected 2003 and 2011 instead of 2002 and 2010, respectively. The years do not affect the conclusion about the regional trend and allow us to gain comparability in the country decompositions.
} 
(such as Brazil, Chile, and Peru). In both types of countries, labor income widened the total income distribution during the period.

Finally, like Cord et al. (2016), we find that the slowdown in the regional trend is a product of countries in which inequality was starting to increase (such as Bolivia, Ecuador, and Mexico) and countries in which the pace of inequality reduction slowed by half (such as Brazil, Chile, and Peru). In both types of countries, labor income widened the total income distribution during the period.

Figure C.1 Decomposition of change in total income inequality, Latin American countries

a. Circa 1993-2003

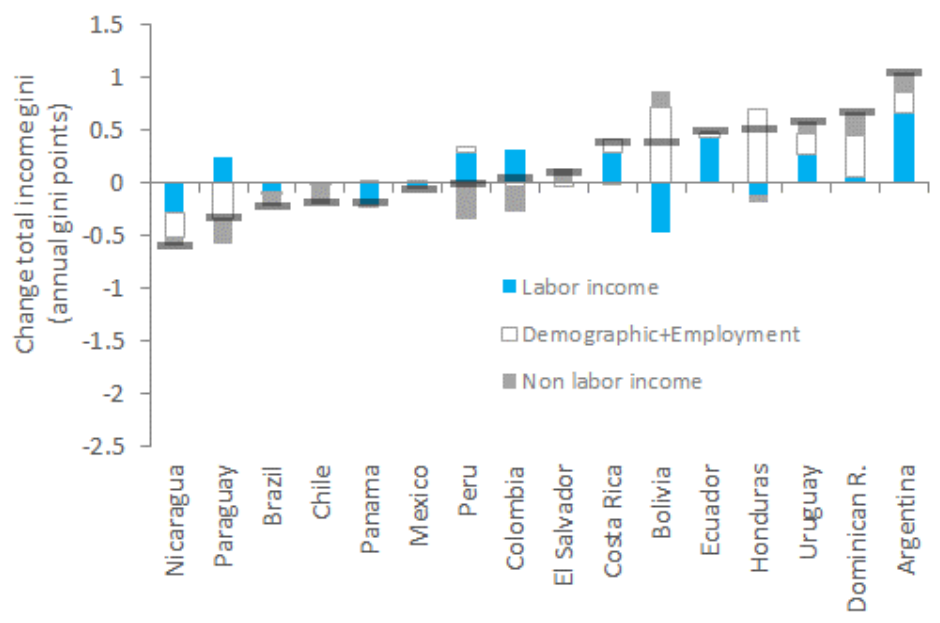

b. Circa 2003-11

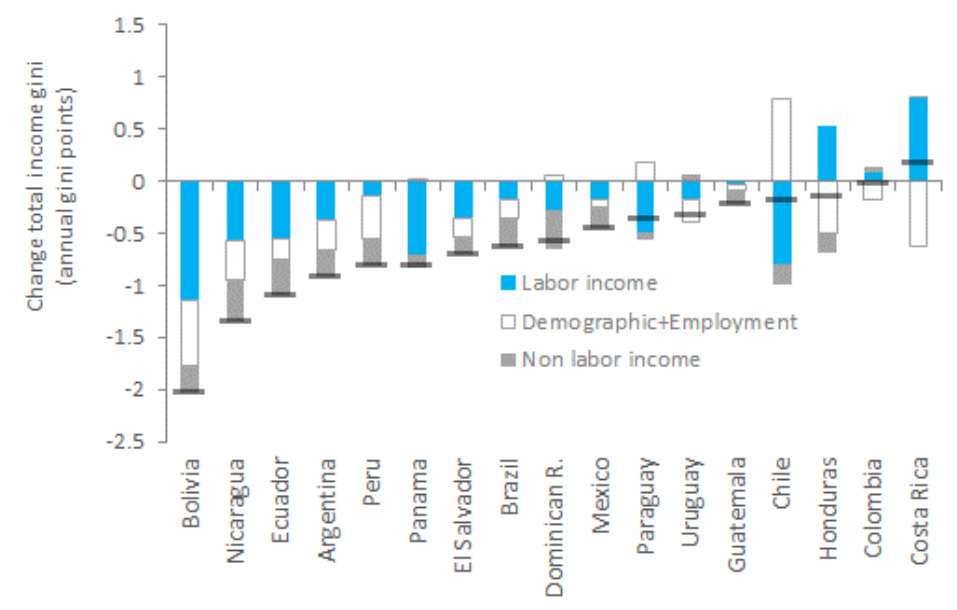




\section{c. Circa $2011-13$}

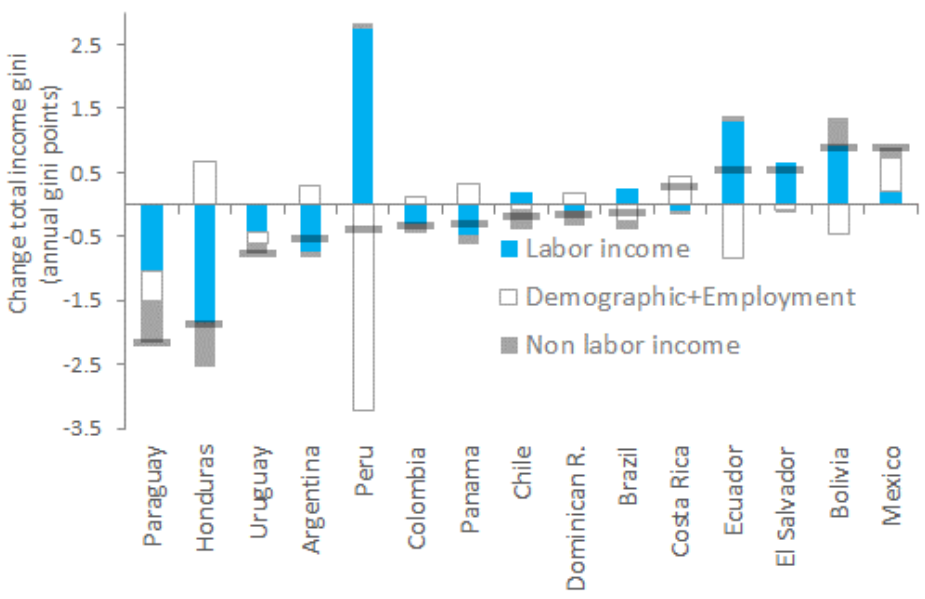

Source: Calculations based on SEDLAC (World Bank and CEDLAS). See annexes A.1 and A.2 for details.

Note: The underlying data have been multiplied by 100. The figures illustrate the contribution of each component to the average change in total household income inequality, the latter represented by the transparent black lines in each bar. The years selected for each country-circa combination may be different depending on survey availability and to assure, to the extent possible, within-country comparability in each period; see annex B.1 for details. The countries are ranked in a range from the country with the most rapid pace in inequality reduction to the country with the most rapid pace of inequality increases over the circa periods of 1993-2003, 2003-11, and 2011-13.

\section{C.2 Correlations between total income inequality and earnings inequality}

Figure C.2.1 Conditional correlation between changes in the Gini coefficient of total income and changes in the Gini coefficient of labor income, Latin America, 1993-2013

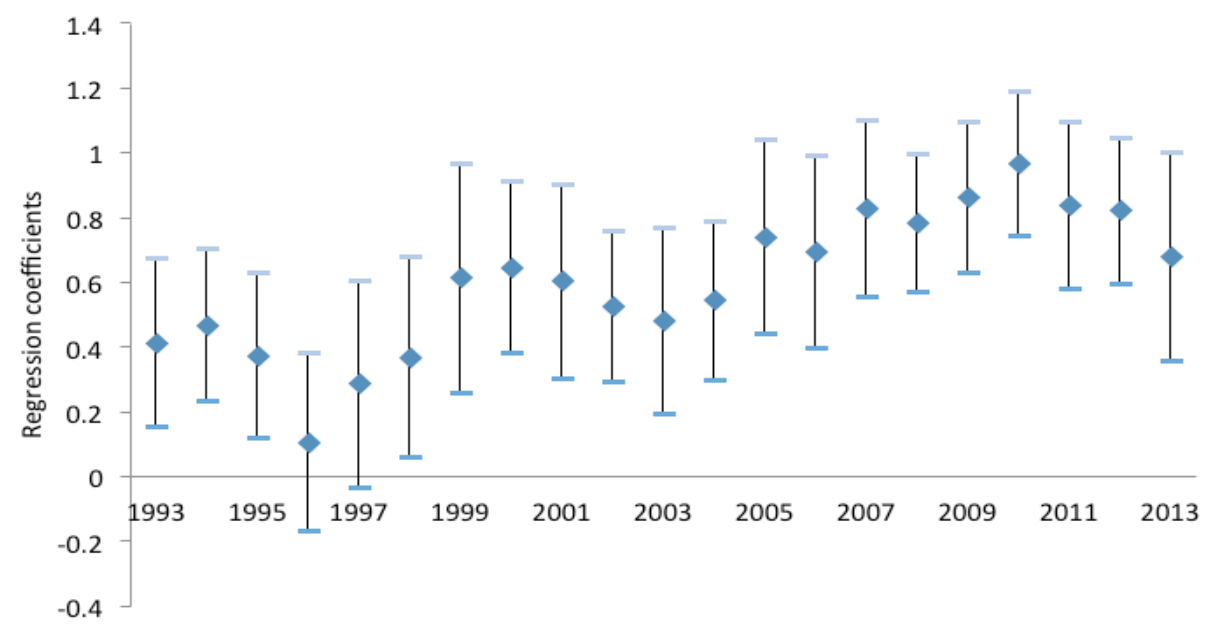

Source: Calculations based on SEDLAC (World Bank and CEDLAS). See annexes A.1 and A.2 for details.

Note: The data represents the coefficients of a country level regression between total income and labor income inequality. The sample of each year is a three year moving average. The labor inequality covers full- time, wage and self-employed, paid workers 15-64 years of age. The values of the 1 st and 100th percentiles of the earnings distribution were trimmed by each gender-education cell. 


\section{Annex D. The rise and fall of labor inequality}

\section{D1. Labor income inequality according to various measures}

a. Theil, mean log deviation, Atkinson $(\mathrm{a}=1)$

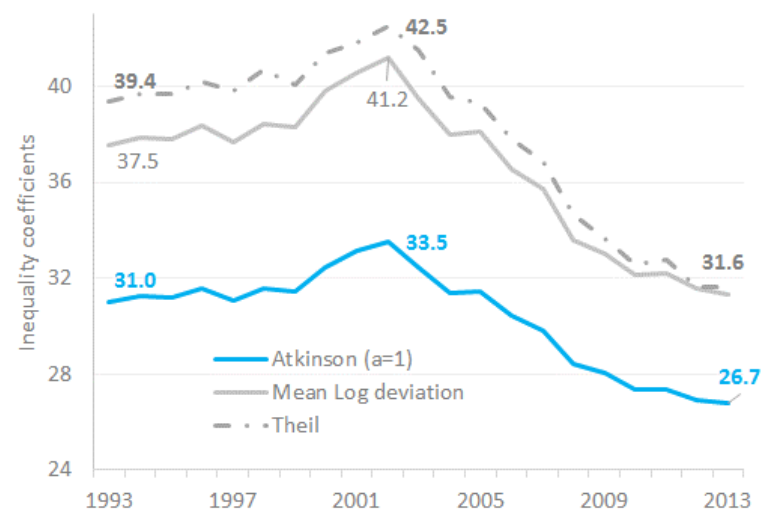

b. Lower and upper tail inequality

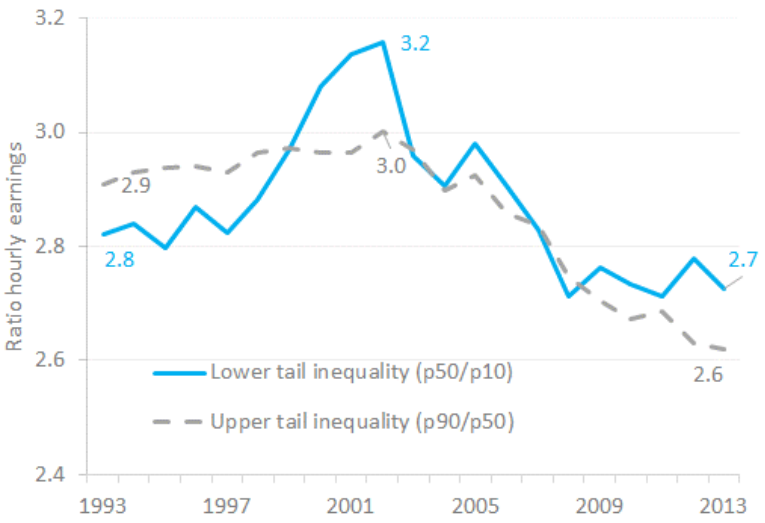

Source: Calculations based on SEDLAC (World Bank and CEDLAS). See annexes A.1 and A.2 for details. Note: The underlying data represent the hourly earnings inequality in each country measure trough different metrics. They have been multiplied by 100.. The sample covers full-time, wage and self-employed, paid workers 15-64 years of age. The values of the 1st and 100th percentiles of the earnings distribution were trimmed by each gender-education cell. The regional aggregate is unweighted average across inequality measures of the 17 countries with frequent data available in the SEDLAC database. If a country-year is missing an arithmetic linear interpolation is applied. To address missing data at the beginning or at the end of the series, the analysis uses the value of the nearest year for which information is available. 
Annex E. Earnings and supply growth in Latin America
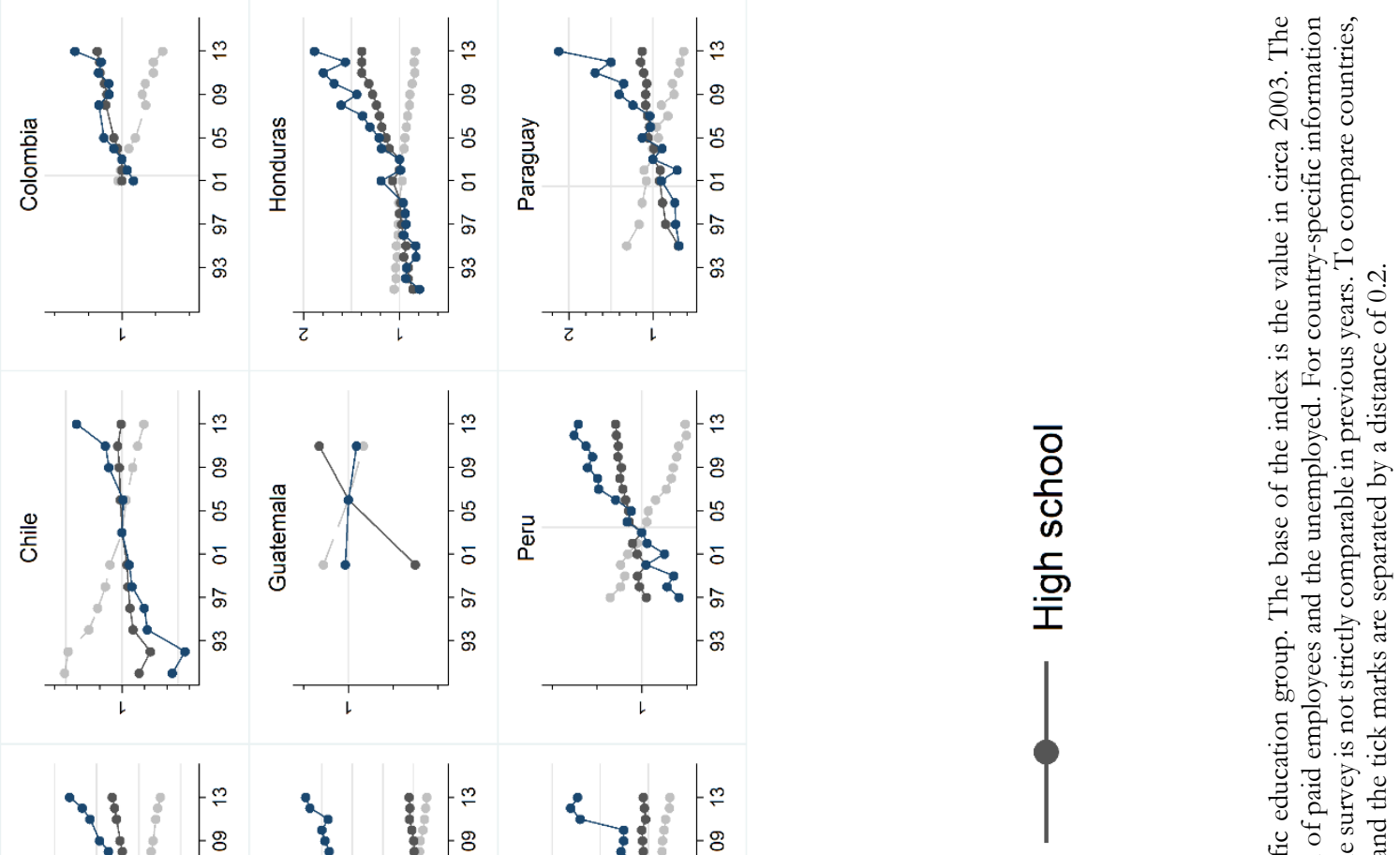

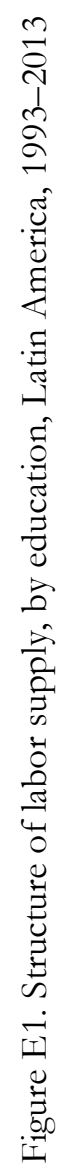
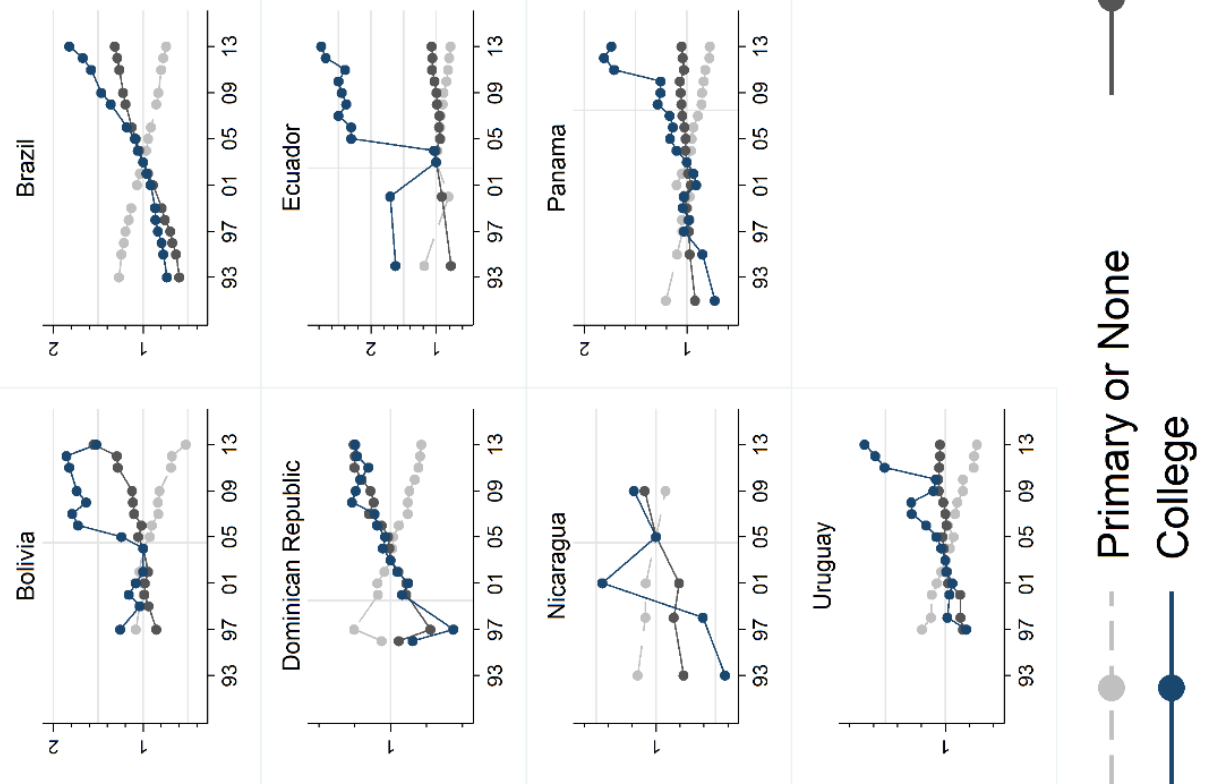

is

to 0 을

들 द्व

䒕矛㝴

论苍

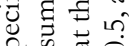

की

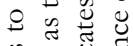

bo

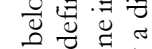

苛告焉
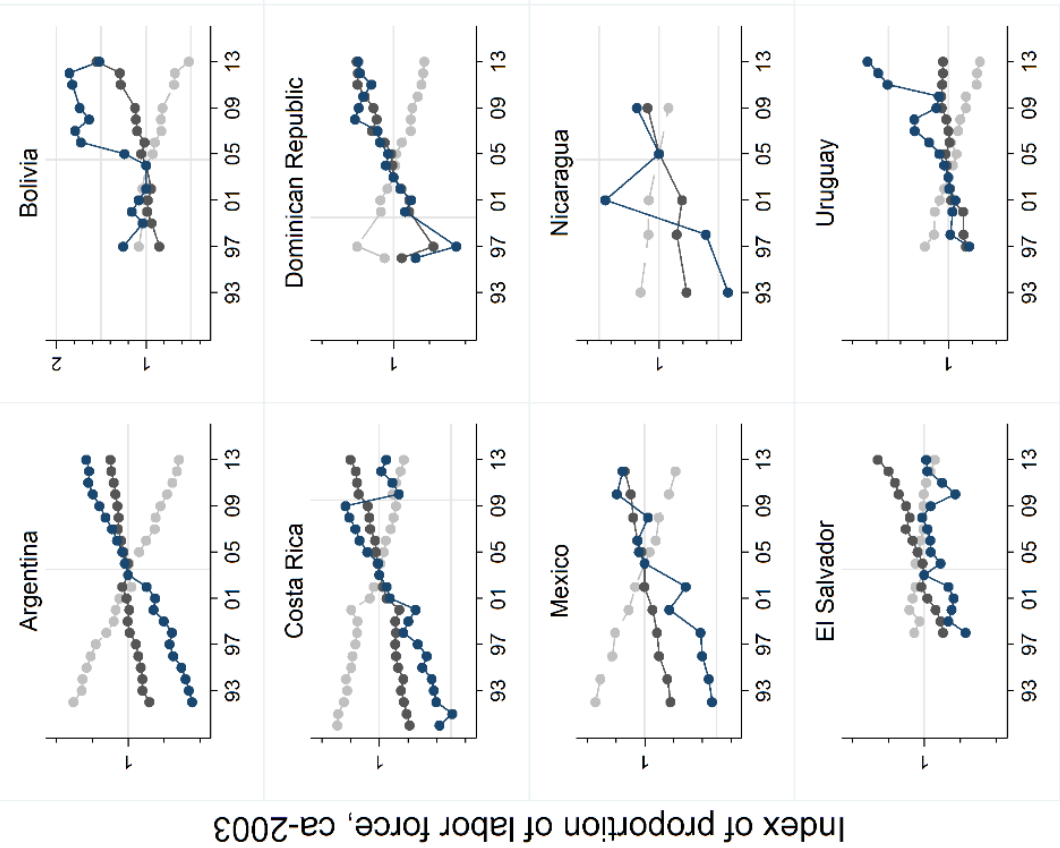

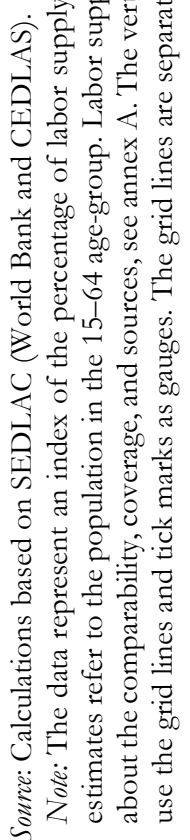




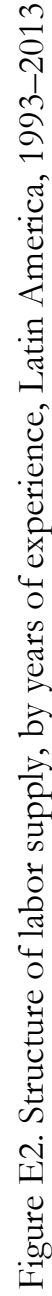
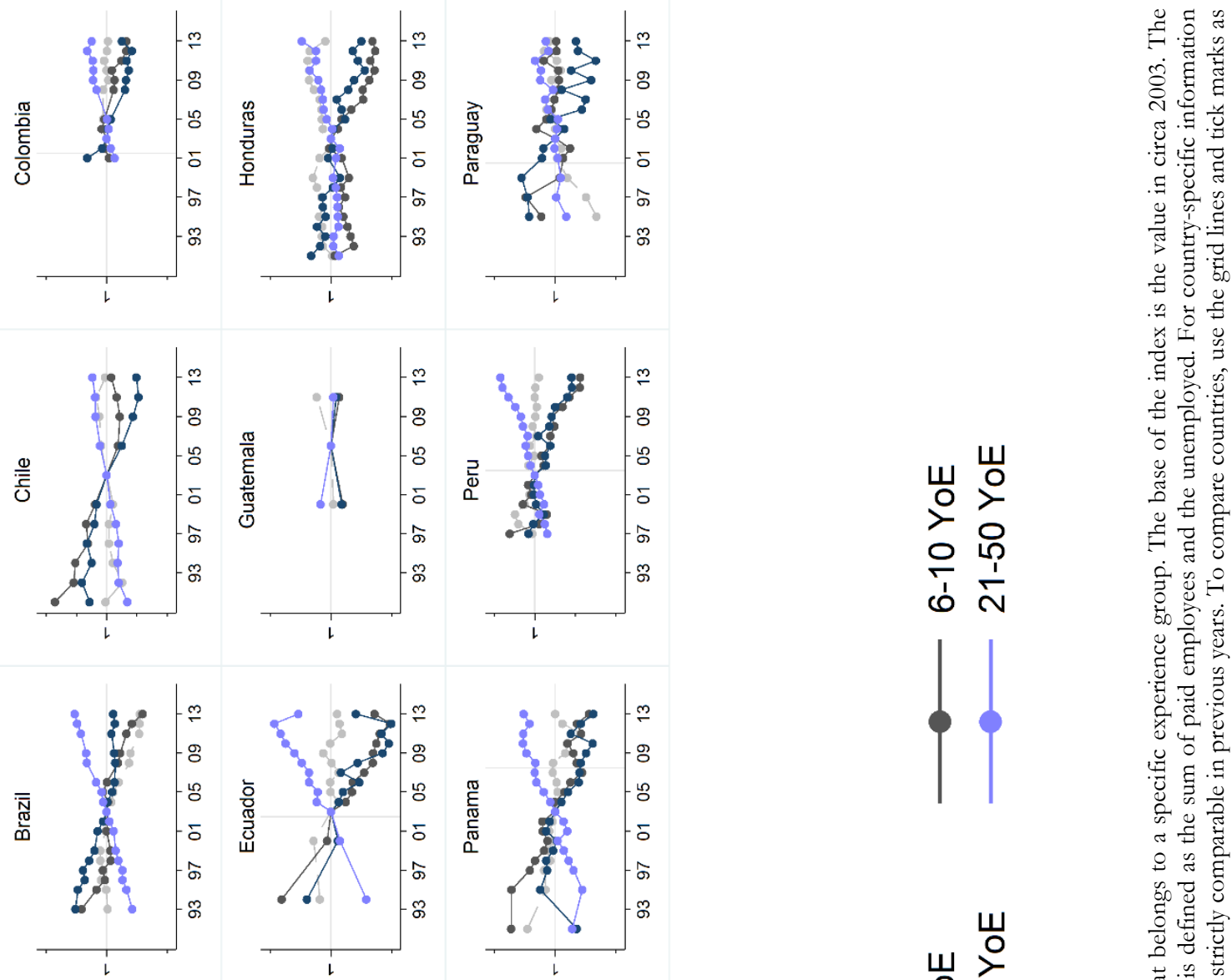

bे -

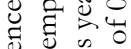

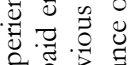

نे

进

के के

के छ

요

So चु है चे

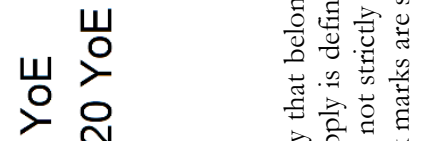

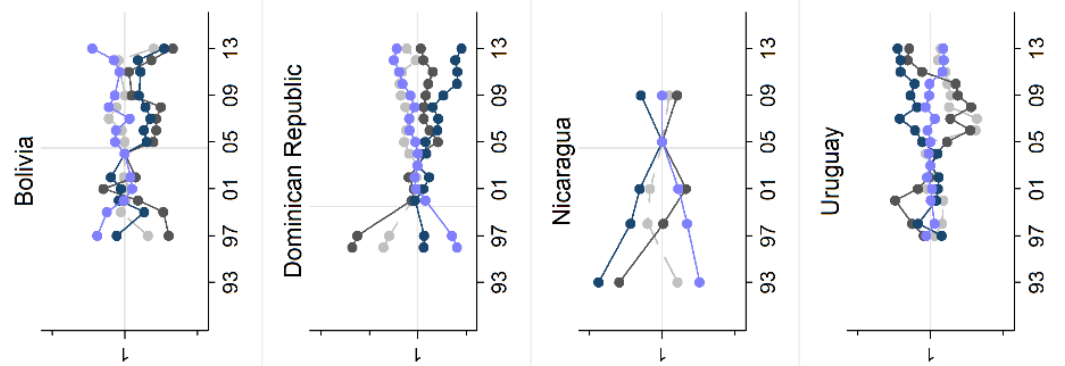

닝 둗

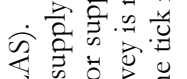

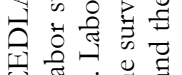

可 西安

당

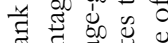

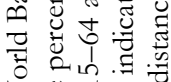

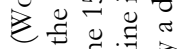

岁岁表完

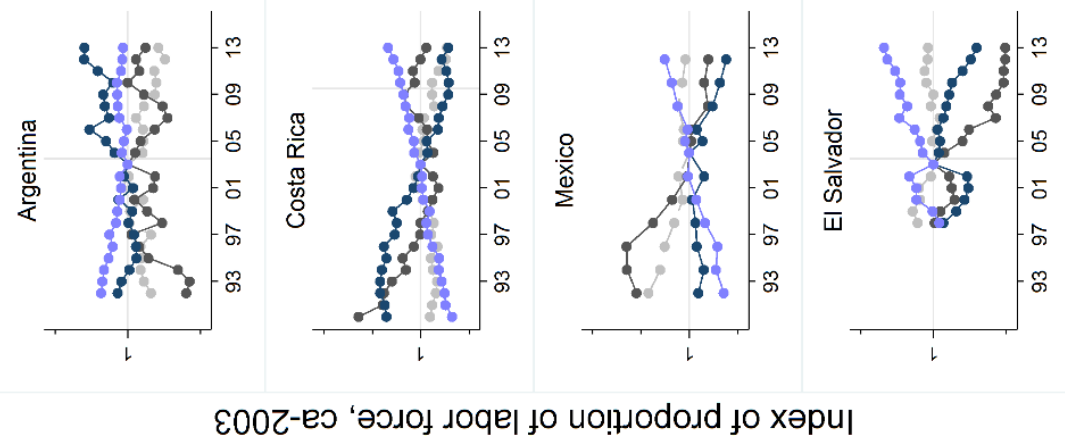

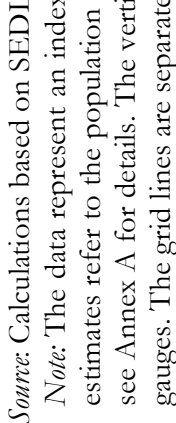




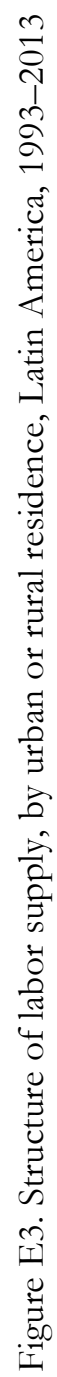

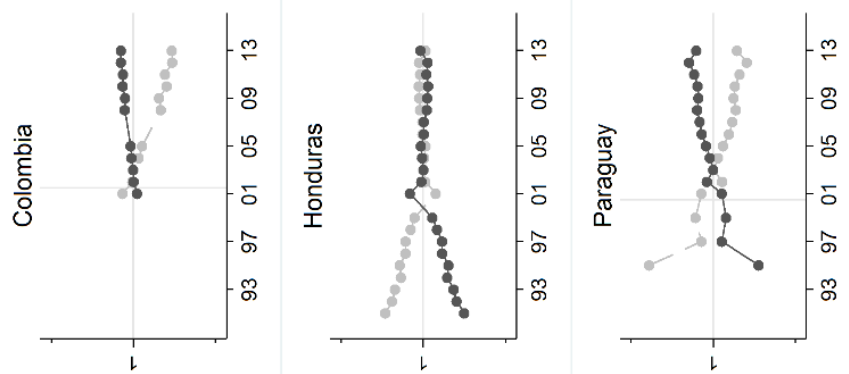

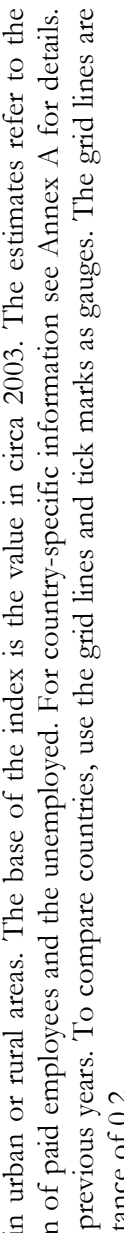

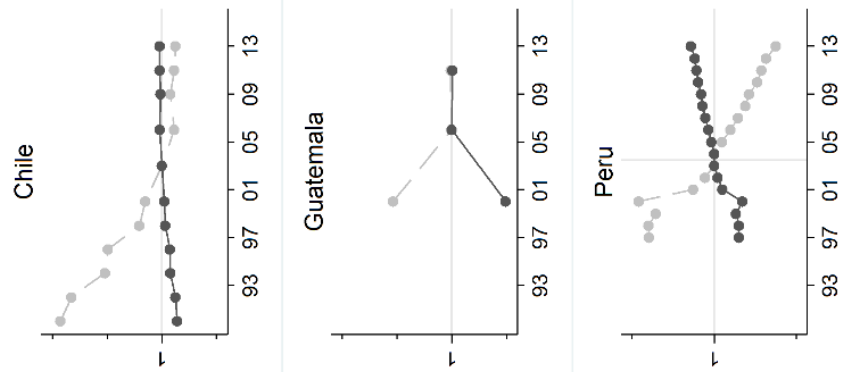

웅
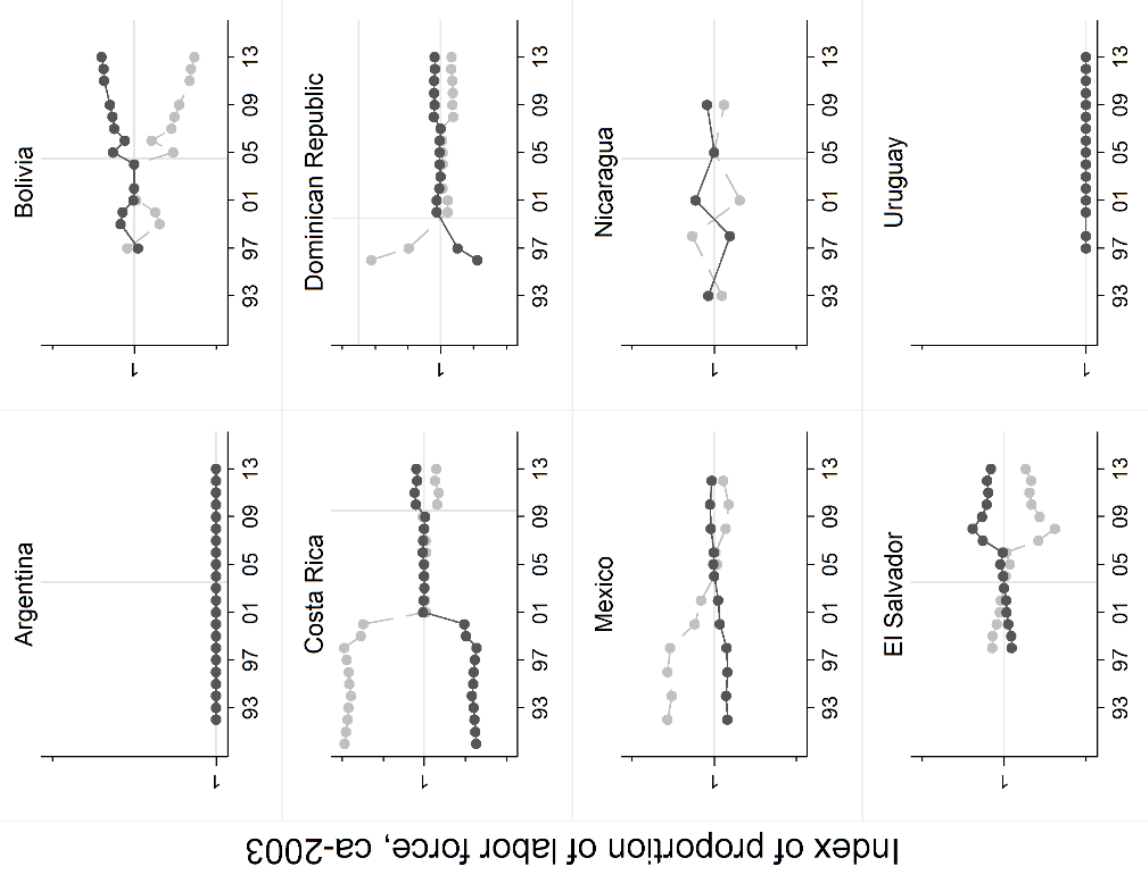

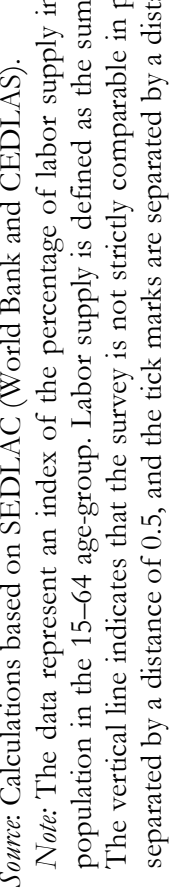



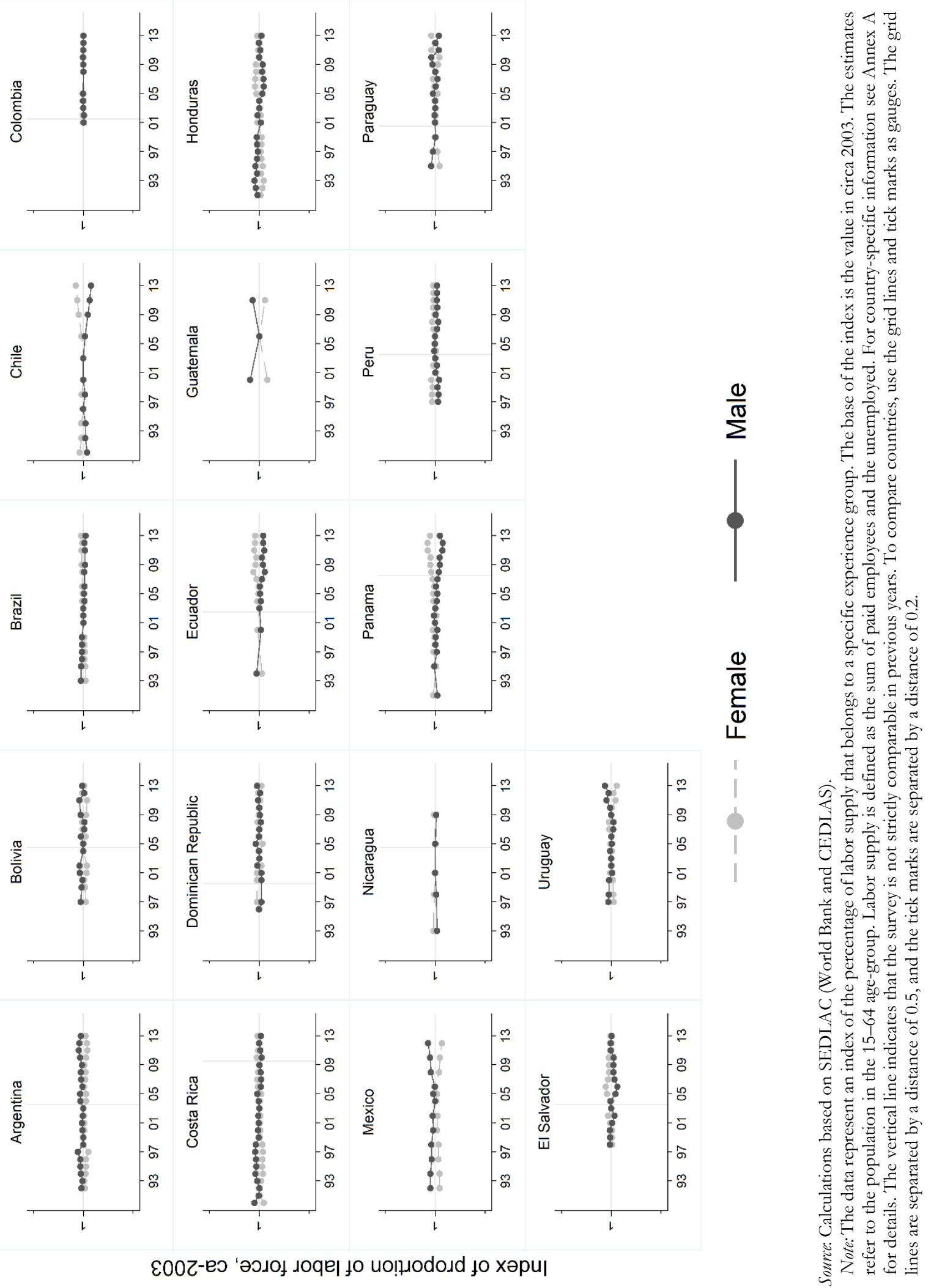


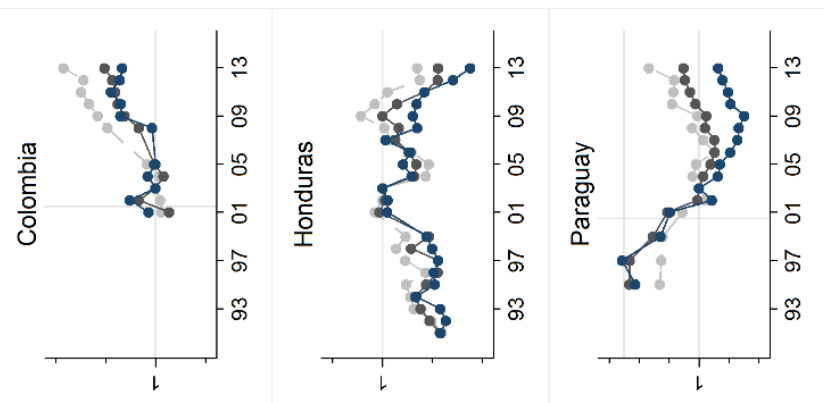

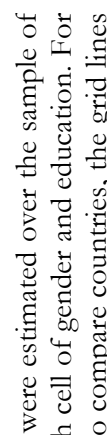
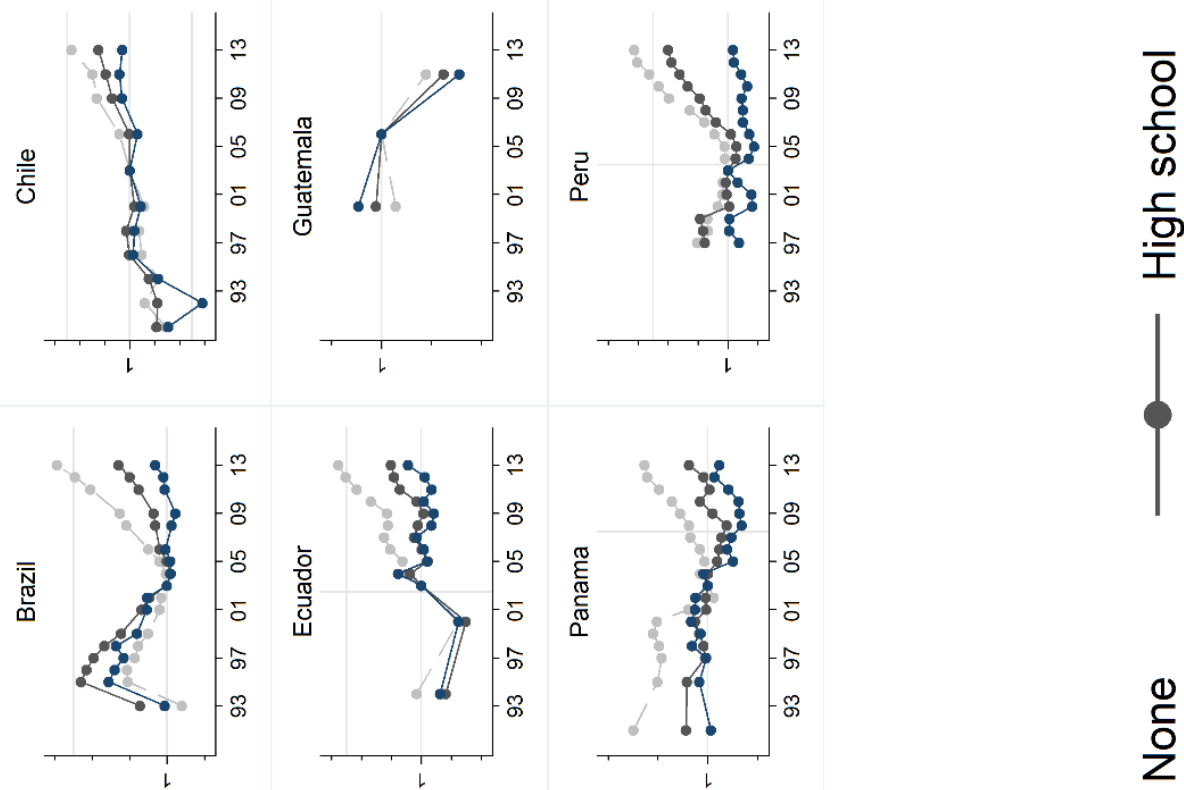

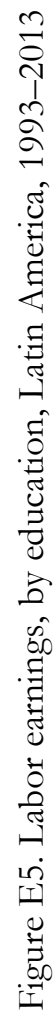

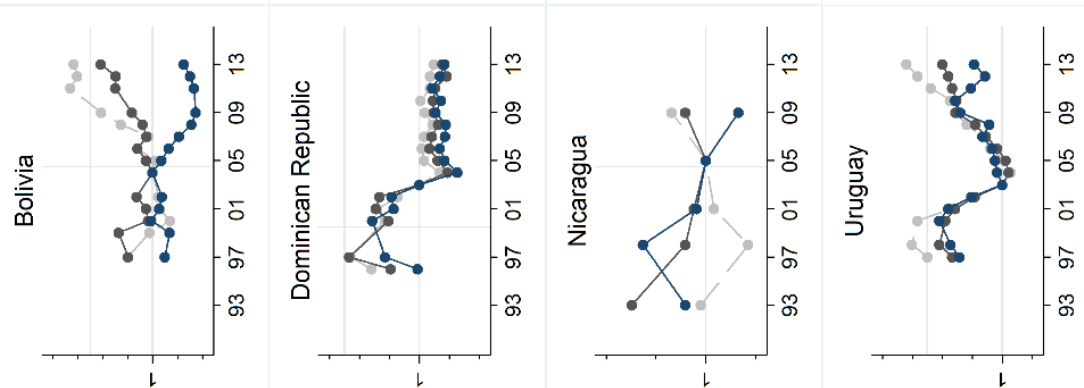

든

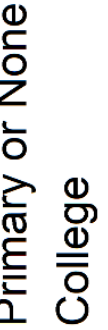

눙

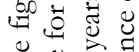

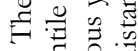

के प्ष

듬

폰 $\exists$

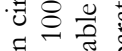

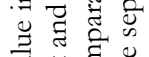

तै

इ

을

.

의

岁品

品

记

․ㅜㅇㅛ

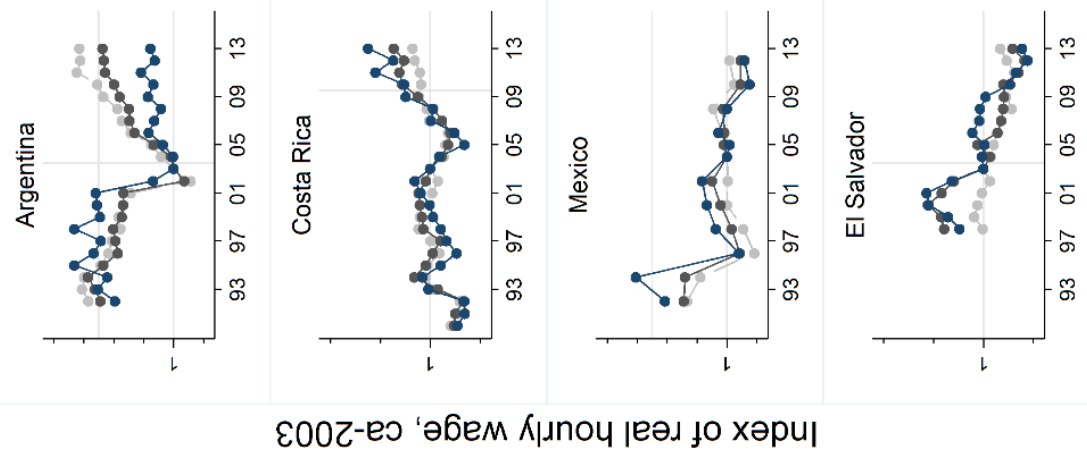

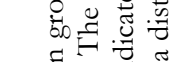

.0.

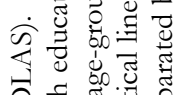

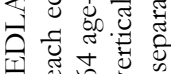

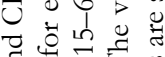

ब

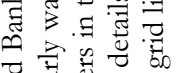

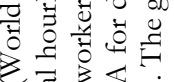

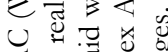

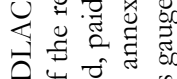

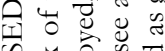

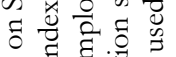

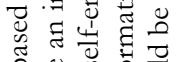

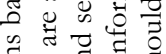

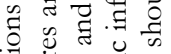

焉步

जु है के के

$\sqrt{1} \frac{1}{2}$ 

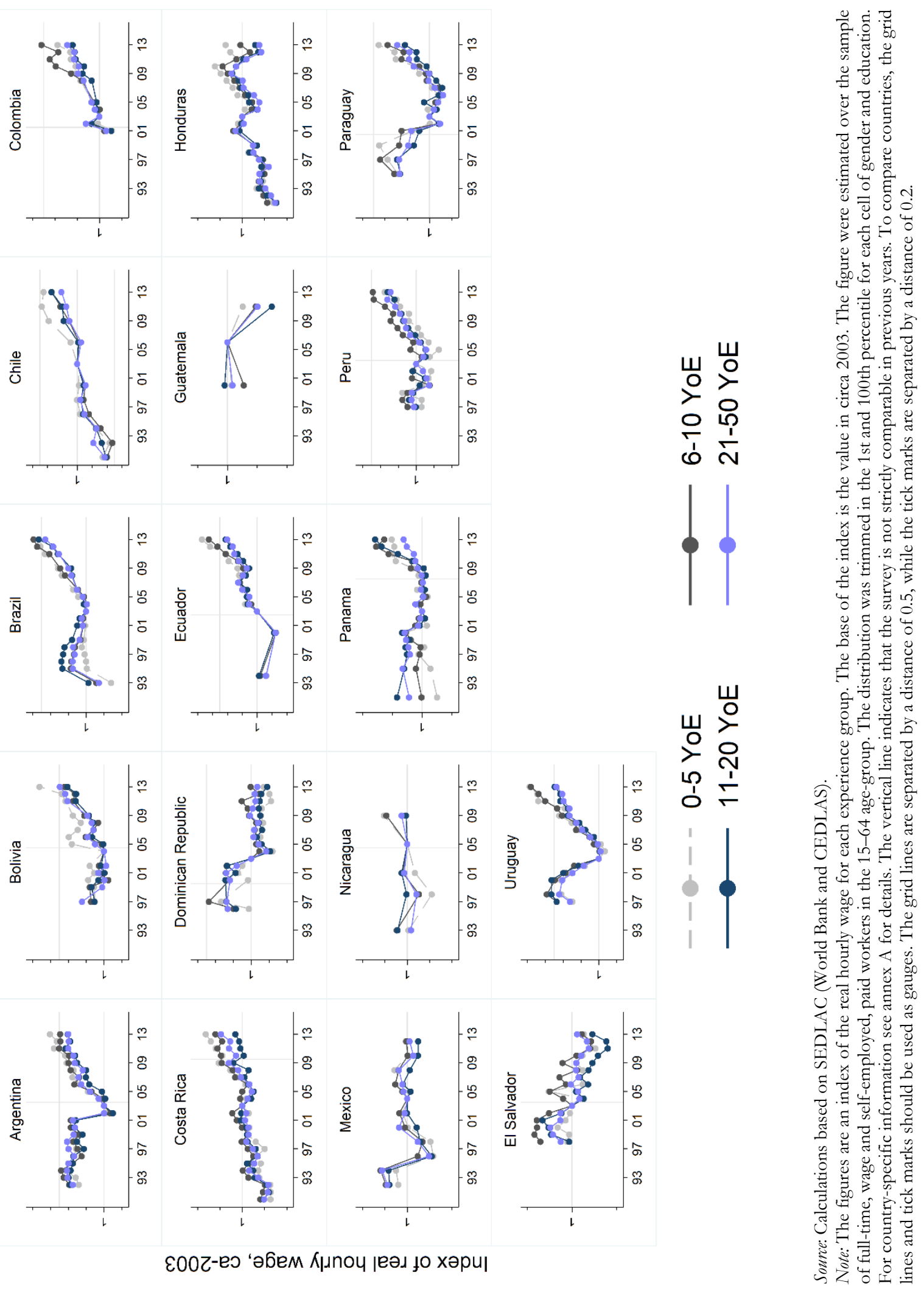

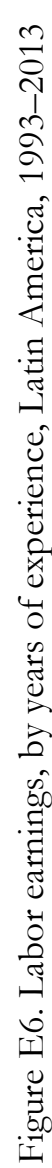
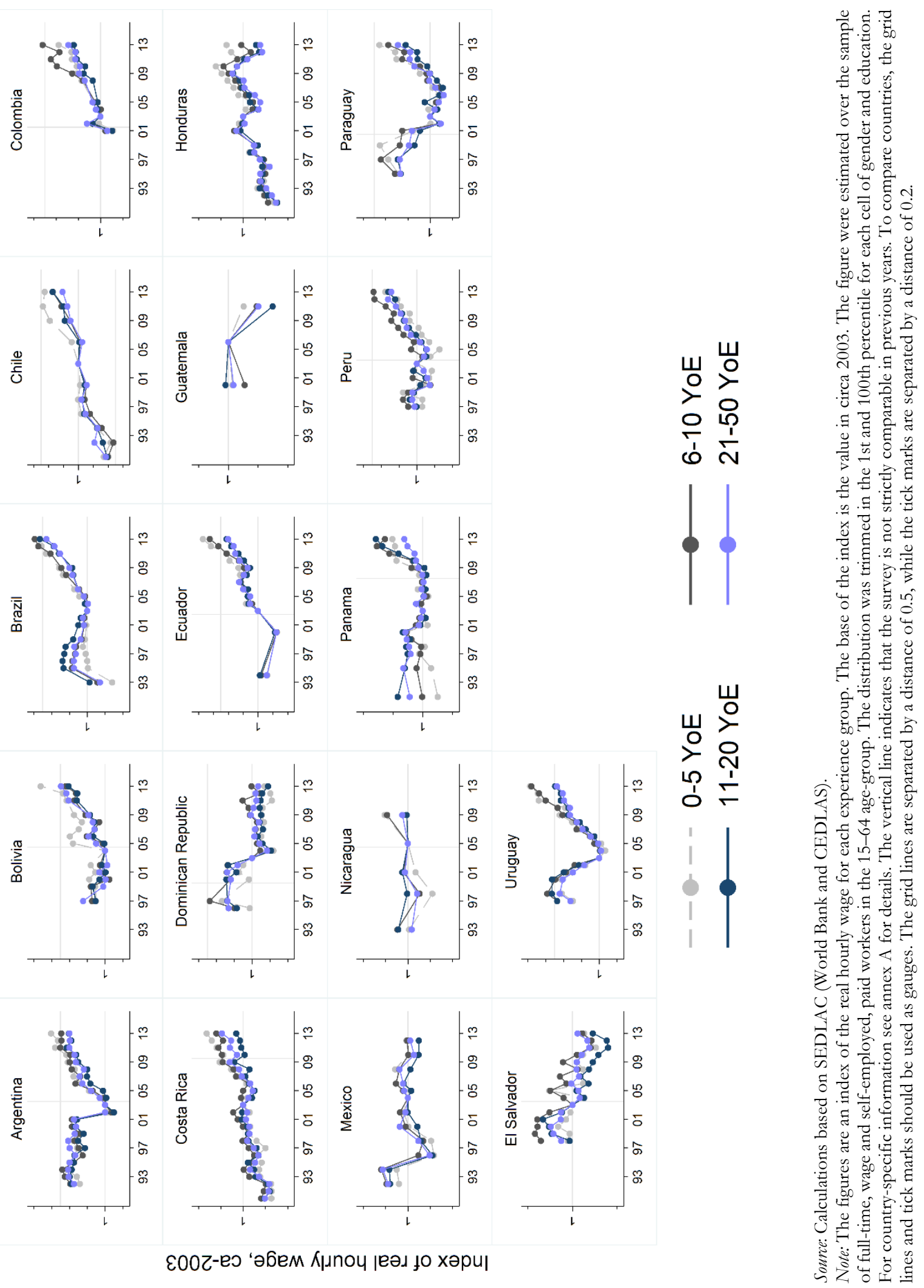

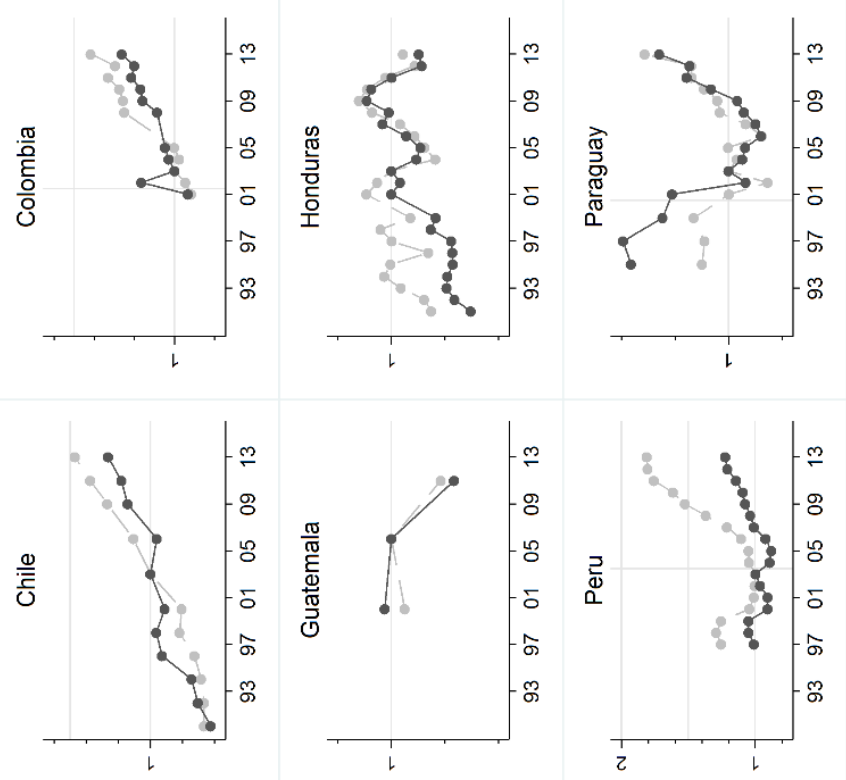

든
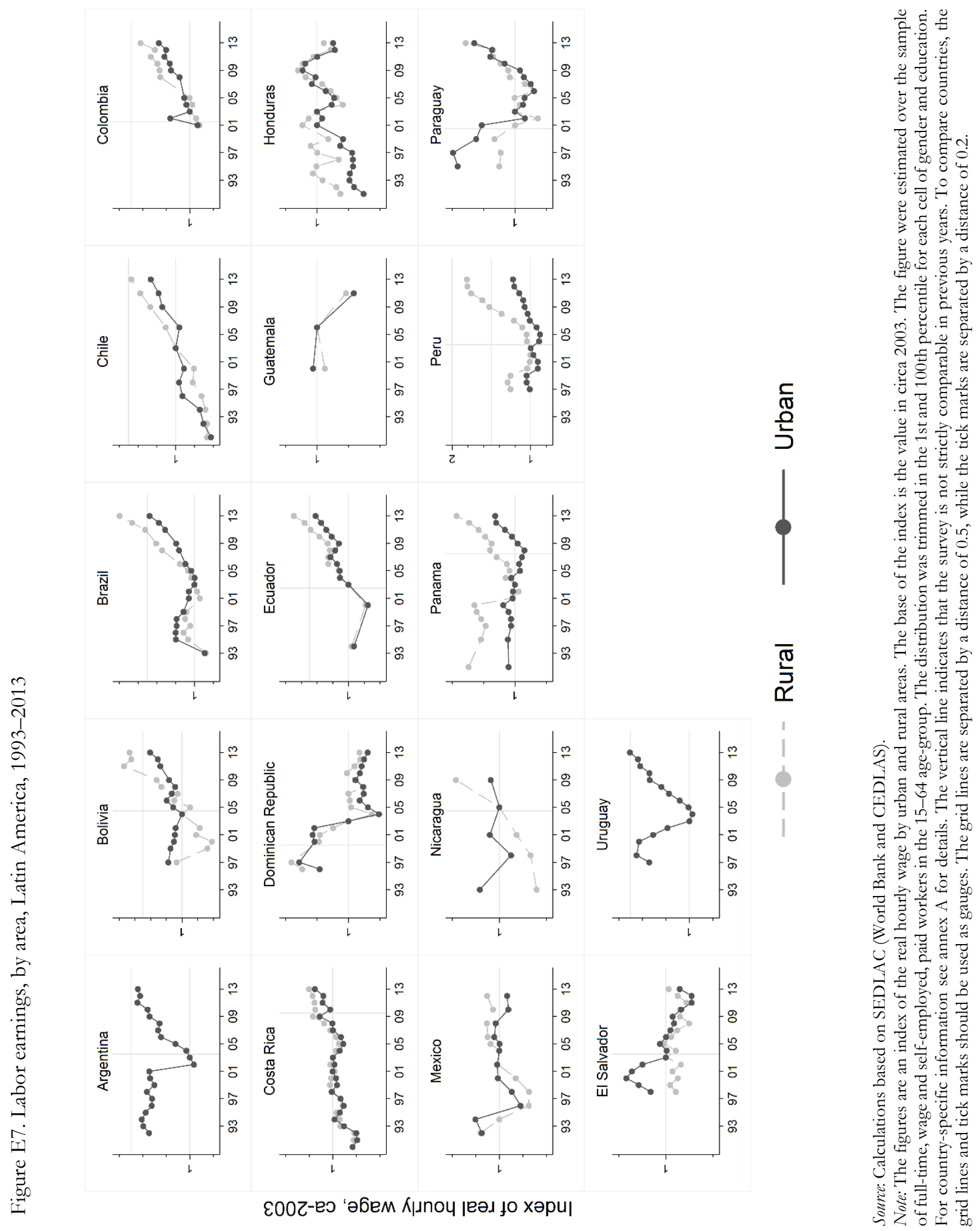

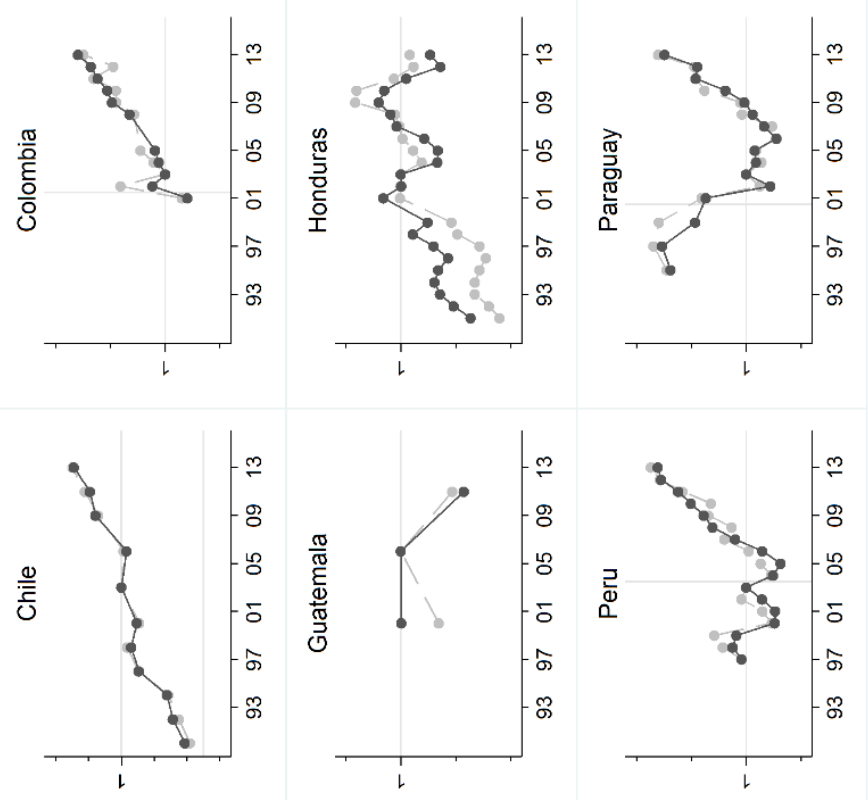

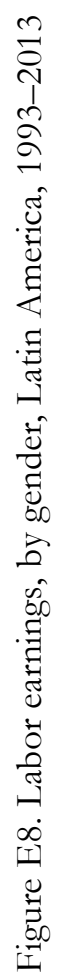

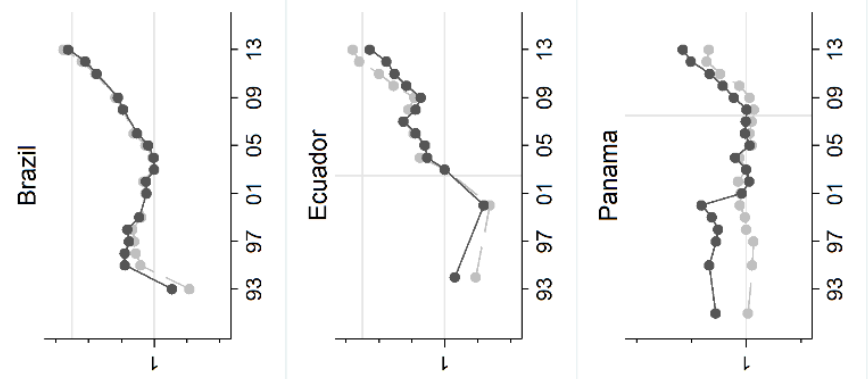

$\frac{\Phi}{\Sigma}$

$\operatorname{sic}_{0}$

3 पू

है के

急

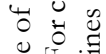

द्व

鹿艺

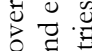

过

g

के पू है

चु

둔웅

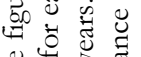

F⿻上丨

के

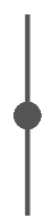

ते

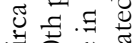

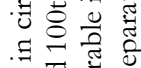

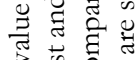

$>0$

声专

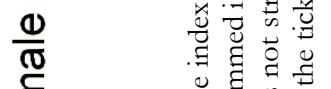

ह

岸学实产

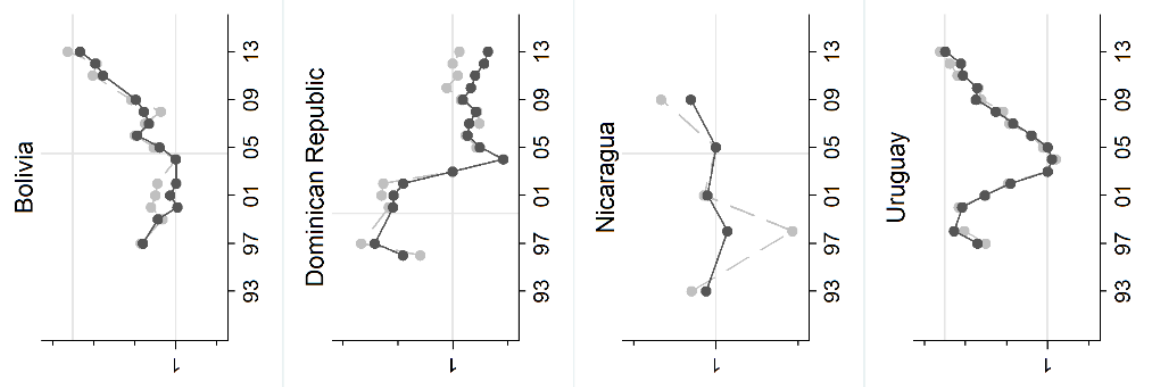

.

क्रि

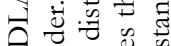

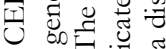

空合家定

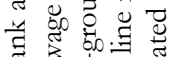

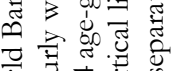

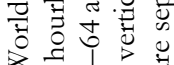

है।

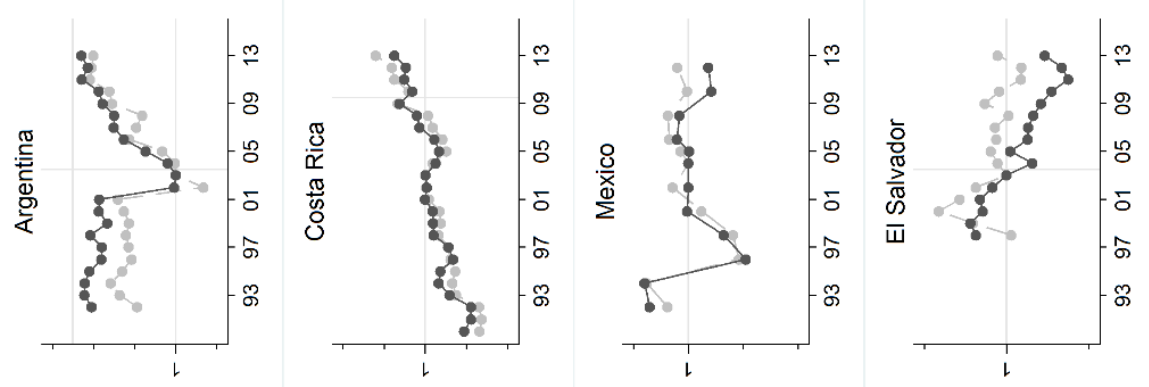

更

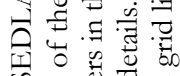

की $x$ 过

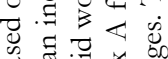

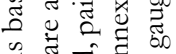

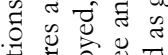

空

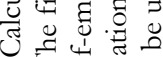

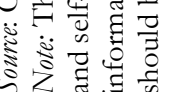

